\title{
Alberta Furbearer Harvest Data Analysis
}

\section{Fish \& Wildifie Division}

WLDIFE CONSERVATION AND BIODIVERSIIY SECHIVI

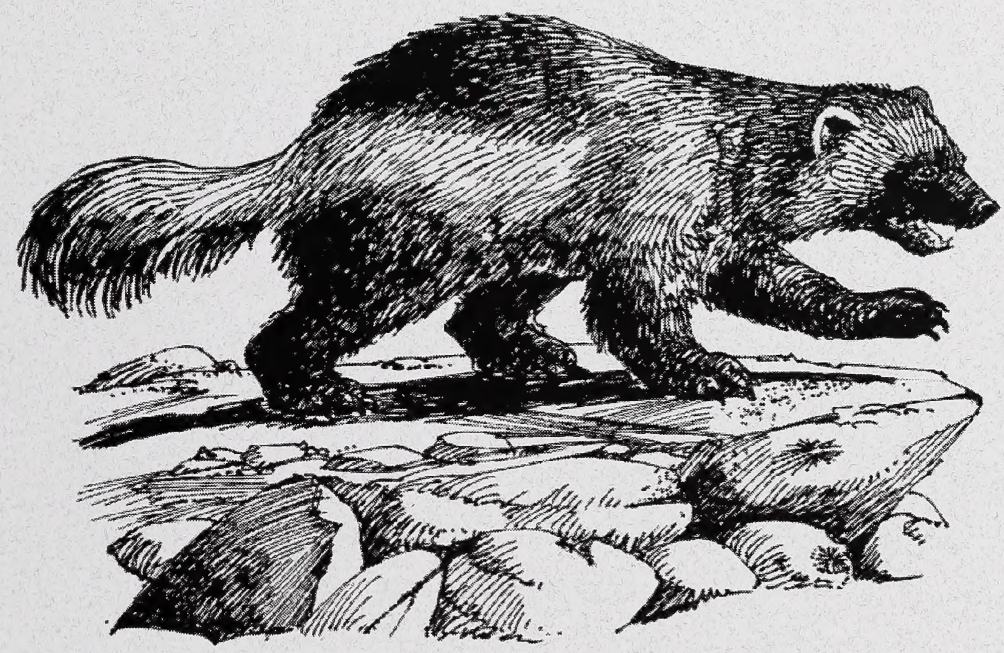

Alberta Species at Risk Report No. 31 



\title{
Alberta Furbearer Harvest Data Analysis
}

\author{
K. G. Poole \\ And \\ G. Mowat
}

Alberta Species at Risk Report No. 31

August 2001

Project Partners:

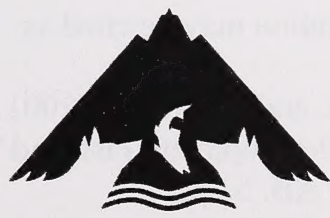


Publication No.: I/048

ISBN: 0-7785-1989-9 (Printed Edition)

ISBN: 0-7785-1990-2 (On-line Edition)

ISSN: 1496-7219 (Printed Edition)

ISSN: 1496-7146 (Online Edition)

Illustration: Brian Huffman

For copies of this report, contact:

Information Centre - Publications

Alberta Environment / Alberta Sustainable Resource Development

Main Floor, Great West Life Building

9920108 Street

Edmonton, Alberta, Canada T5K 2M4

Telephone: (780) 422-2079

OR

Information Service

Alberta Environment / Alberta Sustainable Resource Development

\#100, 311512 Street NE

Calgary, Alberta, Canada T2E 7J2

Telephone: (403) 297-3362

OR

Visit our web site at:

http://www3.gov.ab.ca/srd/fw/riskspecies/

This publication may be cited as:

Poole, K.G. and G. Mowat. 2001. Alberta furbearer harvest data analysis. Alberta Sustainable Resource Development, Fish and Wildlife Division, Alberta Species at Risk Report No. 31. Edmonton, AB. 51 pp. 


\section{DISCLAIMER}

The views and opinions expressed are those of the authors and do not necessarily represent the policies or positions of the Department or of the Alberta Government. 
Digitized by the Internet Archive in 2016 


\section{TABLE OF CONTENTS}

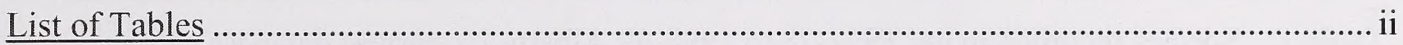

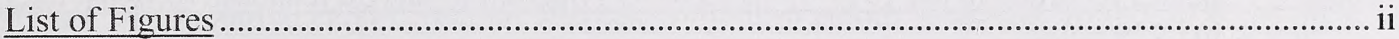

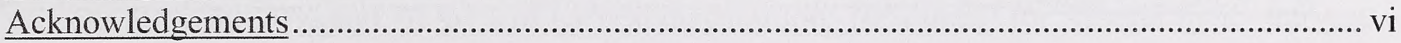

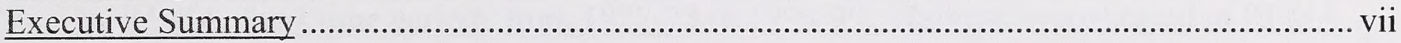

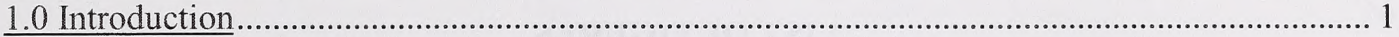

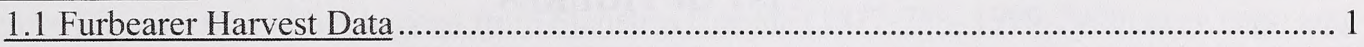

1.2 Factors Affecting Use of Furbearer Harvest Data ............................................................. 3

1.3 Ways to Use Furbearer Harvest Data...................................................................................... 6

1.4 Review of Alberta Furbearer Harvest Data ...................................................................... 7

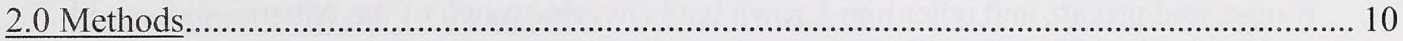

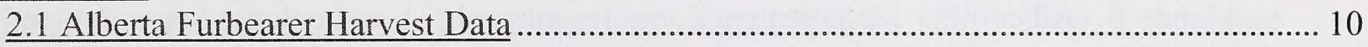

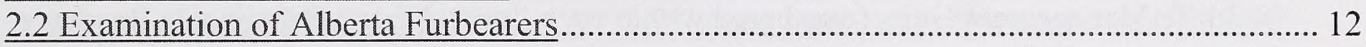

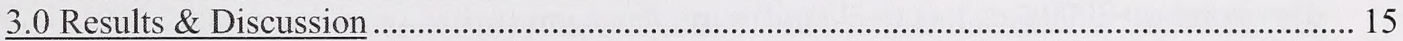

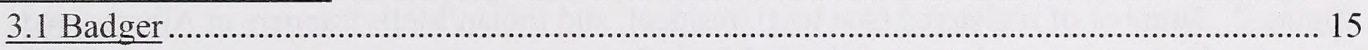

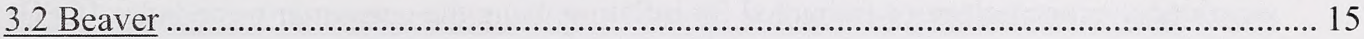

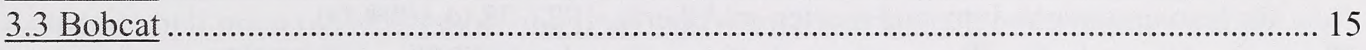

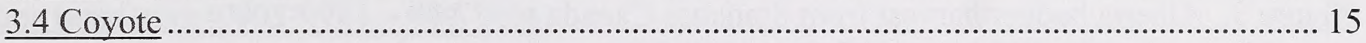

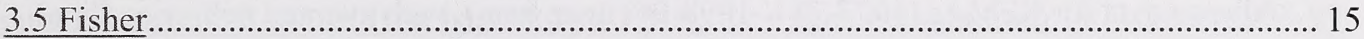

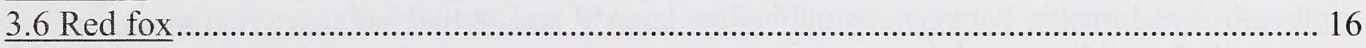

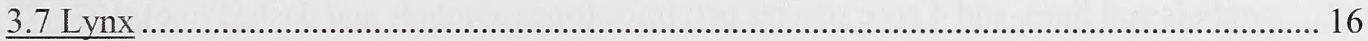

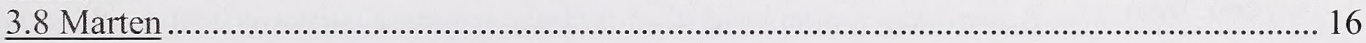

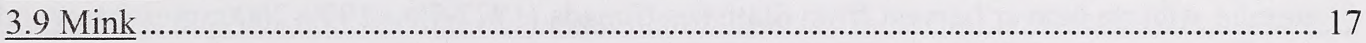

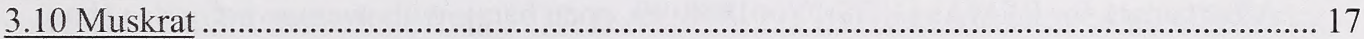

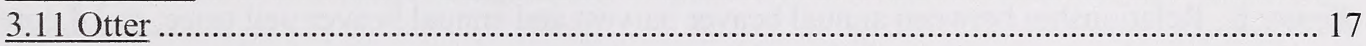

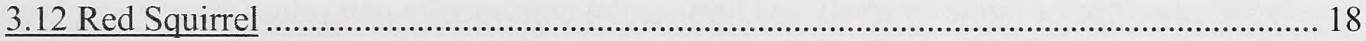

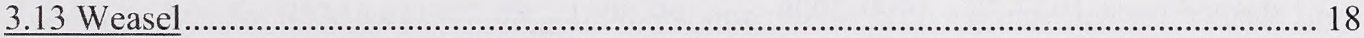

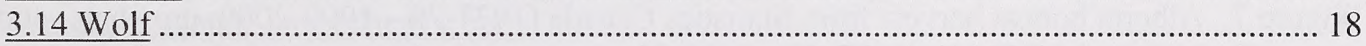

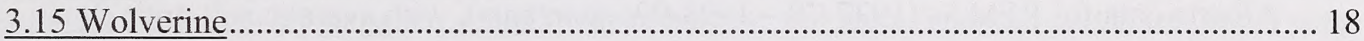

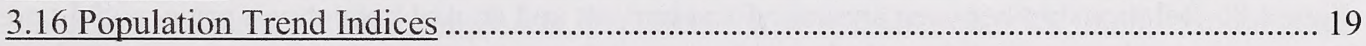

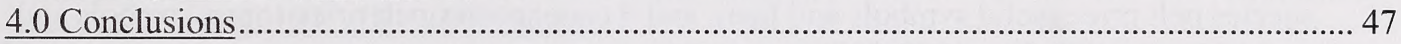

4.1 Recommendations for Alberta Furbearer Data Analysis .................................................... 48

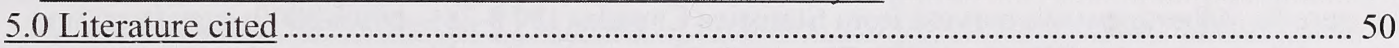




\section{LIST OF TABLES}

Table 1. Species recorded in the 1977-78 to 1998-99 Alberta fur harvest database (original data: $n=4,507,229$ pelts).

\section{LIST OF FIGURES}

Figure 1. A. Registered Fur Management Areas in Alberta. Areas outside of the RFMA include Rocky Mountain National Parks, Wood Buffalo National Park, the Cold Lake Weapons $\underline{\text { Range, and private and other non-Crown land covering much of the Alberta prairie and }}$ parkland. B. Alberta Fur Management Zones (numbered 1-8 and coloured on map), and Wildlife Management Units (numbered within each Zone; Alberta Sustainable Resource Development 2000).

Figure 2. Number of registered (see text), resident, and Indian/Metis trappers in Alberta, and weighted average pelt price (adjucted for inflation using the consumer price index [CPI]) for beaver, coyote, lynx and marten in Alberta, 1977-78 to 1999-00 …................................ 13

Figure 3. Alberta badger harvest from Statistics Canada (1977-78-1999-2000; grey bars) and Alberta data for RFMAs (1977-78 - 1998-99; open bars), with average pelt price (line). .. 20

Figure 4. Relationship between annual badger harvest and annual badger pelt price (solid symbols and line), and 4 core species pelt price (open symbols and dashed line), 1977-78 1999-2000. 20

Figure 5. Alberta beaver harvest from Statistics Canada (1977-78-1999-2000; grey bars) and Alberta data for RFMAs (1977-78 - 1998-99; open bars), with average pelt price (line)... 21

Figure 6. Relationship between annual beaver harvest and annual beaver pelt price, and 4 core species pelt price (solid symbols and line), and 4 core species pelt price (open symbols and dashed line), 1977-78 - 1999-2000. 21

Figure 7. Alberta bobcat harvest from Statistics Canada (1977-78 - 1999-2000; grey bars) and Alberta data for RFMAs (1977-78 - 1998-99; open bars), with average pelt price (line)... 22

Figure 8 . Relationship between annual bobcat harvest and annual bobcat pelt price, and 4 core species pelt price (solid symbols and line), and 4 core species pelt price (open symbols and dashed line), 1977-78 - 1999-2000. 22

Figure 9. Alberta coyote harvest from Statistics Canada (1977-78 - 1999-2000; grey bars) and Alberta data for RFMAs (1977-78 - 1998-99; open bars), with average pelt price (line)... 23 Figure 10. Relationship between annual coyote harvest and annual coyote pelt price, and 4 core species pelt price (solid symbols and line), and 4 core species pelt price (open symbols and dashed line), 1977-78 - 1999-2000. 23

Figure 11. Alberta fisher harvest from Statistics Canada (1977-78 - 1999-2000; grey bars), Alberta data for RFMAs (1977-78 - 1998-99; open bars), and registered data (1989-90 1999-2000; black bars) with average pelt price (light line) and abundance index (heavy line).

Figure 12. Relationship between annual fisher harvest and annual fisher pelt price, and 4 core species pelt price (solid symbols and line), and 4 core species pelt price (open symbols and dashed line), 1977-78 - 1999-2000. 
Figure 13. Average annual fisher harvest by RFMA, for 4 time periods from 1977-78 to 199899. Harvests were scaled to RFMA size. Graduated symbols were consistent among time periods.

Figure 14. Adaptive kernel contours (darkest to lightest colour gradients from 0-10\%, 10-30\%,

$30-50 \%, 50-70 \%$ and $70-90 \%$ of harvest distribution; $10 \%$ lines) for Alberta fisher harvest

by RFMA, for 4 time periods from 1977-78 to 1998-99. Harvests were scaled to RFMA

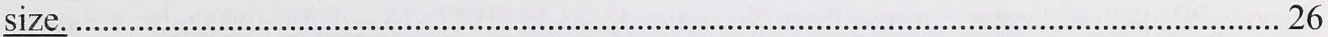

Figure 15. Alberta red fox harvest from Statistics Canada (1977-78 - 1999-2000; grey bars) and

Alberta data for RFMAs (1977-78 - 1998-99; open bars), with average pelt price (line). .. 27

Figure 16. Relationship between annual red fox harvest and annual red fox pelt price, and 4 core

species pelt price (solid symbols and line), and 4 core species pelt price (open symbols and

dashed line), 1977-78 - 1999-2000.

Figure 17. Alberta lynx harvest from Statistics Canada (1977-78 - 1999-2000; grey bars),

Alberta data for RFMAs (1977-78 - 1998-99; open bars), and registered data (1989-90 -

1999-2000; black bars) with average pelt price (light line) and abundance index (heavy

line).

Figure 18. Relationship between annual lynx harvest and annual lynx pelt price, and 4 core

species pelt price (solid symbols and line), and 4 core species pelt price (open symbols and

dashed line), 1977-78 - 1999-2000.

Figure 19. Average annual lynx harvest by RFMA, for 4 time periods from 1977-78 to 1998-99.

Harvests were scaled to RFMA size. Graduated symbols were consistent among time

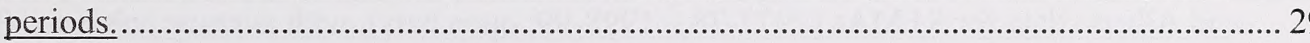

Figure 20. Adaptive kernel contours (darkest to lightest colour gradients from 0-10\%, 10-30\%.

30-50\%, 50-70\% and 70-90\% of harvest distribution; $10 \%$ lines) for Alberta lynx harvest by

RFMA, for 4 time periods from 1977-78 to 1998-99. Harvests were scaled to RFMA size.

Figure 21. Alberta marten harvest from Statistics Canada (1977-78 - 1999-2000; grey bars) and Alberta data for RFMAs (1977-78 - 1998-99; open bars), with average pelt price (light line) and abundance index (heavy line).

Figure 22. Relationship between annual marten harvest and annual marten pelt price, and 4 core species pelt price (solid symbols and line), and 4 core species pelt price (open symbols and dashed line), 1977-78 - 1999-2000. 31

Figure 23. Average annual marten harvest by RFMA, for 4 time periods from 1977-78 to 1998-

99. Harvests were scaled to RFMA size. Graduated symbols were consistent among time

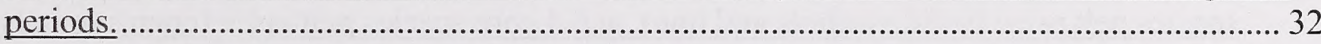

Figure 24. Adaptive kernel contours (darkest to lightest colour gradients from 0-10\%, 10-30\%, 30-50\%, 50-70\% and $70-90 \%$ of harvest distribution; $10 \%$ lines) for Alberta marten harvest by RFMA, for 4 time periods from 1977-78 to 1998-99. Harvests were scaled to RFMA size.

Figure 25. Alberta mink harvest from Statistics Canada (1977-78 - 1999-2000; grey bars) and Alberta data for RFMAs (1977-78 - 1998-99; open bars), with average pelt price (line)... 34 Figure 26. Relationship between annual mink harvest and annual mink pelt price, and 4 core species pelt price (solid symbols and line), and 4 core species pelt price (open symbols and dashed line), 1977-78-1999-2000. 
Figure 27. Alberta muskrat harvest from Statistics Canada (1977-78 - 1999-2000; grey bars) and Alberta data for RFMAs (1977-78 - 1998-99; open bars), with average pelt price (line).

Figure 28. Relationship between annual muskrat harvest and annual muskrat pelt price, and 4 core species pelt price (solid symbols and line), and 4 core species pelt price (open symbols and dashed line), 1977-78 - 1999-2000. 35

Figure 29. Alberta otter harvest from Statistics Canada (1977-78 - 1999-2000; grey bars), Alberta data for RFMAs (1977-78 - 1998-99; open bars), and registered data (1989-90 1999-2000; black bars) with average pelt price (light line) and abundance index (heavy

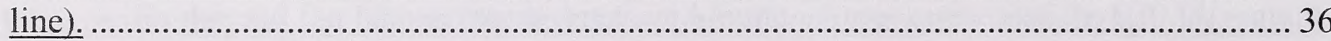

Figure 30. Relationship between annual otter harvest and annual otter pelt price, and 4 core species pelt price (solid symbols and line), and 4 core species pelt price (open symbols and dashed line), 1977-78 - 1999-2000 ........................................................................... 36 Figure 31. Average annual otter harvest by RFMA, for 4 time periods from 1977-78 to 1998-99. Harvests were scaled to RFMA size. Graduated symbols were consistent among time periods...... 37

Figure 32. Adaptive kernel contours (darkest to lightest colour gradients from $0-10 \%, 10-30 \%$, 30-50\%, 50-70\% and 70-90\% of harvest distribution; $10 \%$ lines) for Alberta otter harvest by RFMA, for 4 time periods from 1977-78 to 1998-99. Harvests were scaled to RFMA size. 38

Figure 33. Alberta red squirrel harvest from Statistics Canada (1977-78 - 1999-2000; grey bars) and Alberta data for RFMAs (1977-78 - 1998-99; open bars), with average pelt price (line).

Figure 34. Relationship between annual red squirrel harvest and annual red squirrel pelt price, and 4 core species pelt price (solid symbols and line), and 4 core species pelt price (open symbols and dashed line), 1977-78-1999-2000.

Figure 35. Alberta weasel harvest from Statistics Canada (1977-78 - 1999-2000; grey bars) and Alberta data for RFMAs (1977-78 - 1998-99; open bars), with average pelt price (line)... 40 Figure 36. Relationship between annual weasel harvest and annual weasel pelt price, and 4 core species pelt price (solid symbols and line), and 4 core species pelt price (open symbols and dashed line), 1977-78 - 1999-2000. 40

Figure 37. Alberta wolf harvest from Statistics Canada (1977-78 - 1999-2000; grey bars) and Alberta data for RFMAs (1977-78 - 1998-99; open bars), with average pelt price (line)... 41 Figure 38. Relationship between annual wolf harvest and annual wolf pelt price, and 4 core species pelt price (solid symbols and line), and 4 core species pelt price (open symbols and dashed line), 1977-78-1999-2000. 41

Figure 39. Average annual wolf harvest by RFMA, for 4 time periods from 1977-78 to 1998-99. Harvests were scaled to RFMA size. Graduated symbols were consistent among time periods.

Figure 40. Adaptive kernel contours (darkest to lightest colour gradients from $0-10 \%, 10-30 \%$, $30-50 \%, 50-70 \%$ and $70-90 \%$ of harvest distribution; $10 \%$ lines) for Alberta wolf harvest by RFMA, for 4 time periods from 1977-78 to 1998-99. Harvests were scaled to RFMA size. 43

Figure 41. Alberta wolverine harvest from Statistics Canada (1977-78 - 1999-2000; grey bars), Alberta data for RFMAs (1977-78 - 1998-99; open bars), and registered data (1989-90 - 
1999-2000; black bars) with average pelt price (light line) and abundance index (heavy line).

Figure 42. Relationship between annual wolverine harvest and annual wolverine pelt price, and 4 core species pelt price (solid symbols and line), and 4 core species pelt price (open symbols and dashed line), 1977-78-1999-2000. 44

Figure 43. Average annual wolverine harvest by RFMA, for 4 time periods from 1977-78 to 1998-99. Harvests were scaled to RFMA size. Graduated symbols were consistent among time periods. 45

Figure 44. Adaptive kernel contours (darkest to lightest colour gradients from $0-10 \%, 10-30 \%$, 30-50\%, 50-70\% and 70-90\% of harvest distribution; $10 \%$ lines) for Alberta wolverine harvest by RFMA, for 4 time periods from 1977-78 to 1998-99. Harvests were scaled to RFMA size. 46 


\section{ACKNOWLEDGEMENTS}

We thank Matt Besko, Floyd Kunnas, and Bruce Treichel, Alberta Sustainable Resource Development, for providing the furbearer harvest data, and answering numerous questions about the datasets and the Alberta trapping system. R. Mossman, Sustainable Resource Development, kindly provided the GIS coverage with RFMA numbers, and B. Alain, Statistics Canada, graciously provided the Alberta harvest statistics and consumer price index. Rich Moses, University of Alberta, and Arlen Todd, Sustainable Resource Development, kindly provided a critical review of our draft manuscript. 


\section{EXECUTIVE SUMMARY}

We reviewed the literature to examine the potential uses and limitations of using trapper harvest data to monitor species distribution and population trend. Furbearer harvest data has been collected based on fur dealer returns, trapper affidavits, and pelt sealing (for lynx, fisher, wolverine and otter) in the provincially owned portion of Alberta. No area-specific harvest data are collected from federal or private land although some of this harvest is recorded via export permits. The number of licensed trappers has declined about 10\% between 1977-1999 while average pelt values of four important species (lynx, marten, beaver, and coyote) declined about $70 \%$ during the same period. The number of trappers is unlikely to be an accurate measure of trapper effort in Alberta. We present harvest, price, and distribution of harvest for most furbearers in Alberta. In addition, we attempted to measure changes in abundance by mapping distribution across time and calculating an abundance index based on harvest and pelt price.

The abundance index for fisher suggested comparatively low numbers during the latter half of the 1980s, with an increase in abundance through the 1990s. Spatial distribution of the harvest would also suggest a decline in distribution following 1988-89, notably in the southwest portion of the province. The lynx abundance index and spatial distribution suggested similar low population numbers through the cyclic lows of the 1980s and 1990s, with the lowest abundance during the 1980s, especially in west-central Alberta. Marten abundance showed irregular fluctuations over time with no consistent trend. The spatial distribution of marten harvests showed a possible reduction in marten range in the southern Rocky Mountains by the mid to late 1990s, and an expansion into east-central Alberta. Otter abundance appears to have slowly increased over time. The otter harvest in Alberta is centred in the east-central portions of the province, and appears to have changed little over time except for a possible expansion into westcentral portions of the province.

Irregular fluctuations in the marten index suggest another factor, other than pelt price, is also affecting effort. The same is true for wolverine. The wolverine index is certainly biased because the large variations seen in the index are not possible in a species typified by small annual changes in abundance. The results for wolverine, and to a lesser extent marten, highlight the need to investigate the nature of these indices using a corrected harvest dataset, finer scaled analysis (by region for example), local population data where available, and corroboration from the literature.

To make better use of current and future Alberta furbearer harvest data, we suggest the following for consideration:

1. Alberta trapper harvest data needs to be collected consistently for the entire province. This means setting up a process that includes non-crown and private lands trapped by resident trappers. If possible, harvest data from Federal lands (e.g., WBNP) should be included in this database as well as hunter harvests of relevant species such as coyotes, wolves and wolverines.

2. We suggest that harvest data collection be based on pelt counts, rather than unverified trapper affidavits (memory recall). Although there are biases involved, these data should be collected through licenced fur dealers, with a system that tracks fur sales, and makes fur dealers responsible for data submission and quality. Based on our experience with 
furbearer harvest data in western Canada, we believe that such a system will provide better quality data for use in spatial trend analysis and population trend analysis (with an index to trapper effort; see below).

3. If Alberta decides to retain the trapper affidavit as the primary source for collection of harvest data, we suggest that affidavits be collected at the end of each fur season (MayJune) from all licenced trappers, rather than in the fall from those trappers that are renewing licences. This will help to ensure that the entire trapping community is tallied and reduces "memory loss".

4. We suggest that weasel species be recorded separately, regardless of the data system. Because weasel species are currently lumped in the harvest data, it is of little use for tracking population trend or distribution for any of the three species.

5. We suggest that Alberta needs to develop an index of abundance for each species based on a thorough analysis of correlations between harvest and various indices of effort, and the findings of others. Catch per unit effort indices are most useful as indirect indicators of population trend, and work best when annual harvest efforts are relatively stable. These indices are prone to biases, including the trapper's reaction to perceived increases or decreases in abundance. Alternatively, if a surrogate for effort is not determined, provincial harvest analysis should be restricted to examination of species distribution. More direct methods of measuring trapper effort are most desirable but are rarely practical.

6. Whichever data collection systems are used, data verification routines are essential and required to enhance consistency. These should include front-end verification routines to catch entry errors. In addition, each year all collected data should be summarized and scrutinized for accuracy and validity.

7. We have presented a preliminary examination of distribution for selected Alberta furbearers. A more detailed examination is warranted, but first a thorough clean-up of all databases needs to be done. Errors need to be reconciled using original dataforms and a single source selected for analysis. Further investigation of correlates to harvest may also be desirable using the cleaned database. 


\subsection{INTRODUCTION}

Most jurisdictions in North America collect trapper harvest data in one form or another on an annual basis (Obbard et al. 1987). In Canada, these data are summarized and reported by Statistics Canada for each jurisdiction (Statistics Canada 2000). Use of these data within jurisdictions varies widely. Some jurisdictions use these data to reflect population size or trends; however, most also recognize that problems exist using such data at face value. One of the central questions is whether furbearer harvest levels correlate to population size, and whether the correlation is good enough to be used as a monitoring tool without any measure or index of trapper effort. In addition, if the correlation between harvest level and population size is not close, can the data be used to monitor species distribution?

Here we examined possible methods of using furbearer harvest data from Alberta to evaluate furbearer population abundance, trend and distribution. Primary objectives of this study were:

- Review the literature on the advantages and disadvantages of using trapper harvest data.

- Determine what furbearer data is available for Alberta, how it is collected, potential biases, and what species are recorded.

- Examine the correlation between harvest level, pelt price, and number of trappers for Alberta data.

- Provide a general protocol for using historical trapping records to examine population trend data in distribution and abundance.

- Point out gaps in the data and suggest changes to harvest data collection protocols to improve species abundance and distribution information in the future.

\subsection{Furbearer Harvest Data}

Erickson (1982) provided a comprehensive review of furbearer harvest data collection sources, much of which is equally relevant today. These are summarized below in point form:

1. Registration of pelts can be via compulsory (mandatory) reporting by the harvester, or compulsory inspection. Usually, pelts are marked (often termed "sealed") during the inspection and data on sex or size are collected at the same time. It is assumed that all harvested animals are submitted; thus compliance by harvesters is essential. Rigorous enforcement helps ensure compliance. Regulations must specify that all animals be submitted even if they are not destined for the fur market (e.g., trophy use, domestic use, etc.).

Advantages: This method is potentially accurate, and harvesters can provide additional information, including date, location, and if pelts or carcasses are submitted to authorities, biological data can be obtained.

Disadvantages: It is unsuitable for large harvests, better for species with well-defined management needs, typically low abundance, limited distribution, or low tolerance to harvest. 
2. Trader transaction reports (fur dealer records) are records of fur purchases maintained by licensed furtraders. It is crucial that only original sales are tabulated, because pelts may be traded among traders, resulting in multiple tabulation of single pelts. Imported non-resident furs must be identified, and resident furs sold outside the jurisdiction can be estimated from trapper mail surveys. Traders should record for each transaction the permit information, species, and harvest location (trapline, wildlife management unit, etc.), so that the harvest can be summarized on an area-specific basis. Compliance by furtraders is crucial. Both hunted and trapped species can be tracked by this system as long as the majority of furs are sold on the open market.

Disadvantages: This method includes only animals that were marketed. When pelt prices are high, this generally includes all fur taken. But when prices are low, recreationally motivated harvests often are not sold and actual harvest is underestimated. Concurrent mail surveys can be used to estimate hunter harvest of furbearers that are also important game animals.

3. Export permits are documents authorizing shipment of furs across provincial or state borders. While they are a convenient method to estimate commercial harvests, they provide no information on harvests that do not enter the fur trade (recreational harvest or domestic use; as above). Generally, this method does not identify the specific locations of harvest within the jurisdiction. In Canada, interprovincial enforcement cooperation deters illegal shipments.

4. Furtaker reports (trapper affidavits) are important in Canada where public lands are managed using registered traplines. All harvesters return report forms at the end of each season (or in the fall when re-applying for a trapping license), thus the entire population of trappers is tallied, not just its successful members. Harvest effort (trap-nights) can be obtained, although in practice this is rarely done.

Disadvantages: Subject to a variety of response and non-response biases; trappers either understate actual harvests to "protect" productive trapping areas, or exaggerate their catch to pamper their egos or reflect what their catch should have been under "normal" circumstances. This method is most useful if the response rate is sufficient to allow tabulation of harvests directly from reports, rather than through extrapolation from partial returns.

5. Sample surveys (or mailout questionnaires) do not directly enumerate the harvest, but obtain data from a representative sample to estimate the efforts and success of the entire population. Precision of the estimates can be estimated from the survey itself. It is possible to collect data on harvest effort and success rates.

Disadvantages: Mail surveys do not get full response rates, an inherent problem to sample surveys. This method is also subject to a variety of response and non-response biases. 


\section{$\underline{1.2 \text { Factors Affecting Use of Furbearer Harvest Data }}$}

A number of authors have examined the use of furbearer harvest data to study trends in population abundance and distribution (Erickson 1981, 1982; Strickland and Douglas 1981; Raphael 1994; Strickland 1994; Chilelli et al. 1996; Lewis and Zielinski 1996; Petersen 1997). Most agree that harvest returns may be roughly indicative of, but do not directly represent, real population changes. For example, Petersen (1997) used harvest data to show trends in wolverine (scientific names provided in Table 1) population size in Alberta from 1970 to 1995, but nevertheless stated that harvest data probably do not accurately reflect population size or trends in the province.

A host of factors can influence trapper effort and success, and hence harvest returns, including changes in target species population numbers, season length, quota changes, trap type restrictions, fur prices, weather, socio-economic conditions, trapper skill and motivation, subsidies, mode of transportation, and access (Brand and Keith 1979, Erickson 1981, 1982, Todd and Boggess 1987, Mowat 
Table 1. Species recorded in the 1977-78 to 1998-99 Alberta fur harvest database (original data; $n=4,507,229$ pelts).

\begin{tabular}{|c|c|c|c|}
\hline Species & $\begin{array}{l}\text { Scientific } \\
\text { name }\end{array}$ & No. of pelts & Comments \\
\hline Badger & $\begin{array}{l}\text { Taxidea } \\
\text { taxus }\end{array}$ & 1,800 & Over 1,000 harvested in $1977-78:$ data error? \\
\hline Bear-black & $\begin{array}{l}\text { Ursus } \\
\text { americanus }\end{array}$ & 2,367 & \\
\hline Bear-grizzly & Ursus arctos & 32 & 21 recorded in 1985-86: data error? \\
\hline Beaver & $\begin{array}{l}\text { Castor } \\
\text { canadensis }\end{array}$ & 632,972 & \\
\hline Bobcat & Lynx rufus & 729 & $\begin{array}{l}520 \text { harvested from } 1 \text { RFMA in 1984-85: data } \\
\text { error? }\end{array}$ \\
\hline Cougar & $\begin{array}{l}\text { Felis } \\
\text { concolor }\end{array}$ & 22 & None recorded since $1982-83$ \\
\hline Coyote & Canis latrans & 104,830 & \\
\hline Fisher & $\begin{array}{l}\text { Martes } \\
\text { pennanti }\end{array}$ & 36,281 & \\
\hline Fox - red & $\begin{array}{l}\text { Vulpes } \\
\text { vulpes }\end{array}$ & 17,464 & Recorded by colour phase to $1995-96$ \\
\hline Fox - arctic & $\begin{array}{l}\text { Alopex } \\
\text { lagopus }\end{array}$ & 66 & Most from $1977-78$ to $1980-91$ \\
\hline Lynx & $\begin{array}{l}\text { Lynx } \\
\text { canadensis }\end{array}$ & 62,878 & \\
\hline Marten & $\begin{array}{l}\text { Martes } \\
\text { americana }\end{array}$ & 180,684 & \\
\hline Mink & $\begin{array}{l}\text { Mustela } \\
\text { vison }\end{array}$ & 93,692 & \\
\hline Muskrat & $\begin{array}{l}\text { Ondatra } \\
\text { zibethicus }\end{array}$ & 647,809 & \\
\hline Other & & 41,712 & Up to 17,000 "units" some years, 0 in others? \\
\hline Otter & $\begin{array}{l}\text { Lontra } \\
\text { canadensis }\end{array}$ & 6,229 & \\
\hline Rabbit (hare) & Lepus sp. & 2,768 & 2,752 pelts in $1977-78$; data error! \\
\hline Raccoon & $\begin{array}{l}\text { Procyon } \\
\text { lotor }\end{array}$ & 1,810 & 1,550 pelts in 1998-99: data error \\
\hline Skunk & $\begin{array}{l}\text { Mephitis } \\
\text { mephitis }\end{array}$ & 1,208 & 691 pelts in $1982-83$ : data error? \\
\hline Squirrel - red & $\begin{array}{l}\text { Tamiasciurus } \\
\text { hudsonicus }\end{array}$ & $2,475,518$ & \\
\hline Weasel & Mustela spp. & 189,818 & \\
\hline Wolf & Canis lupus & 5,526 & \\
\hline Wolverine & Gulo gulo & 1,014 & $\begin{array}{l}145 \text { pelts in 1982-83: suspicious ( } 1 \text { RFMA with } \\
44 ? \text { ) }\end{array}$ \\
\hline
\end{tabular}


et al. 2000). Each factor can influence harvest returns independently, or in conjunction with other factors. For example, snowmobiles became readily available in the late 1950 s and early 1960s, likely influencing trapper coverage, access and attitudes. Harvest of some species may be influenced by market adjustments of other species, as increased incidental take, or as effort is diverted towards more valuable species (Erickson 1981).

Fur prices have often been suggested as influencing harvest returns. In Missouri, there was a positive correlation between market values (mean pelt value) and annual harvest for raccoon and coyote, but not muskrat and beaver (Erickson 1981). Seasonal trapping mortality of lynx in central Alberta increased 2-4 fold with a doubling of pelt prices (Brand and Keith 1979). Lynx harvest levels in northwestern Canada during the 1990 peak were significantly below peaks observed during the early 1960 s, 1970 s, and 1980 s, probably related to the 10 -fold decrease in pelt prices over the last half of the 1980's, and hence lower trapper effort (Mowat et al. 2000). This decrease in trapper effort was real; NWT trappers related that they were not interested in spending money on gas and equipment for $\$ 60$ lynx when they received over $\$ 600$ per pelt only a few years earlier (Mowat et al. 2000). Many turned to wage jobs rather than trapping; the number of active trappers in the NWT dropped from about 3,200 in the mid-1980s to 1,400 in the early 1990s (NWT Resources, Wildlife and Economic Development, Yellowknife). However, while fur prices likely affect harvest effort over the short term, it may not be valid to compare and contrast inflation-adjusted prices and harvests that occurred decades apart.

Powell (1993) found a positive relationship between fisher pelt price and the number of fisher harvested in Canada from 1948-77. To examine trends in fisher harvest in California from 1919 to 1946, Lewis and Zielinski (1996) used both mean fisher pelt price and mean price of sympatric species (species that occur in the same ecosystems), reasoning that captures of fisher would increase with effort expended towards the capture of these sympatric species. They found that the number of fishers harvested was related to the number of licenses sold and the grand mean pelt price, but not fisher pelt price or the number of sympatric species harvested. Note that annual sample size was small in this analysis $(\bar{x}=19$ fishers $)$.

Chilelli et al. (1996) examined river otter harvest data in 7 northeastern states. They found otter harvest was positively correlated with beaver harvest, and with average beaver pelt price from the previous year. However, only a few states showed correlations between otter harvest and licence fees, season length, trapping effort, bag limit or pelt prices, suggesting that river otter harvest cannot be reliably predicted from otter management regulations or socio-economic influence in this region.

Other studies have reported relationships between furbearer harvest and pelt prices (Butler 1942, Bailey 1981), season length (Parsons and Brown 1981), and the number of trapper licences sold (Chabreck et al. 1985). In the northeastern states, otter harvest may be incidental to beaver trapping (Bailey 1981). 
Sex and age ratios in the harvest of most species change as the season progresses. For example, among lynx populations, trapper harvests are generally biased towards yearlings and males early in the season, with increased proportions of kittens in the harvest after Christmas (Bailey et al. 1986, Quinn and Thompson 1987, Slough and Mowat 1996, Poole 1997). Female otters occurred in greater proportion earlier in the season, regardless of the length of the trapping period (Chilelli et al. 1996); suggesting that among-year comparisons of sex ratios must control for season of capture.

\subsection{Ways to Use Furbearer Harvest Data}

A number of researchers have outlined data requirements for determining the status of furbearer populations. Harvest per trapper or harvest per successful trapper are generally not considered useful indicators, as they measure only success rate (Strickland 1994). Total harvest and success rate can remain high even as the population declines if trappers expend more effort (Thompson and Colgan 1987), or success rate may decline if there is an increase in the number of trappers capturing the same number of animals (Erickson 1982).

Catch per unit effort (CUE; Dixon 1981), also known as harvest per unit of trapping effort (HUE; Strickland 1994) can be used as an indirect indicator of population trend (Chilelli et al. 1996). This index is widely used in fisheries (Ricker 1975). Wilson et al. (1996) suggested that estimates of abundance can only be determined when harvest effort is accurately quantified, i.e., expenditure, number of trappers, or unit effort (trap-nights). This analysis assumes population closure (a reasonable assumption at a large scale and for most species), and that vulnerability to trapping does not vary among trapping periods (a more tenuous assumption). Also, the unit of effort, which is affected by the type of trap used, trap set, weather, and trap density, must be consistent from year to year (Caughley 1977). Thus while CUE may not be reliable on its own, it may be valuable in combination with other sources of data (Strickland 1994). Reliable CUE indices require that trappers keep accurate records. Fortin and Cantin (1990) found that CUE correlated strongly $(r=0.99)$ with marten density. Small harvests $(<100)$ can increase the potential for error using CUE indices (Strickland 1994).

Raphael (1994) suggested that harvest records can be useful for determining local presence of a species, and moderately useful for geographic distribution, relative abundance, trend, and density, assuming harvest effort is quantified. These data are best verified with trends derived from sitespecific studies. Erickson (1982) suggested that harvest data may indicate geographical differences in abundance, and even identify temporal shifts in abundance and distribution.

More accurate analysis or trends in furbearer populations can be obtained by combining harvest level, a measure of trapping effort, and age-specific pregnancy rates, litter size, and survival (Strickland 1994). However, the latter 3 variables require extensive carcass collections and ongoing field research studies, beyond the scope of most jurisdiction-wide monitoring efforts. CUE can be combined with sex and age ratios to monitor harvest rates and population trend in 
furbearer populations (Strickland and Douglas 1981, Strickland 1994). This works for species where a relationship between sex or age ratio in the harvest and relative harvest intensity has been established. This relationship is primarily a result of differences in vulnerability between sexes; generally males have greater vulnerability to harvest than females because of their greater range and more intense response to scent baits. Young animals tend be more vulnerable than adults for similar reasons. For example, sex ratio in the harvest can be used as an inexpensive method to determine harvest level for fisher, where it was established through field research that in years when the sex ratio favoured females "the harvest (and presumably the population) declined" (Strickland and Douglas 1981). The proportion of kittens in the lynx harvest has been used to indicate relative recruitment, and gauge the timing of season closures during cyclic lows (Slough 1996).

Dixon (1981) suggested that it is also possible to determine population trend by using changes in the proportion of a species in the harvest relative to harvest of other species, on the assumption that 1 species is generally caught as a bi-product of harvest efforts on others. This in effect is an examination of the change in species composition of the total harvest. This analysis works best when all species can be captured in the same trap types, 5-6 species are used in the calculations, and the sample sizes among species are approximately equal.

\subsection{Review of Alberta Furbearer Harvest Data}

Alberta manages its fur harvest on Crown land using a registered trapline system, established to eliminate competitiveness in wild fur harvest by allocating exclusive trapping rights for a defined area (Slough et al 1987). Begun in 1939, the approximately 1,700 Registered Fur Management Areas (RFMA) comprise about $56 \%$ of the province's area (Fig. 1). Registered trappers (senior licence holders and their trapping partners) are licenced to trap on an RFMA for 5-year renewable terms (but see Trapper Effort, below). Average size of an RFMA is about $185 \mathrm{~km}^{2}$ (range 26$2,050 \mathrm{~km}^{2}$; Slough et al. 1987). Harvesting of furbearers is managed via quotas and seasons within Wildlife Management Units (WMU) in the 8 Fur Management Zones, defined in the Alberta guide to trapping regulations as "large tracts of land having similar environmental features" (Alberta Sustainable Resource Development 2000; Fig. 1).

Federal lands, primarily Wood Buffalo National Park (WBNP), and private and other non-Crown lands are not included in the RFMA system. Trappers on private and other non-Crown lands, covering much of Alberta's prairie and parkland, are licenced under resident fur management licences. In addition, Indian and Métis fur management licences are granted for within the boundaries of Indian Reserves and Métis Settlements. Indian and Métis are allowed to trap within WBNP; these data are available from the park office in Fort Smith, NWT. Animals harvested from federal, private and other non-Crown lands may find their way into the Alberta data system if mandatory registered animals (see below) are sold in Alberta, or if the fur is exported from the province. If the fur buyer notes a WBNP trapping number, it may be incorrectly entered as an RFMA (F. Kunnas, Alberta Sustainable Resource Development, personal communication). Trapping is not permitted within the Rocky Mountain National Parks. 
Alberta implemented a computerized fur harvest data system in 1977-78, derived initially from fur dealer returns (Slough et al. 1987). All data were cross-referenced to RFMA number. Twenty-two species are covered in this database (Table 1). Starting in 1988-89, mandatory registration was implemented for 4 species, lynx, fisher, wolverine and otter, under a system which recorded the trappers name and address, species taken, method of capture, sex, both harvest and registration date, and RFMA and Wildlife Management Unit (WMU). Trappers had to present the pelts from these 4 species to government offices within 30 days of the close of the season. Starting in 1996-97, fur harvest summaries were based on trapper affidavits; essentially each trapper reported his or her previous years' catch when re-applying for a trapping licence in the fall. Since trapper affidavits are not collected until the fall after the close of the previous trapping year, summaries from export permits are generally provided to Statistics Canada for annual provincial reporting.

No area-specific furbearer harvest data are collected from resident trappers in the "white zone" outside of the RFMAs (B. Treichel, Wildlife Information Specialist, Alberta Sustainable Resource Development, personal communication), which includes private and other non-Crown land covering much of the Alberta prairie and parkland. A proportion of some species harvested in the white zone, notably beaver and coyote, end up recorded in export permits. Similarly, hunted species, primarily coyote, also may end up recorded in export permits. Theoretically, any of the 4 species requiring mandatory registration, lynx, wolverine, fisher and otter, should be tallied in the registered species files. However, all records in the 4 registered species databases had associated RFMA numbers, suggesting that no "non-RFMA" areas were represented.

Trapper questionnaires were conducted annually in Alberta from roughly the late 1970s to the late 1980s (A. Todd, Alberta Sustainable Resource Development, personal communication). Trappers on RFMAs were questioned on the presence, trend and abundance of a variety of wildlife, including 7 species of furbearers, and trapper effort was assessed by the number of days spent on trapping areas (Meredith and Todd 1979, Skinner and Todd 1988). Except for years 1977 and 1987, these annual questionnaires were not available to us. 

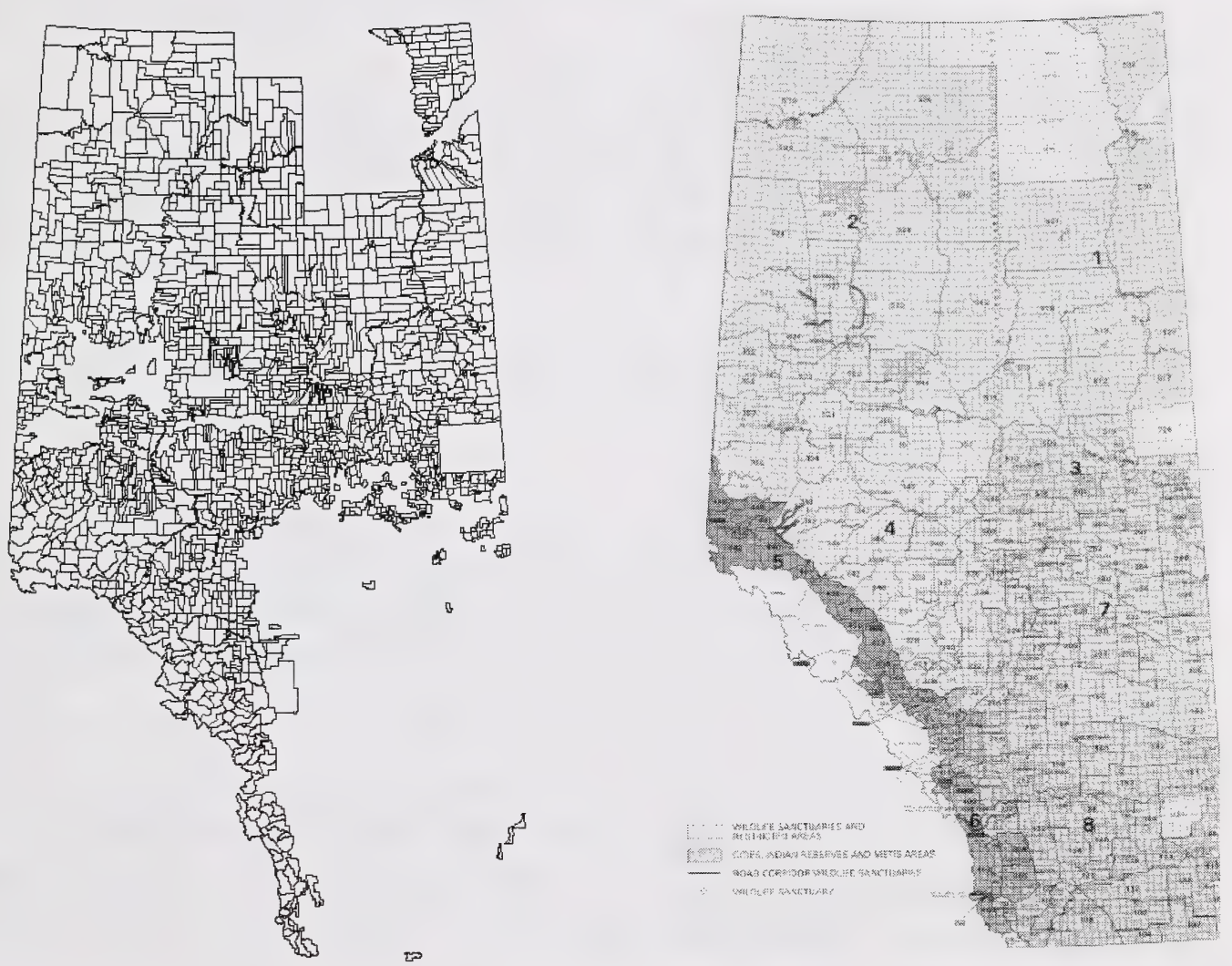

Figure 1. A. Registered Fur Management Areas in Alberta. Areas outside of the RFMA include Rocky Mountain National Parks, Wood Buffalo National Park, the Cold Lake Weapons Range, and private and other non-Crown land covering much of the Alberta prairie and parkland. B. Alberta Fur Management Zones (numbered 1-8 and coloured on map), and Wildlife Management Units (numbered within each Zone; Alberta Sustainable Resource Development 2000).

Boyd et al. (1977) and Boyd (1977) examined RFMA data derived from trapper affidavits in Alberta from 1970-71 to 1974-75. These examinations included harvest values and trapping trends, and the relative distribution and extent of the harvest of individual furbearer species at the scale of 1:250,000 map sheets. 


\subsection{METHODS}

\section{$\underline{2.1 \text { Alberta Furbearer Harvest Data }}$}

Three (partially overlapping) sources of Alberta furbearer data were obtained:

1. An Access database covering all species harvested between 1977-78 and 1998-99 from registered trappers RFMA (156,988 records and 4,507,229 pelts), which includes RFMA number. Sources prior to 1996-97 are from fur dealer returns, and from 1996-97 on are from harvester affidavits, all from registered trappers. To our knowledge, fur dealer returns were not tabulated after 1996-97.

2. Four Excel spreadsheets covering registered species harvests (fisher, lynx, otter and wolverine) from 1988-89 to 1999-2000. Includes RFMA number, date harvested and date registered, and sex. The source for these data was mandatory registrations, and would theoretically cover all trappers in Alberta.

3. Three Excel spreadsheets covering annual fur sales from 1996-97 to 1998-99. Includes number of each species taken by RFMA number for each year. The source for these data was trapper affidavits from registered trappers. These data were identical to source \#1 for all years except 1996-97 and the inconsistency in that year is unexplained. These data were not used in any analysis, primarily because of the inconsistencies in 1996-97 with the longer time period Access database.

We also obtained hard copy Statistics Canada summaries of the Alberta harvest and total value by species from 1977-78 to 1998-99 (Statistics Canada 2000); we believe that these data were derived from export permit sales. We used the Statistics Canada data to obtain annual mean pelt price for each species. We obtained the consumer price index $(1992=100)$ for Alberta from Statistics Canada to adjust pelt prices for inflation (B. Alain, Statistics Canada, Truro, Nova Scotia, personal communication).

Data errors were obvious in all electronic datasets. In the Access database (\#1 above), species names were not consistent (e.g., marten versus martin), and suspicious harvest levels were numerous (Table 1). RFMA 9, not a valid trapping area (F. Kunnas, Alberta Sustainable Resource Development, personal communication), often had high or suspicious values; most of these were associated with the first year of the computer dataset (1977-78). Incorrect RFMA numbers (those $>2,940$ ) were present, mostly from the first few years of the dataset. For approximately $15 \%$ of registered species records, the recorded date harvested was days to years after the date registered, making it difficult to assign harvest year in many cases since obviously one or the other date was in error. Fully 1,130 lynx were registered 2-8 years after the reported harvest date and represented possible errors; we suspect that it is unlikely that trappers would wait years to register and sell lynx pelts. Year 1900 versus 2000 entry errors were numerous.

Annual fur sales spreadsheets (\# 3 above) contained some incorrect RFMA numbers $(>2,940)$ and suspicious harvest levels (e.g., 999 marten in each of 2 RFMAs in the same year). Miscoded 
species were suspected (but unverified) because of unusually high harvests for species that should not be harvested in such high numbers (e.g., 15 wolverines from 1 RFMA in 1 year, 481 raccoons in 1 year from another). Annual harvest numbers among the 3 electronic data sources over the 1996-97 to $1998-99$ seasons varied from as little as $4 \%$ to as much as $100 \%$ difference, with annual trapper affidavits always higher than pelt registration numbers (see figures below).

The above-mentioned errors added a great degree of uncertainty and inaccuracy to the data. We were forced to either delete the data, or make judgement calls as to how to "fix" it. Our handling of suspected data errors varied depending somewhat upon how we analyzed the data. We standardized species names for analysis. We deleted obviously suspicious or highly unusual harvest values, although these spurious records would have limited impact on spatial analysis. We deleted data when RFMA number equalled 9 or was greater than 3,000. In the dataset for the 4 species requiring mandatory submission (registration), we corrected obvious year 1900/2000 errors, and we somewhat arbitrarily assumed the harvest date was correct where the year registered and year harvested differed.

The various fur datasets posed a number of problems for analysis, including which dataset to use for which species and which application. For the 4 registered species, we had 3 differing annual harvest estimates for 1996-97 to 1998-99, all of which generally differed from Statistics Canada numbers (presumably from export permits). For most species, annual harvests from Statistics Canada were higher, in some cases significantly higher, than those obtained from fur dealer records/trapper affidavits (Access database). Exceptions to this generalization often occurred after 1996-97, for example, bobcat, otter and wolf harvests from trapper affidavits were considerably higher than recorded in Statistics Canada statistics. For fisher, annual harvests from Statistics Canada were always higher than the other 2 datasets, and the Access database varied either higher or lower than annual values obtained from the registered database. For lynx, the annual harvests recorded in the Statistics Canada files were higher than from the registered database, which were in turn almost always higher than the fur dealer records/trapper affidavits.

Species primarily harvested outside of the RFMAs (e.g., badger, coyote) were generally poorly represented in the Access (fur dealer record/trapper affidavit) and annual (trapper affidavit) databases. At the extreme, only 4\% of badger harvest since 1977-78 (as determined from Statistics Canada records) were recorded as harvested on RFMAs in the fur dealer/trapper affidavit databases. Other species poorly recorded in RFMA-related databases were coyote $(16 \%$ of the harvest from Statistics Canada since 1977-78), red fox (30\%), and muskrat (30\%). Half to two-thirds of bobcat $(51 \%)$, beaver $(53 \%)$, mink $(60 \%)$, red squirrel $(64 \%)$, wolf $(66 \%)$, and weasel $(68 \%)$ were recorded in RFMA-related databases compared to Statistics Canada data, while there was better agreement between datasets for species harvested primarily in more northern boreal habitats covered by RFMAs (lynx: 76\%; fisher: 81\%; marten: 82\%; otter: $85 \%$; wolverine: $86 \%$ ). The distribution of each species in Alberta and the expected harvest by resident trappers appeared to be closely related to the proportion of the total harvest (as compared to Statistics Canada, export permit numbers) represented in the RFMA-related databases. 
This disparity in harvest numbers derived from the RFMA-based systems meant that it was unrealistic to conduct spatial trend analysis on species where a significant proportion of the provincial harvest came from prairie or parkland habitats (resident trappers). It also suggests that even annual provincial harvests from RFMA-based systems would under-estimate "true" harvests (presumably more closely approximated by provincial export permits) by upwards of $15-95 \%$. Therefore, we used the Access database to examine temporal and spatial harvest trends pertaining to species primarily harvested in the areas covered by the RFMAs (wolf, lynx, fisher, marten, otter and wolverine). While annual harvest numbers from all 3 data sources were displayed, examination of annual harvests over time was conducted using Statistics Canada data.

\subsection{Examination of Alberta Furbearers}

Trapper effort: We examined use of the number of trappers licenced in Alberta over time as a surrogate for trapper effort (Fig. 2). While resident trapper (those trapping outside of RFMAs) numbers declined markedly over time, dropping about $85 \%$ from the early 1980 s to the late 1990 s, the number of registered trappers (those trapping on RFMAs) declined only marginally (10\%). In 1996-97 the requirement for trapping partners to be registered was dropped, resulting in an instant decline of about 1,000 registered trappers (B. Treichel, Alberta Sustainable Resource Development, personal communication). In an attempt to standardize these data, we added 1,026 trappers (the difference of registered trappers between 1995-96 and 1996-97) to all subsequent years. Even with this correction, we suggest that the number of registered trappers is not a good indicator of trapping effort, primarily because it does not represent the number of active trappers, but only those that kept their RFMA active, (i.e., essentially all RFMA holders). It is very unlikely that trapper effort in Alberta declined by only $10 \%$ over 


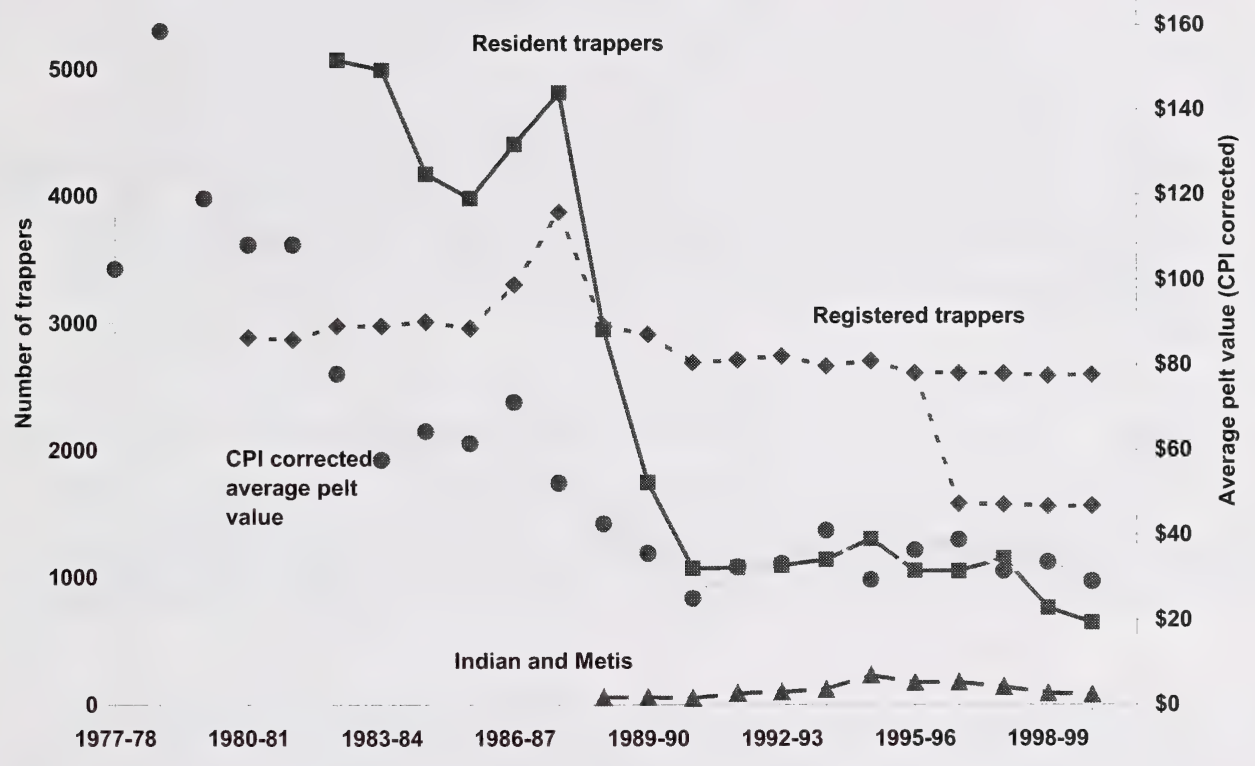

Figure 2. Number of registered (see text), resident, and Indian/Metis trappers in Alberta, and weighted average pelt price (adjucted for inflation using the consumer price index [CPI]) for beaver, coyote, lynx and marten in Alberta, 1977-78 to 1999-00.

the past 22 years. Trapper questionnaires suggested that trapper spent fewer days on their traplines in 1987 (mean of 69 days) compared with 1977 (82 days; Meredith and Todd 1979, Skinner and Todd 1988).

Fur prices have often been suggested as driving harvest effort and influencing harvest returns (see discussion above). Lewis and Zielinski (1996) found that number of fishers harvested in California was positively related to the price paid for a group of sympatric species. To derive an index of trapper effort over time we combined total harvest and value (inflation adjusted) to obtain an average pelt price for the 4 "bread and butter" species in the Alberta fur system: lynx, marten, beaver and coyote. These 4 species have consistently contributed the greatest total value to the Alberta harvest, and we reasoned that fluctuations in trapper effort would most likely correlate to the price paid for these 4 core species. Average price for these species declined roughly $70 \%$ from the late 1970 s to the late 1990 s (Fig. 2) and correlated well with the number of resident trappers $\left(r^{2}=0.83, P=0.0001\right)$, but not the adjusted number of registered trappers $\left(r^{2}=\right.$ $0.15, P=0.09)$.

Alberta fur harvest analysis: Following we provide graphic display and analysis of Alberta furbearer data on a species by species basis. Annual provincial harvests were displayed using Statistics Canada data, summaries from the Access database of fur dealer returns and trapper 
affidavits for RFMAs, and the data from the registered species. Analyses were not conducted for species taken in very low numbers or of negligible furbearer management priority (grizzly bear, cougar, arctic fox, rabbit, raccoon, and skunk), or black bears (we assume primarily taken through hunting). We used Pearson rank correlation (SAS Institute 1997) to examine the relationship between annual harvest and 1) inflation-adjusted pelt price for that species, 2) average pelt price for the 4 core species, and 3) annual harvest and pelt price for species for which we believed there would be a correlation (based on trapping practises or spatial/ecosystem overlap). Correlation data are presented for the best-fit relationships we obtained, and are depicted as regression lines and $r^{2}$ values calculated by MS Excel. We acknowledge that our process was somewhat ad hoc, and was prone to spurious results.

For selected species (fisher, marten, lynx, otter and wolverine) we provided a proposed crude index of abundance. We based these indices of abundance on the strongest correlations between that species annual harvest and pelt price (fisher, lynx, and marten), or the pelt price of a species that we or the literature suggests to a large extent drives the harvest for that species (otter with beaver, and wolverine with lynx). These indices of abundance were derived from the ratio of harvest numbers to pelt price; we scaled each index by a factor 10 to 1,000 for display purposes.

We conducted spatial analysis using ArcView (ESRI, Redlands, California, USA) and Home Range Extension (Rodgers and Carr 1998). All spatial analyses were limited by a lack of data from areas not covered by RFMAs. Temporal analysis of spatial trend data was realistic only for those species harvested primarily within the boreal ecoregions and covered by RFMAs: fisher, marten, lynx, otter, wolf, and wolverine. Spatial analysis was conducted using 4 5-6 year time periods between 1977-78 and 1998-99, averaged among years within each time period. To provide comparable "harvest densities" among RFMAs of different sizes we dividing by township size (which was the only unit of area for each RFMA we had available to us). We used adaptive kernel analysis (Rodgers and Carr 1998) to visually examine changes in species distribution among the 4 time periods. These kernels, which show contour lines or isopleths of utilization (harvest) distribution, are presented in figures in colour gradients from darkest $(10 \%$ kernel encompassing the central $10 \%$ of harvest) to lightest (70-90\% kernels encompassing the central $70-90 \%$ of harvest). Core areas of harvest could be considered to fall within the darkest 2 $(30 \% \mathrm{kernel})$ or $3(50 \% \mathrm{kernel})$ isopleths. 


\subsection{RESULTS \& DISCUSSION}

\section{$\underline{3.1 \text { Badger }}$}

Annual badger harvest decreased significantly over time (Fig. 3). Badgers harvested in RFMAs made up only a small fraction of the annual harvest as determined by export permits (Statistics Canada). Annual harvest was positively related to average badger pelt price $\left(r^{2}=0.73, P<\right.$ $0.001)$ and average core species pelt price $\left(r^{2}=0.83, P<0.001\right.$; Fig. 4). Badger harvests were correlated with coyote harvests $\left(r^{2}=0.36, P=0.0024\right)$ and coyote pelt price during the same year $\left(r^{2}=0.83, P<0.0001\right)$.

\section{$\underline{3.2 \text { Beaver }}$}

Beaver harvest declined over time (Fig 5), with annual harvest positively related to average beaver pelt price $\left(r^{2}=0.66, P<0.001\right)$ and average core species pelt price $\left(r^{2}=0.49, P=0.002\right.$; Fig. 6).

\section{$\underline{3.3 \text { Bobcat }}$}

Bobcat harvest varied on an annual basis, but showed a general trend of declining numbers (Fig $7)$ that was poorly correlated with average bobcat pelt price $\left(r^{2}=0.25, P=0.025\right)$ and not correlated with average core species pelt price $\left(r^{2}=0.05, P=0.33\right.$; Fig. 8). Low annual sample size $(\leq 51)$ and suspected missing data in some years limited the usefulness of this analysis. Bobcat harvests were weakly correlated with coyote harvests $\left(r^{2}=0.18, P=0.046\right)$ and not correlated with coyote pelt price during the same year $\left(r^{2}=0.03, P=0.40\right)$.

\section{$\underline{3.4 \text { Coyote }}$}

While coyote harvests have generally declined over time, the decline has been less dramatic than seen in other species (Fig. 9). Coyote harvest was positively and linearly correlated with average coyote pelt price $\left(r^{2}=0.35, P=0.003\right)$ and with average core species pelt price $\left(r^{2}=0.33, P=\right.$ $0.005)$, but a logistic relationship with average coyote pelt price better explained the data $\left(r^{2}=\right.$ $0.48, P=0.003$; Fig. 10).

\subsection{Fisher}

After peaking in the early 1980s, fisher harvests initially declined while prices increased (Fig. 11). Some of the observed changes may have been related to season closures and restrictive quotas imposed beginning in the late 1980s. The annual harvest levels from the 3 data sources in 
the 1990s match one-another with a few exceptions. Fisher harvest was positively correlated with average fisher pelt price $\left(r^{2}=0.34, P=0.003\right)$ and with average core species pelt price $\left(r^{2}=\right.$ $0.27, P=0.01$; Fig 12). Fisher harvests were not correlated with marten harvests $\left(r^{2}=0.02, P=\right.$ $0.5)$ or marten pelt price during the same year $\left(r^{2}=0.003, P=0.8\right)$. The decline in fisher harvest during a period of increasing pelt price observed between 1984-1987 suggests a declining population. Spatial distribution of the harvest would also suggest a decline in distribution following 1988-89, notably in the southwest portion of the province (from period 2 to 3; Figs. 13 and 14). Zone closures should not have influenced the spatial distribution of the harvest to any great extent since the decline in spatial distribution of the harvest occurred in areas not affected by closures.

\section{$\underline{3.6 \text { Red fox }}$}

Red fox harvests declined over the study period (Fig. 15). Red fox harvest was poorly correlated with average fox pelt price $\left(r^{2}=0.22, P=0.025\right)$ and with average core species pelt price $\left(r^{2}=\right.$ $0.37, P=0.002)$; here again a logistic relationship with average core species pelt price better explained the data $\left(r^{2}=0.45, P=0.003\right.$; Fig. 16). We expected fox harvests to be correlated with coyote harvest in the prairie and parkland portions of Alberta, and with lynx harvests in the more boreal (RFMA) portions. Fox harvests were correlated with coyote harvests $\left(r^{2}=0.46, P=\right.$ $0.0004)$ and with coyote pelt price during the same year $\left(r^{2}=0.006, P=0.30\right)$. Similarly, red fox harvests were correlated with lynx harvests $\left(r^{2}=0.43, P=0.0007\right)$ and with lynx pelt price during the same year $\left(r^{2}=0.29, P=0.008\right)$.

\section{$\underline{3.7 \text { Lynx }}$}

Lynx harvests and average pelt varied significantly (Fig 17), presumably driven by the cyclic nature of population changes and season closures and restrictive quotas imposed beginning in the late 1980s. Lynx harvest did not correlate with average lynx pelt price over this time period $\left(r^{2}=\right.$ $0.10, P=0.15)$, but did positively correlate with average core species pelt price $\left(r^{2}=0.64, P<\right.$ 0.0001 ; Fig. 18). Relative density of the lynx harvest changed markedly throughout the province since the cyclic peak of the early 1980s (Fig. 19), with a suggested reduction in lynx distribution in portions of west-central Alberta (Fig. 20; Todd 1985). Todd (1985) pointed out a period of conservation concern between 1982-83 and 1989-90 and our analysis supports this concern.

\section{$\underline{3.8 \text { Marten }}$}

Marten harvests and pelt price peaked in the late 1980s, but otherwise showed little trend over the 23 years of data (Fig. 21). We are unable to account for the unusually high harvest recorded from trapper affidavit returns for RFMAs in 1996-97; 2 RFMAs with a suspicious 999 marten harvested each were already removed from the summary, but other significant errors in these data likely are still present. Marten harvests showed a moderate positive correlation with average 
marten pelt price $\left(r^{2}=0.57, P<0.0001\right)$, but no correlation with average core species pelt price $\left(r^{2}=-0.04, P=0.86\right.$; Fig 22). The spatial distribution of marten harvests showed a possible reduction in marten range in the southern Rocky Mountains by the mid to late 1990s, and a significant shift in harvest and presumably populations into east-central Alberta (Figs. 23 and 24).

\section{$\underline{3.9 \text { Mink }}$}

Mink harvests declined over the study period, following a steady decline in mink pelt price (Fig 25). Mink harvests showed moderate to strong correlations with average mink pelt price $\left(r^{2}=\right.$ $0.60, P<0.0001)$ and average core species pelt price $\left(r^{2}=0.76, P<0.0001\right.$; Fig 26$)$. Among the 4 core species individually, mink harvests showed the strongest correlations with lynx harvests $\left(r^{2}=0.71, P<0.0001\right)$, coyote pelt price $\left(r^{2}=0.69, P<0.0001\right)$, and beaver pelt price $\left(r^{2}=0.65\right.$, $P<0.0001)$. Mink harvests were also correlated with muskrat harvests $\left(r^{2}=0.74, P=0.0001\right)$ and with muskrat pelt price during the same year $\left(r^{2}=0.85, P=0.0001\right)$.

\section{$\underline{3.10 \text { Muskrat }}$}

Muskrat harvest declined over time, following closely with average pelt price (Fig. 27). Muskrat harvests showed a strong positive correlation with average muskrat pelt price $\left(r^{2}=0.73, P<\right.$ $0.0001)$ and average core species pelt price $\left(r^{2}=0.66, P<0.0001\right.$; Fig 28). Muskrat harvests were also correlated with both beaver harvests $\left(r^{2}=0.67, P=0.0001\right)$ and pelt price during the same year $\left(r^{2}=0.55, P=0.0001\right)$, and with mink harvests $\left(r^{2}=0.74, P=0.0001\right)$ and pelt price $\left(r^{2}=0.67, P=0.0001\right)$.

\section{$\underline{3.11 \text { Otter }}$}

The Alberta otter harvest fluctuated over time, with no obvious trend (Fig. 29). The annual harvest levels from the 3 data sources in the late 1990s were poorly correlated, with the number of registered otter recorded lower than the other 2 data sources. Otter harvests showed a weak positive correlation with mean otter pelt price $\left(r^{2}=0.31, P=0.006\right)$ and average core species pelt price $\left(r^{2}=0.19, P=0.035\right.$; Fig 30$)$. Otter harvests were correlated with beaver harvests $\left(r^{2}=\right.$ $0.31, P=0.006)$ and beaver pelt price during the same year $\left(r^{2}=0.65, P=0.0007\right)$. However, these results do not tell us whether beaver pelt price or harvest is more highly correlated with otter harvest because beaver harvest and price are also correlated. The otter harvest in Alberta is centred in the east-central portions of the province, and appears to have change little over time except for a possible expansion into west-central portions of the province (Figs. 31 and 32). 
Red squirrel harvests fluctuated from over 1.3 million pelts in $1979-80$ to $<30,000$ in recent years (Fig. 33). Red squirrel harvests showed a weak positive correlation with mean red squirrel pelt price $\left(r^{2}=0.18, P=0.045\right)$ and average core species pelt price $\left(r^{2}=0.28, P=0.009\right.$; Fig 34). Among the 4 core species individually, red squirrel harvest was best correlated with lynx harvests $\left(r^{2}=0.34, P=0.004\right)$.

\section{$\underline{3.13 \text { Weasel }}$}

Weasel harvest declined over time, while pelt price showed no overall trend over time (Fig. 35). Weasel harvests showed a weak, non-significant negative correlation with mean weasel pelt price $\left(r^{2}=-0.15, P=0.07\right)$, and a positive correlation with average core species pelt price $\left(r^{2}=0.52, P\right.$ $<0.0001$; Fig 36). Three species of weasel are found in Alberta (Fagerstone 1987), and likely 2 of them (short-tailed weasel [Mustela erminea] and long-tailed weasel [M. frenata]) are combined in fur records. Among the 4 core species individually, weasel harvest was best correlated with lynx pelt price $\left(r^{2}=0.49, P=0.0002\right)$ and coyote pelt price $\left(r^{2}=0.46, P=\right.$ $0.0004)$. Weasel harvests were also correlated with mink harvests $\left(r^{2}=0.64, P=0.0001\right)$ and with mink pelt price during the same year $\left(r^{2}=0.69, P=0.0001\right)$.

\section{$\underline{3.14 \text { Wolf }}$}

The Alberta wolf harvest generally declined over time, with the reported harvest from RFMAs lower than the export permit-derived harvests, except since 1996-97 (Fig. 37). Since the late 1970s average pelt price has also declined, but has appeared to level off in the past decade. Wolf harvests showed a weak positive correlation with mean wolf pelt price $\left(r^{2}=0.24, P=0.018\right)$, and a stronger positive correlation with average core species pelt price $\left(r^{2}=0.51, P<0.0001\right.$; Fig 38). Spatial analysis of wolf harvest data suggests a reduction in harvest distribution in the northern portions of the province, and increased wolf distribution down the Rocky Mountains and foothills of western Alberta (Figs. 39 and 40).

\section{$\underline{3.15 \text { Wolverine }}$}

Wolverine harvests and average pelt price declined during the study period, although this might have been related to restrictive quotas imposed beginning in the late 1980s (Fig. 41). Annual harvests from export permits, registered reports, and RFMA fur dealer records and trapper affidavit differed within each year. Wolverine harvests showed a positive correlation with mean wolverine pelt price $\left(r^{2}=0.31, P=0.006\right)$, and a stronger positive correlation with average core species pelt price $\left(r^{2}=0.52, P<0.0001\right.$; Fig 42$)$. Spatial analysis of wolverine harvest data was hampered somewhat by low sample sizes (Figs. 43 and 44). A reduction in the density of harvest 
locations was apparent over time. Wolverine harvests were correlated with lynx harvests $\left(r^{2}=\right.$ $0.40, P=0.0012)$ and with lynx pelt price during the same year $\left(r^{2}=0.58, P=0.0001\right)$.

\subsection{Population Trend Indices}

The abundance index for fisher suggests comparatively low numbers during the latter half of the 1980 s, with a rebound in abundance through the 1990s (Fig.11). The lynx abundance index suggests similar low population numbers through the cyclic lows of the 1980s and 1990s, with the lowest abundance during the 1980s (Fig. 17). Marten abundance shows a pattern of irregular fluctuations over time with no consistent trend (Fig. 21). Otter abundance appears to have slowly increased over time (Fig. 29), and the same trend is seen in wolverine abundance, albeit with greater variance (Fig. 41). Irregular fluctuations in the marten index suggest another factor is affecting effort. The same is true for wolverine. The wolverine index is certainly biased because the large variations seen in the index are not possible in a species typified by small annual changes in abundance. The results for wolverine, and to a lesser extent marten, highlight the need to investigate the nature of these indices using a corrected harvest dataset, finer scaled analysis (by region for example), local population data where available, and corroboration from the literature. 


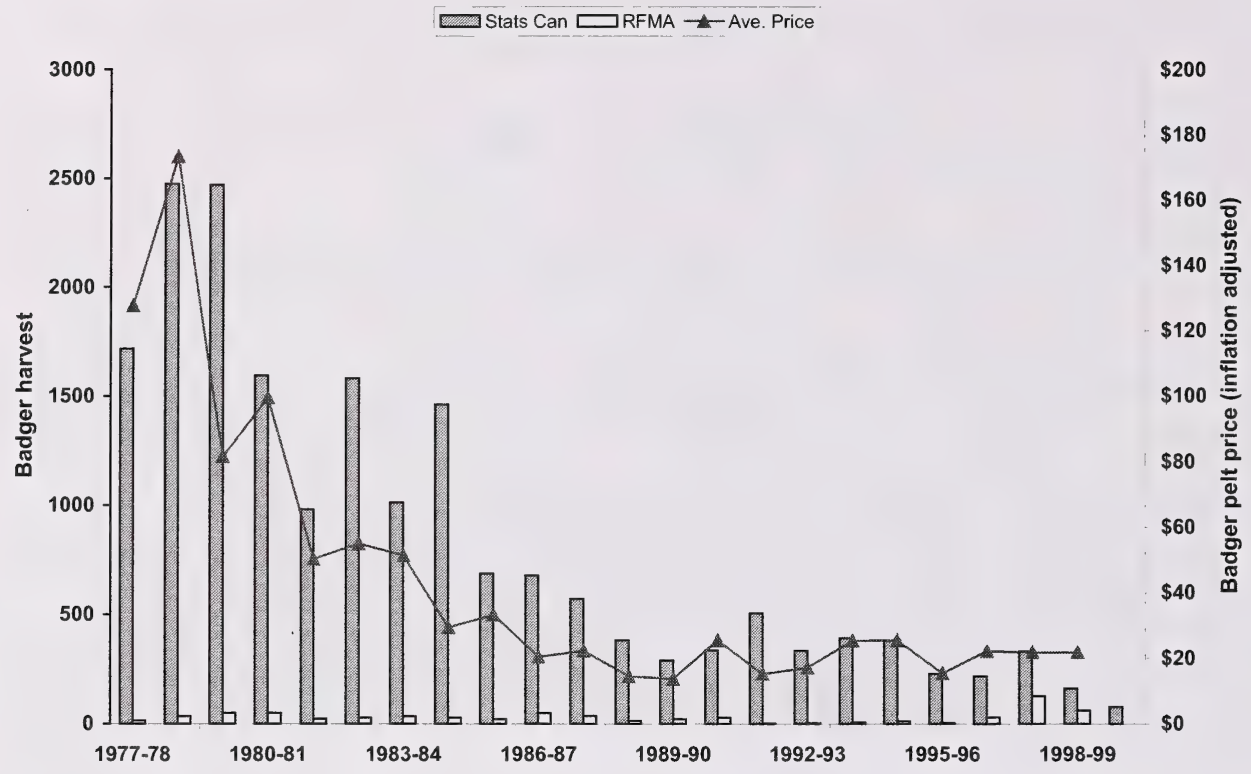

Figure 3. Alberta badger harvest from Statistics Canada (1977-78 - 1999-2000; grey bars) and Alberta data for RFMAs (1977-78 - 1998-99; open bars), with average pelt price (line).

\section{Badger}
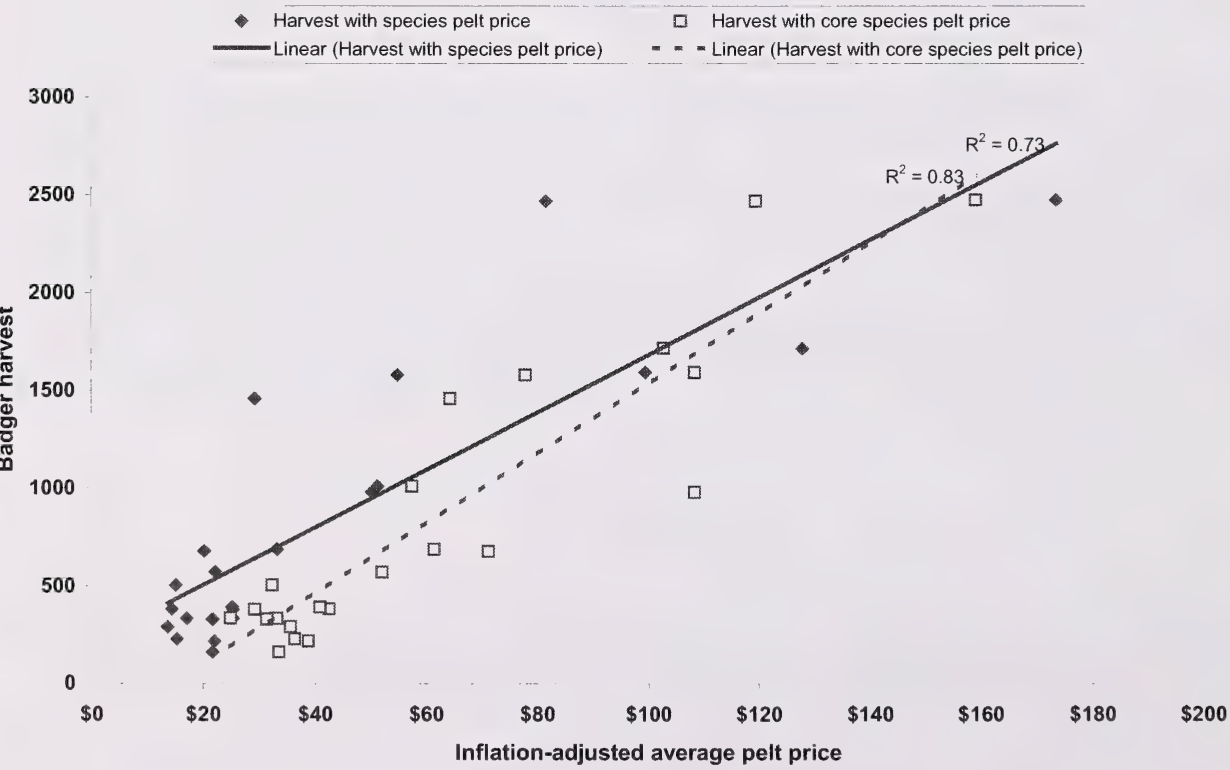

Figure 4. Relationship between annual badger harvest and annual badger pelt price (solid symbols and line), and 4 core species pelt price (open symbols and dashed line), 1977-78 - 19992000. 


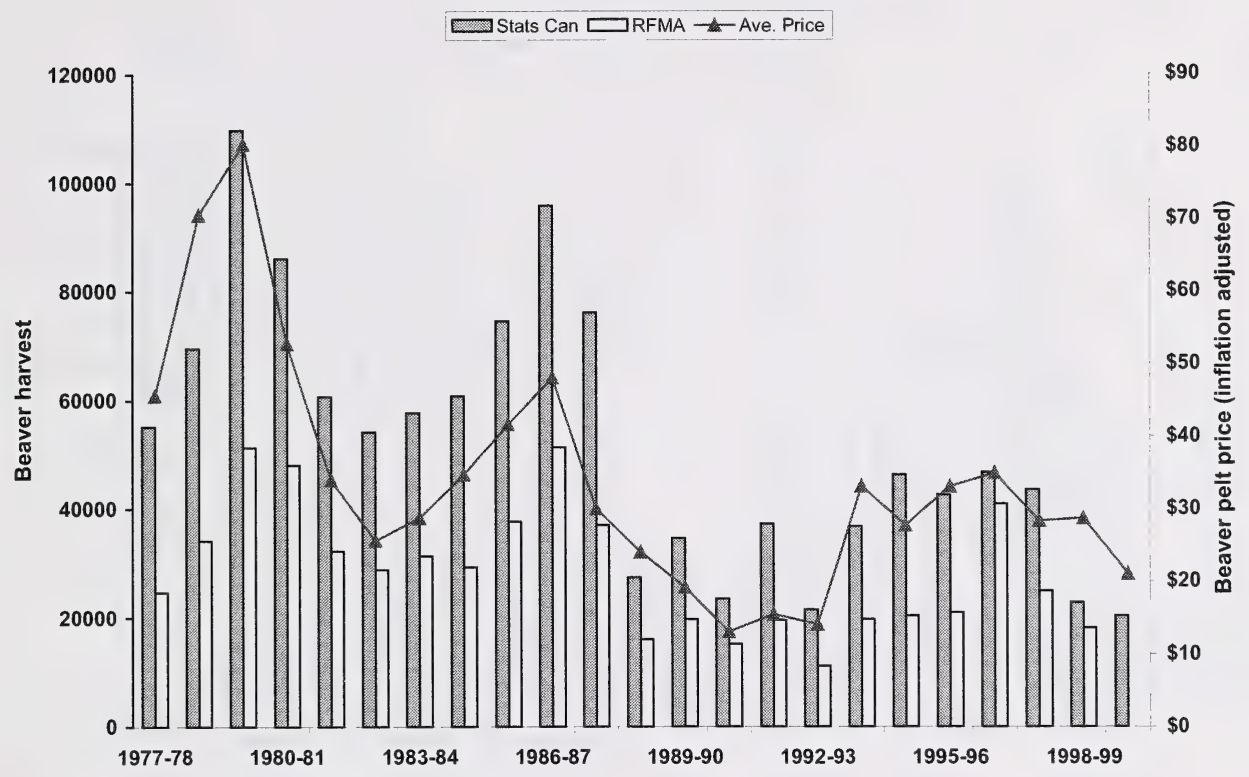

Figure 5. Alberta beaver harvest from Statistics Canada (1977-78 - 1999-2000; grey bars) and Alberta data for RFMAs (1977-78 - 1998-99; open bars), with average pelt price (line).

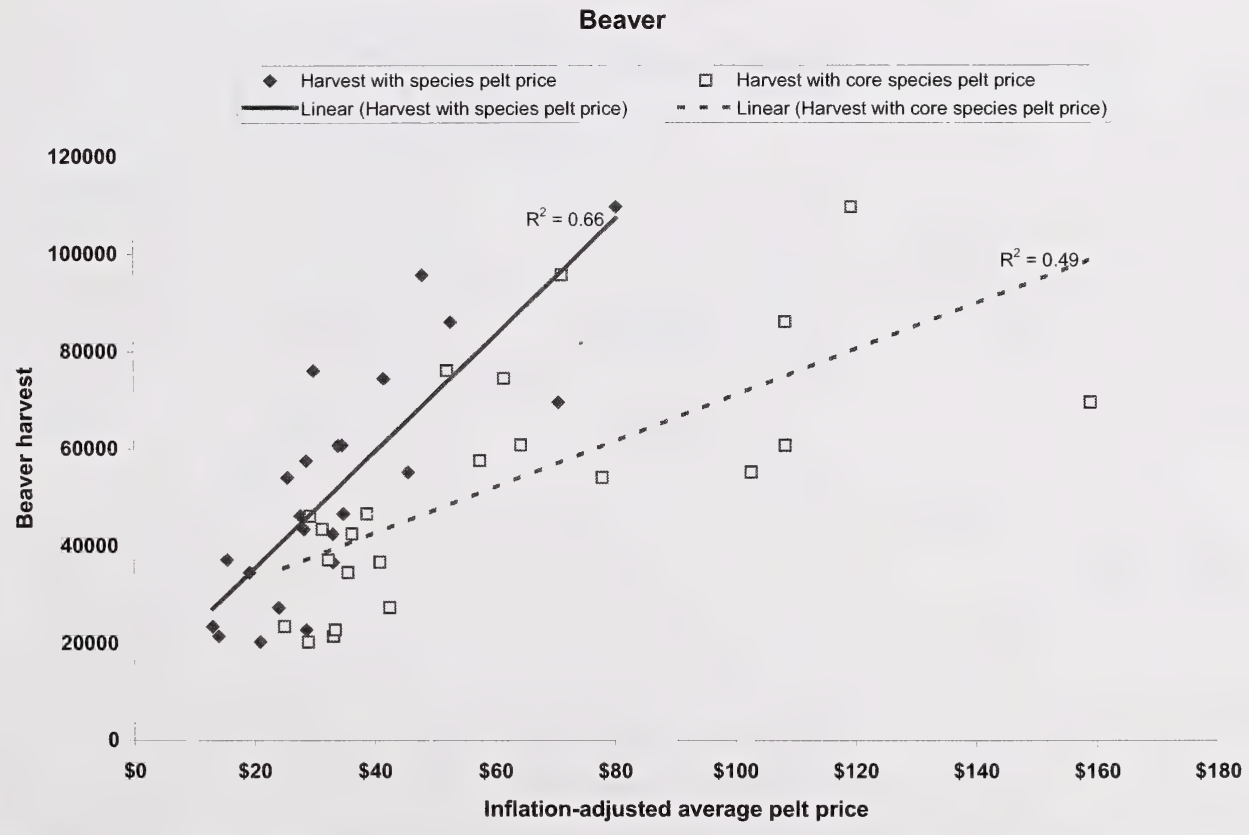

Figure 6. Relationship between annual beaver harvest and annual beaver pelt price, and 4 core species pelt price (solid symbols and line), and 4 core species pelt price (open symbols and dashed line), 1977-78 - 1999-2000. 


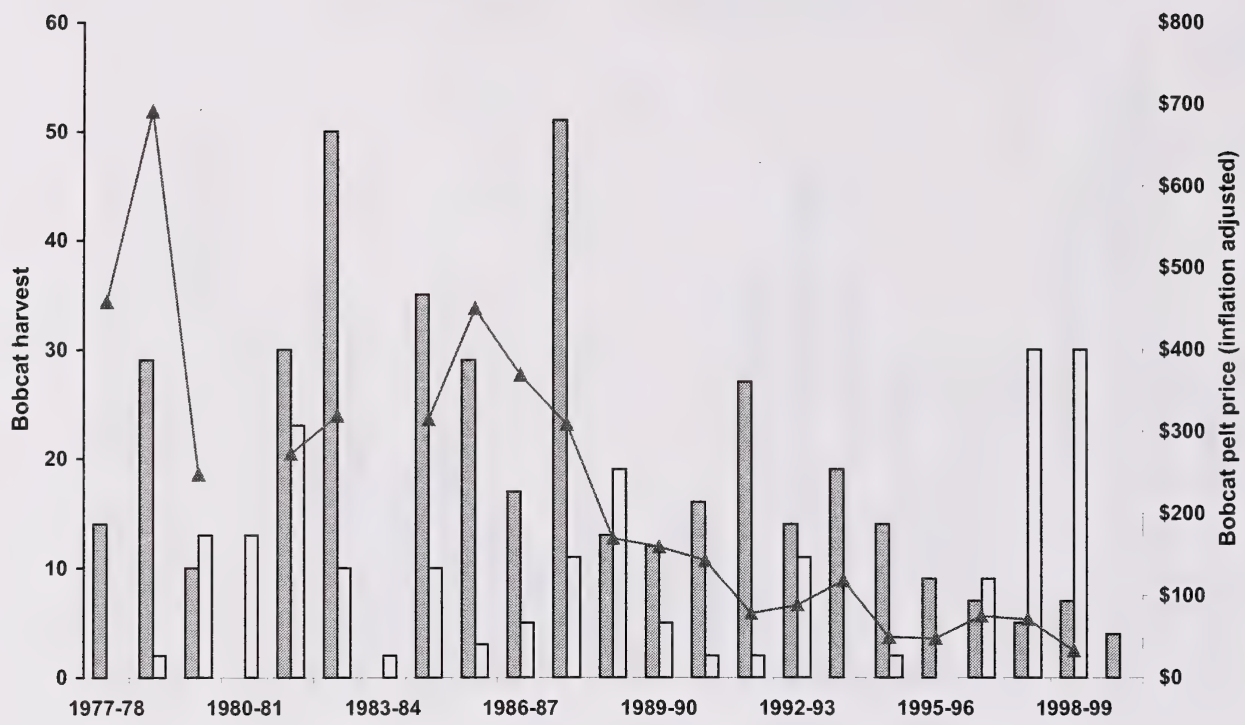

Figure 7. Alberta bobcat harvest from Statistics Canada (1977-78 - 1999-2000; grey bars) and Alberta data for RFMAs (1977-78 - 1998-99; open bars), with average pelt price (line).

\section{Bobcat}

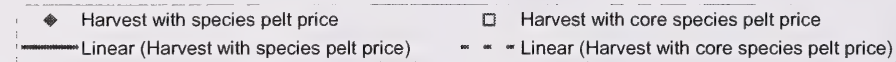

60

$50 \square \square$

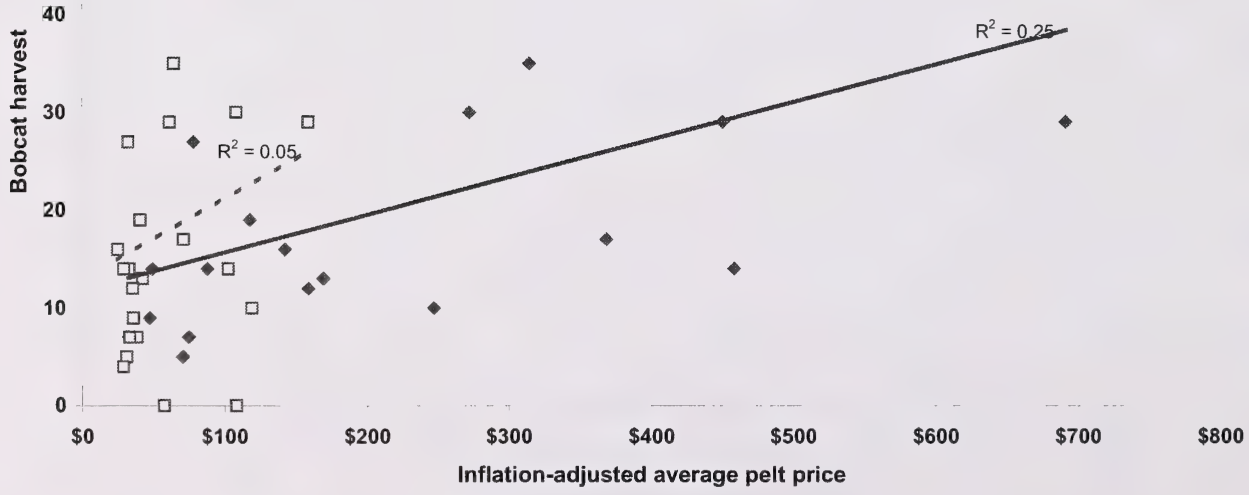

Figure 8. Relationship between annual bobcat harvest and annual bobcat pelt price, and 4 core species pelt price (solid symbols and line), and 4 core species pelt price (open symbols and dashed line), 1977-78 - 1999-2000. 


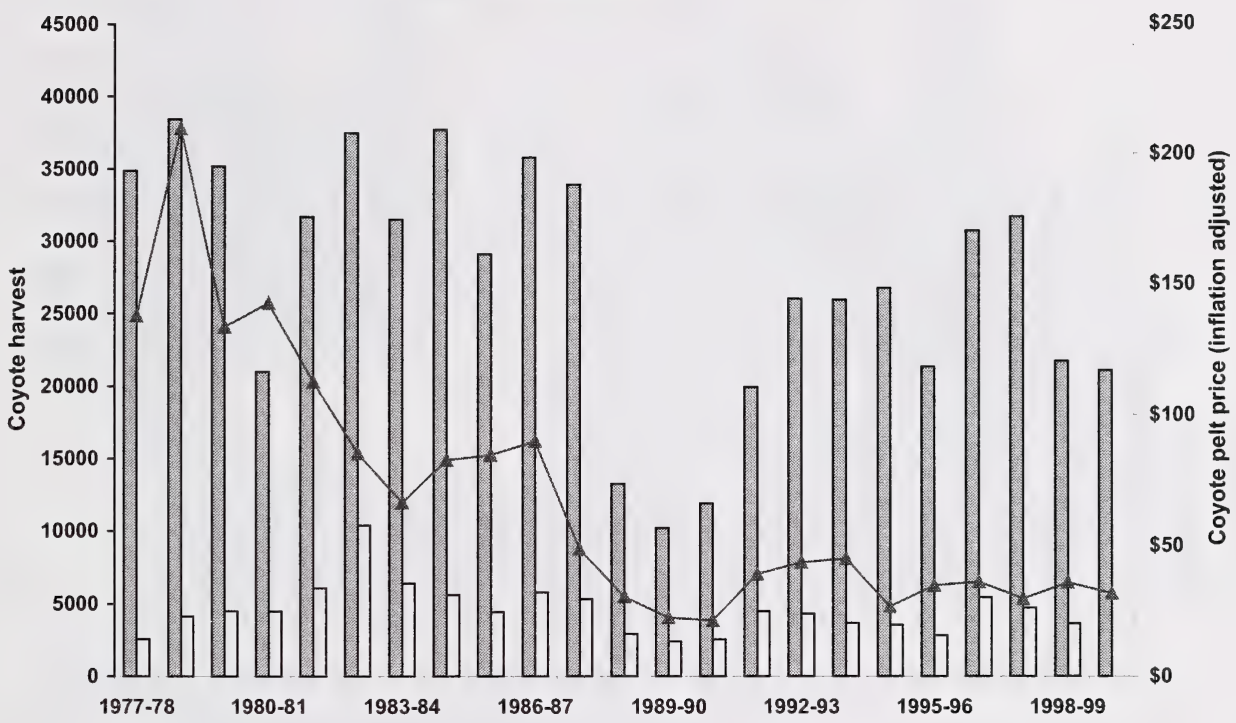

Figure 9. Alberta coyote harvest from Statistics Canada (1977-78 - 1999-2000; grey bars) and Alberta data for RFMAs (1977-78 - 1998-99; open bars), with average pelt price (line).

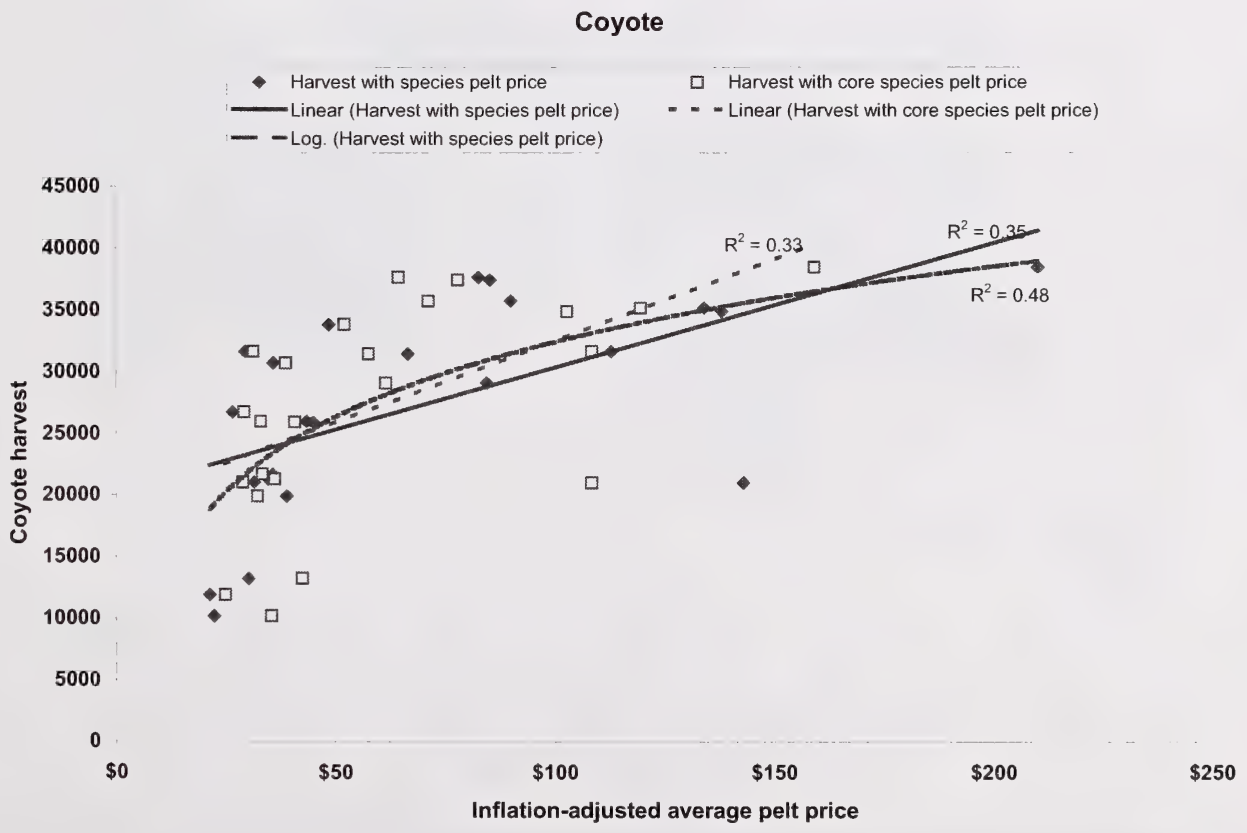

Figure 10. Relationship between annual coyote harvest and annual coyote pelt price, and 4 core species pelt price (solid symbols and line), and 4 core species pelt price (open symbols and dashed line), 1977-78 - 1999-2000. 


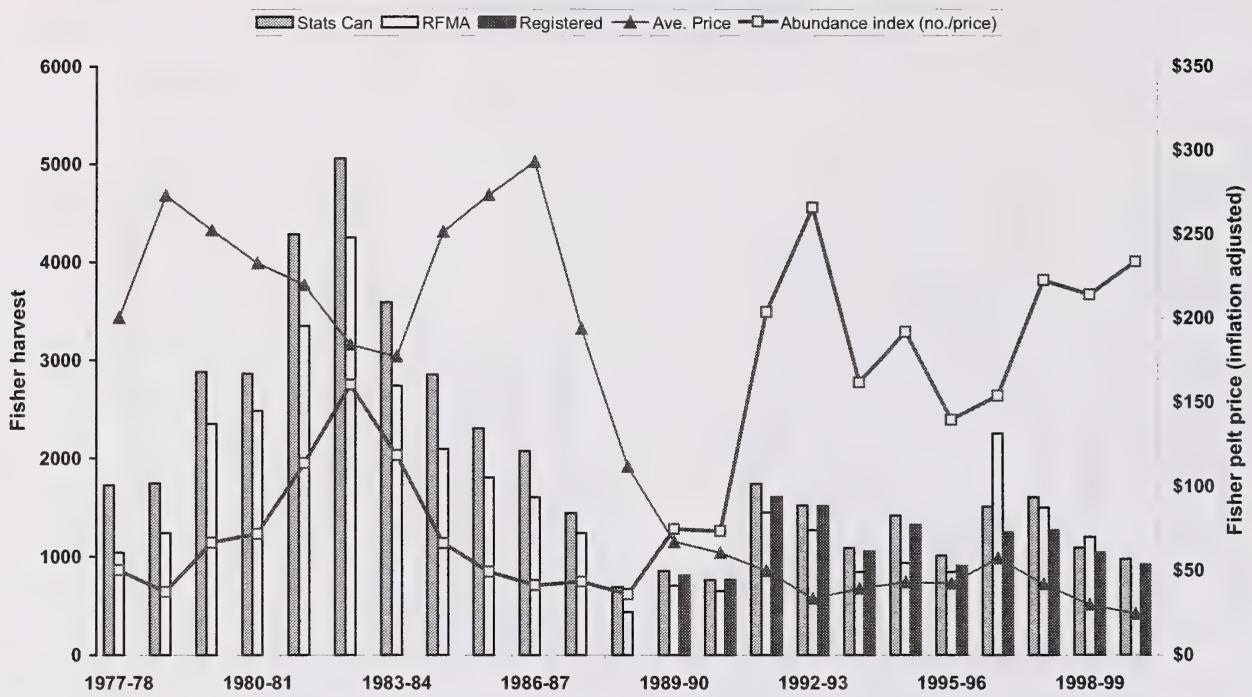

Figure 11. Alberta fisher harvest from Statistics Canada (1977-78 - 1999-2000; grey bars), Alberta data for RFMAs (1977-78 - 1998-99; open bars), and registered data (1989-90 - 19992000; black bars) with average pelt price (light line) and abundance index (heavy line).

Fisher

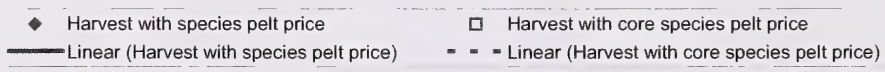

6000

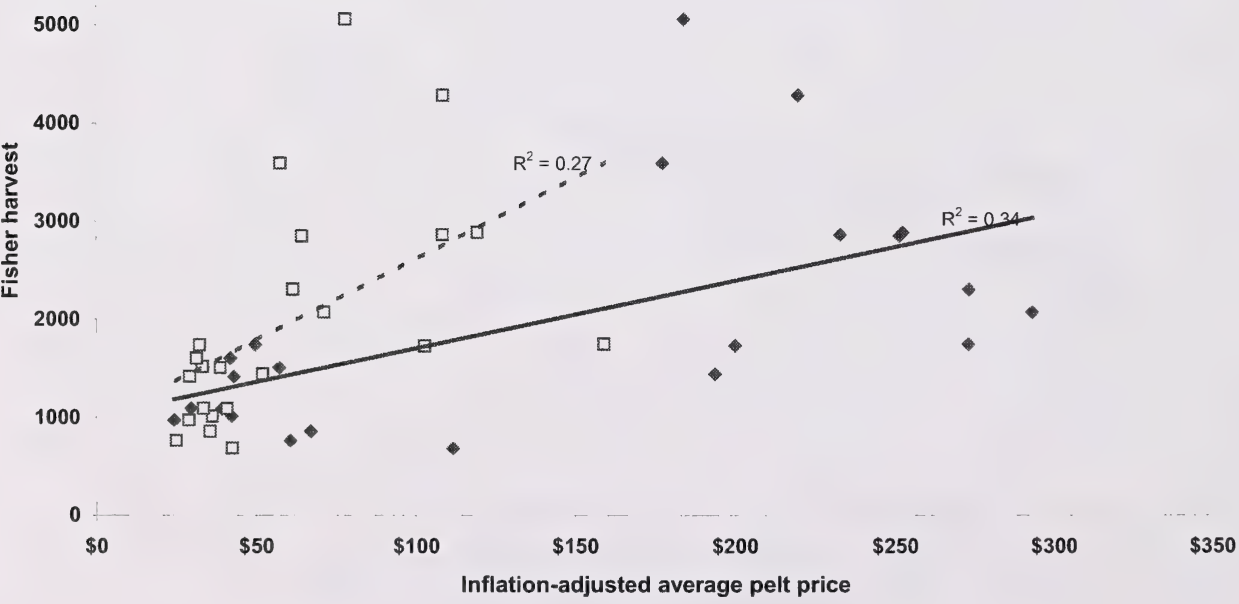

Figure 12. Relationship between annual fisher harvest and annual fisher pelt price, and 4 core species pelt price (solid symbols and line), and 4 core species pelt price (open symbols and dashed line), 1977-78 - 1999-2000. 


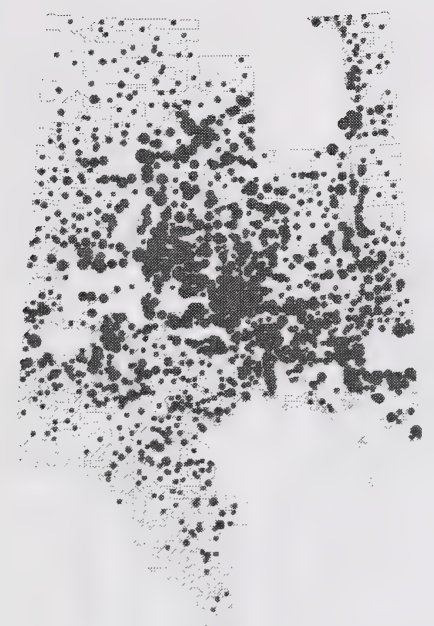

$1977-78$ to

1982-83

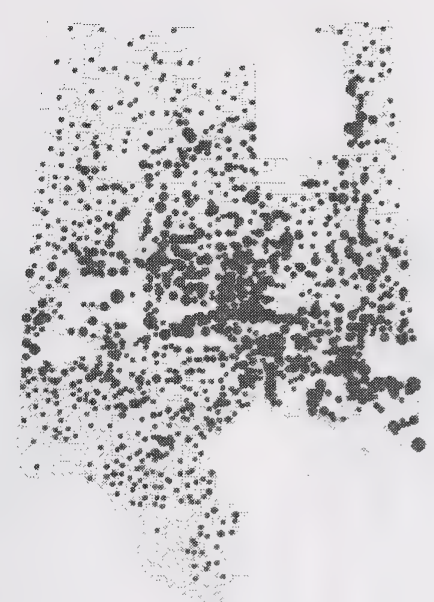

1983-84 to

1988-89

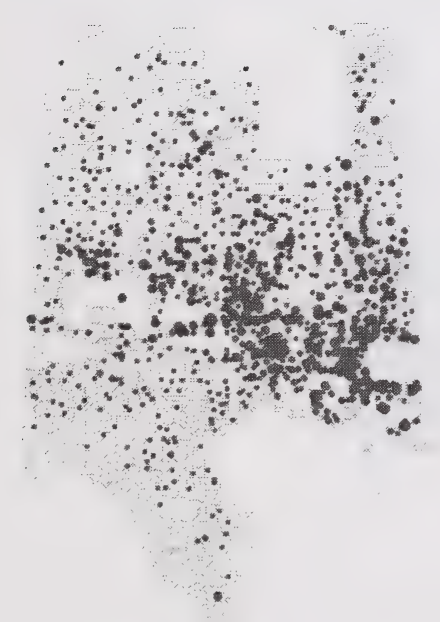

$1989-90$ to

1993-94

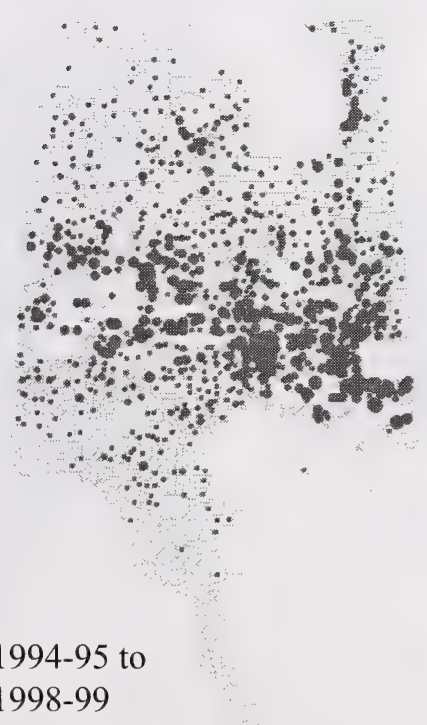

1998-99

Figure 13. Average annual fisher harvest by RFMA, for 4 time periods from 1977-78 to 199899. Harvests were scaled to RFMA size. Graduated symbols were consistent among time periods. 

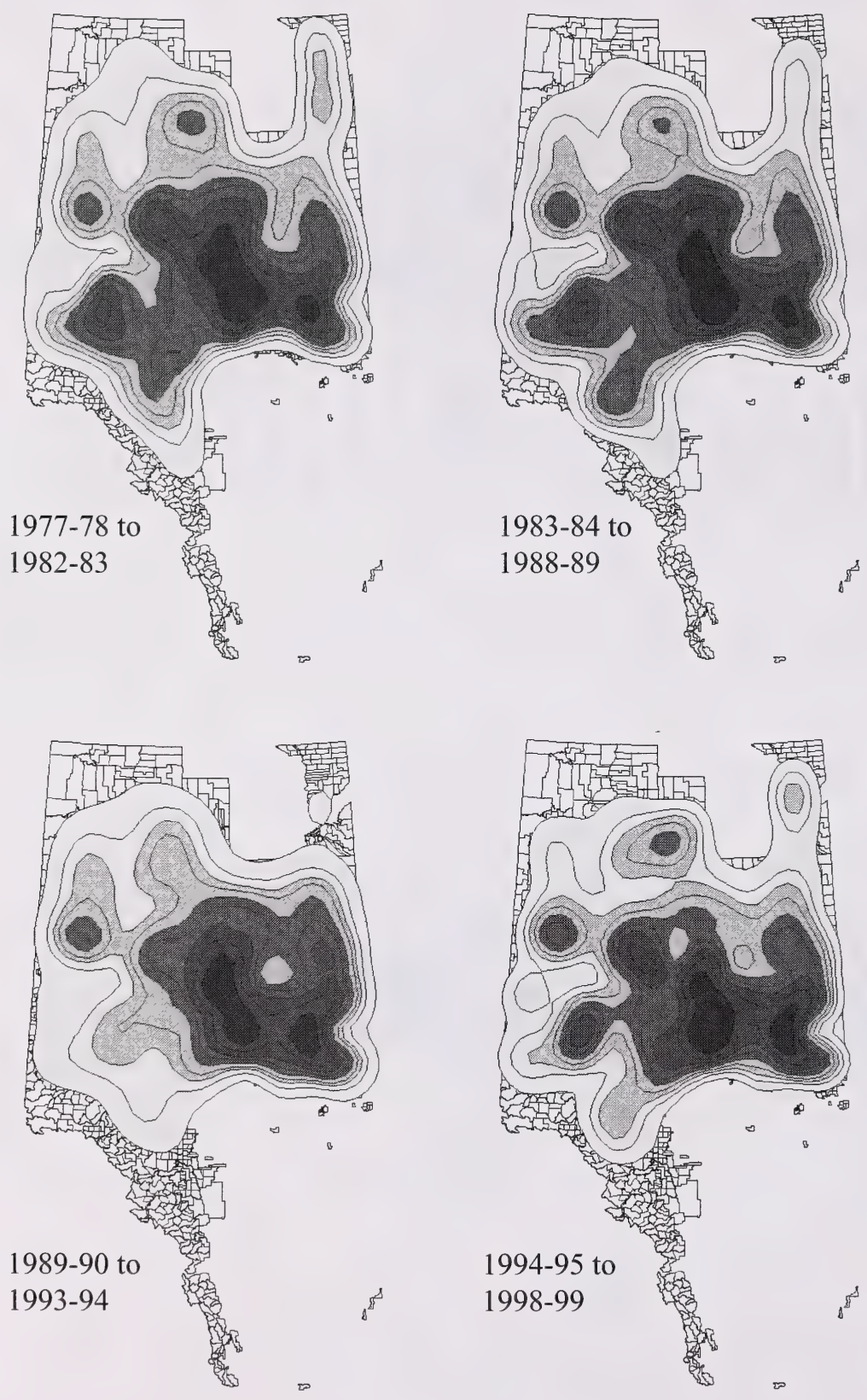

Figure 14. Adaptive kernel contours (darkest to lightest colour gradients from $0-10 \%, 10-30 \%$, $30-50 \%, 50-70 \%$ and $70-90 \%$ of harvest distribution; $10 \%$ lines) for Alberta fisher harvest by RFMA, for 4 time periods from 1977-78 to 1998-99. Harvests were scaled to RFMA size. 


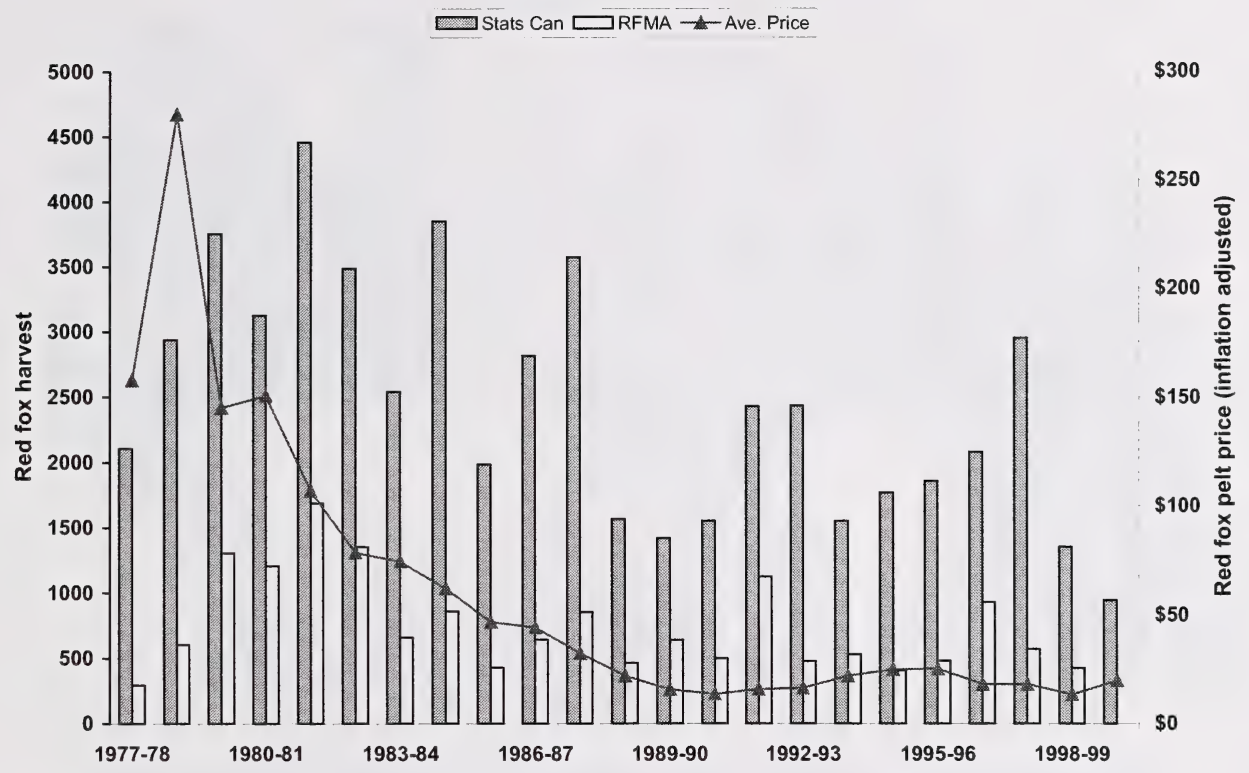

Figure 15. Alberta red fox harvest from Statistics Canada (1977-78 - 1999-2000; grey bars) and Alberta data for RFMAs (1977-78 - 1998-99; open bars), with average pelt price (line).

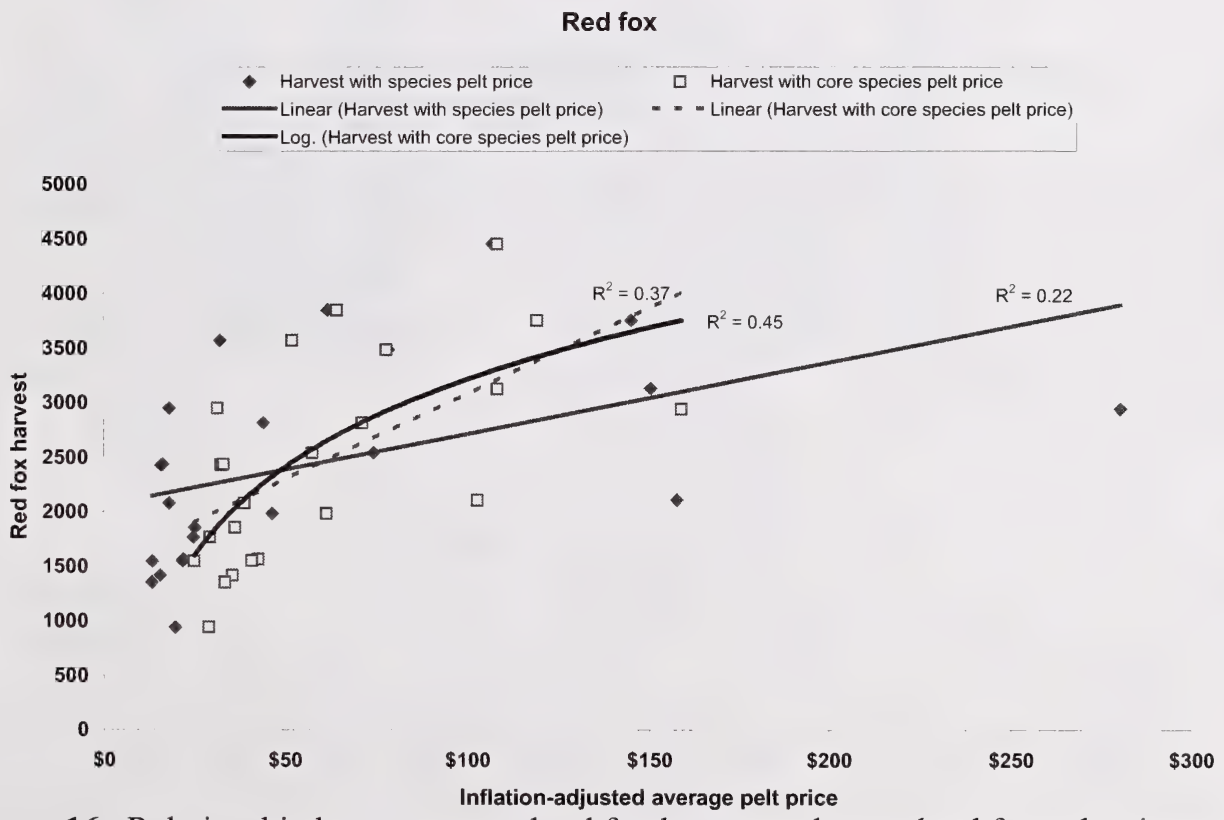

Figure 16. Relationship between annual red fox harvest and annual red fox pelt price, and 4 core species pelt price (solid symbols and line), and 4 core species pelt price (open symbols and dashed line), 1977-78 - 1999-2000. 


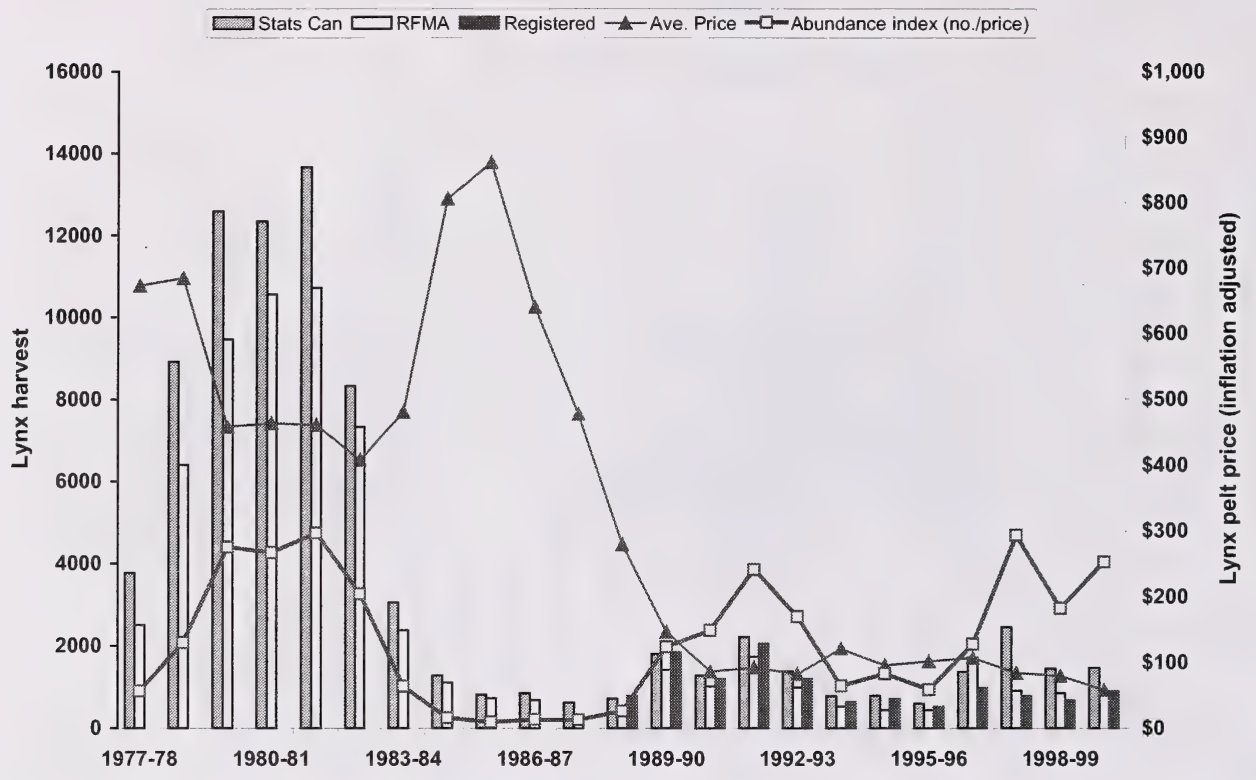

Figure 17. Alberta lynx harvest from Statistics Canada (1977-78 - 1999-2000; grey bars), Alberta data for RFMAs (1977-78 - 1998-99; open bars), and registered data (1989-90 - 19992000; black bars) with average pelt price (light line) and abundance index (heavy line).

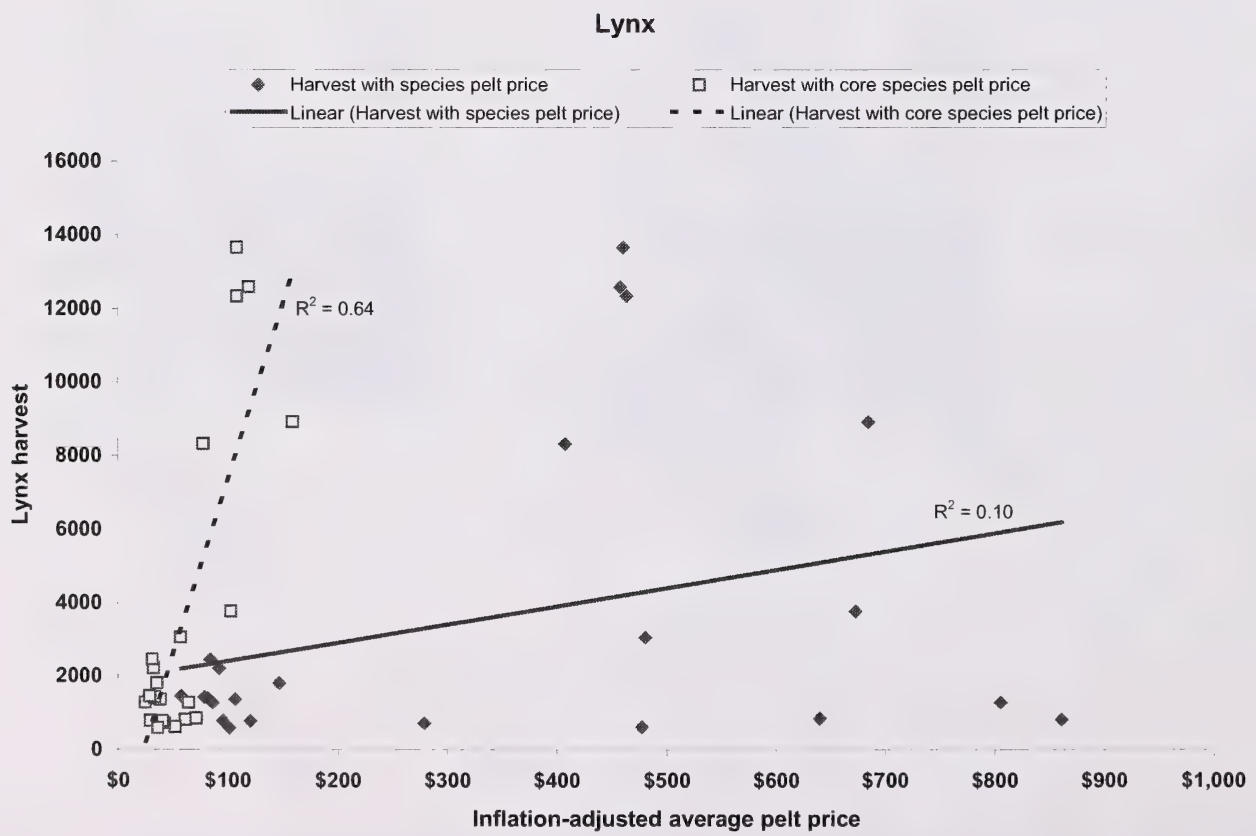

Figure 18. Relationship between annual lynx harvest and annual lynx pelt price, and 4 core species pelt price (solid symbols and line), and 4 core species pelt price (open symbols and dashed line), 1977-78 - 1999-2000. 

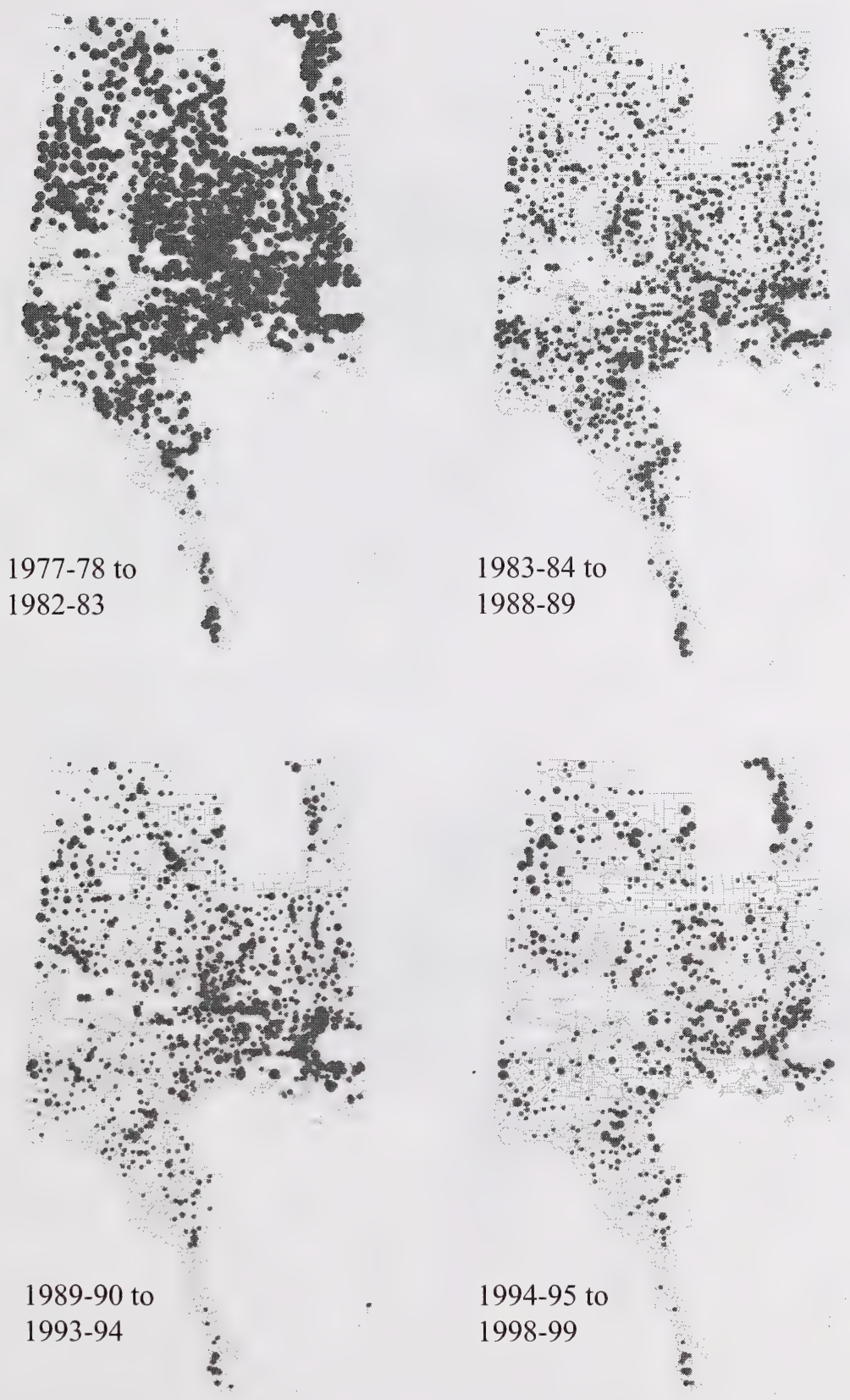

Figure 19. Average annual lynx harvest by RFMA, for 4 time periods from 1977-78 to 1998-99. Harvests were scaled to RFMA size. Graduated symbols were consistent among time periods. 

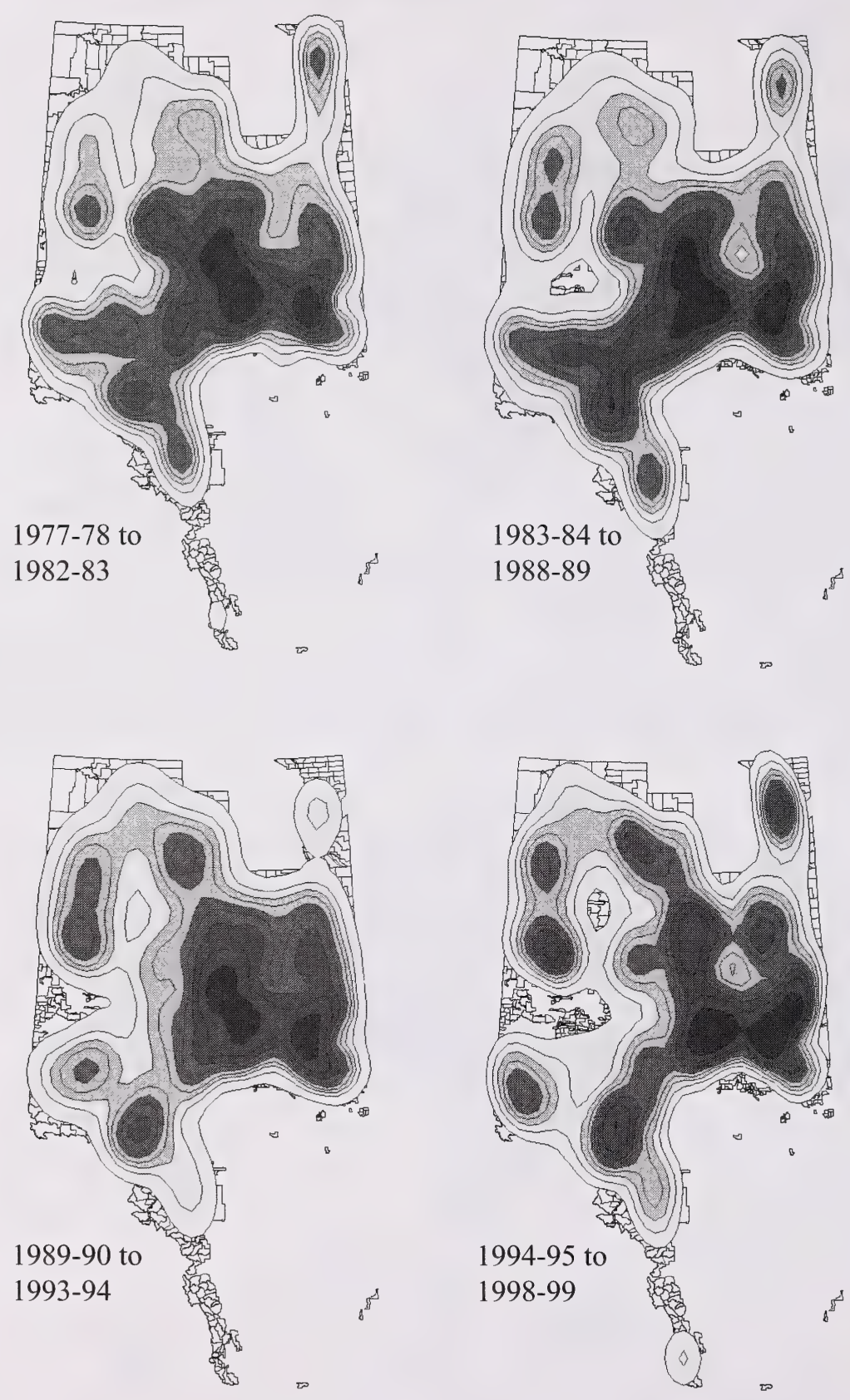

Figure 20. Adaptive kernel contours (darkest to lightest colour gradients from $0-10 \%, 10-30 \%$, $30-50 \%, 50-70 \%$ and $70-90 \%$ of harvest distribution; $10 \%$ lines) for Alberta lynx harvest by RFMA, for 4 time periods from 1977-78 to 1998-99. Harvests were scaled to RFMA size. 


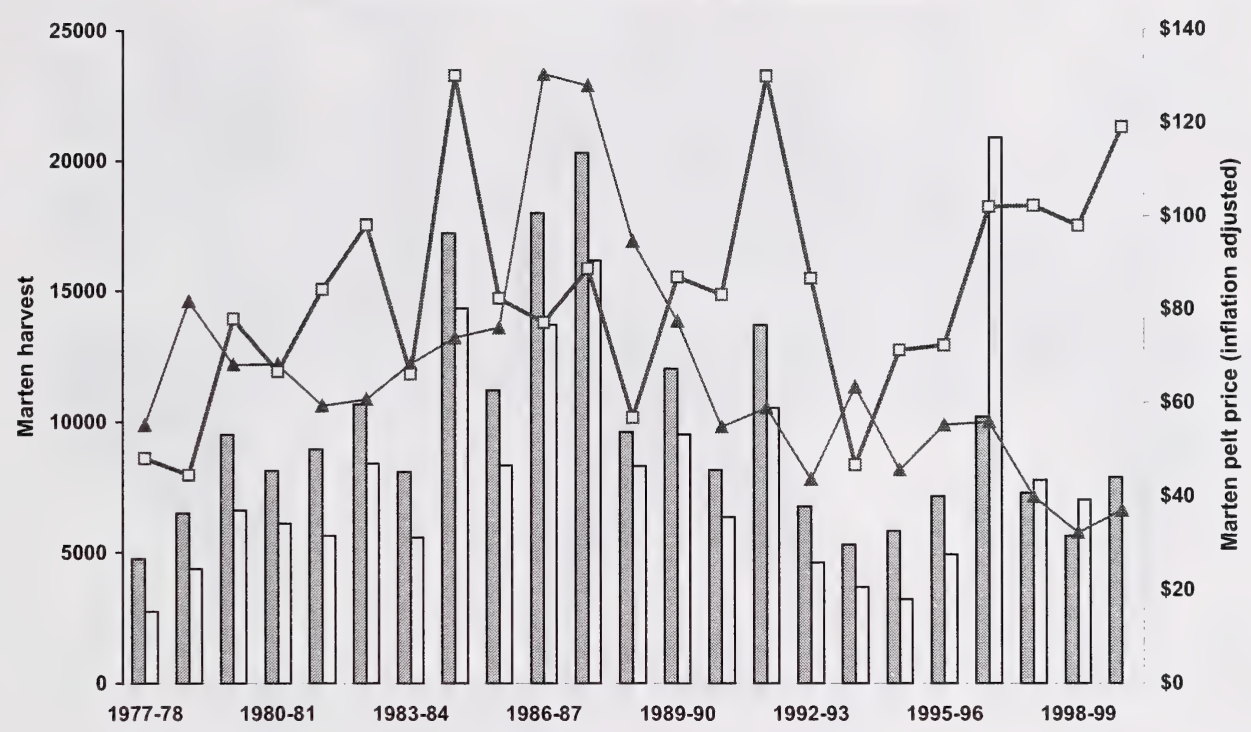

Figure 21. Alberta marten harvest from Statistics Canada (1977-78 - 1999-2000; grey bars) and Alberta data for RFMAs (1977-78 - 1998-99; open bars), with average pelt price (light line) and abundance index (heavy line).

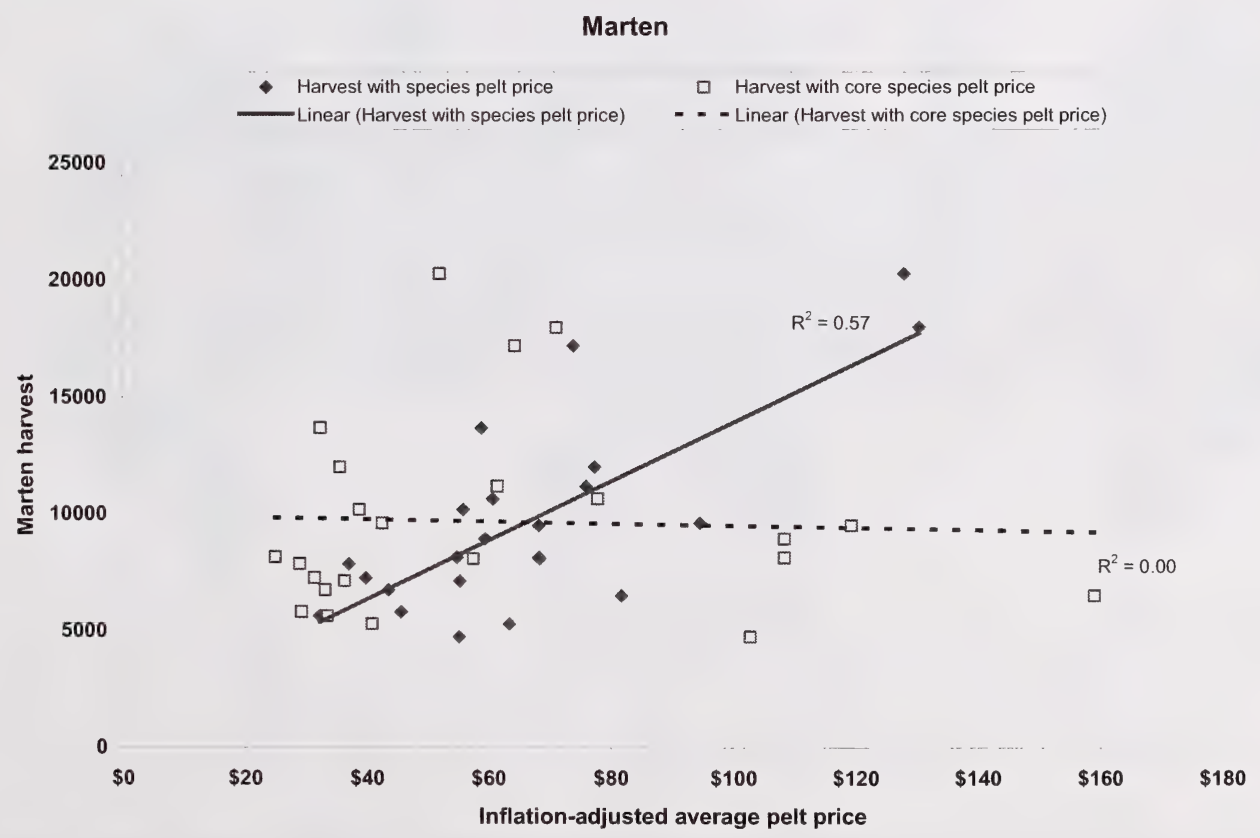

Figure 22. Relationship between annual marten harvest and annual marten pelt price, and 4 core species pelt price (solid symbols and line), and 4 core species pelt price (open symbols and dashed line), 1977-78 - 1999-2000. 

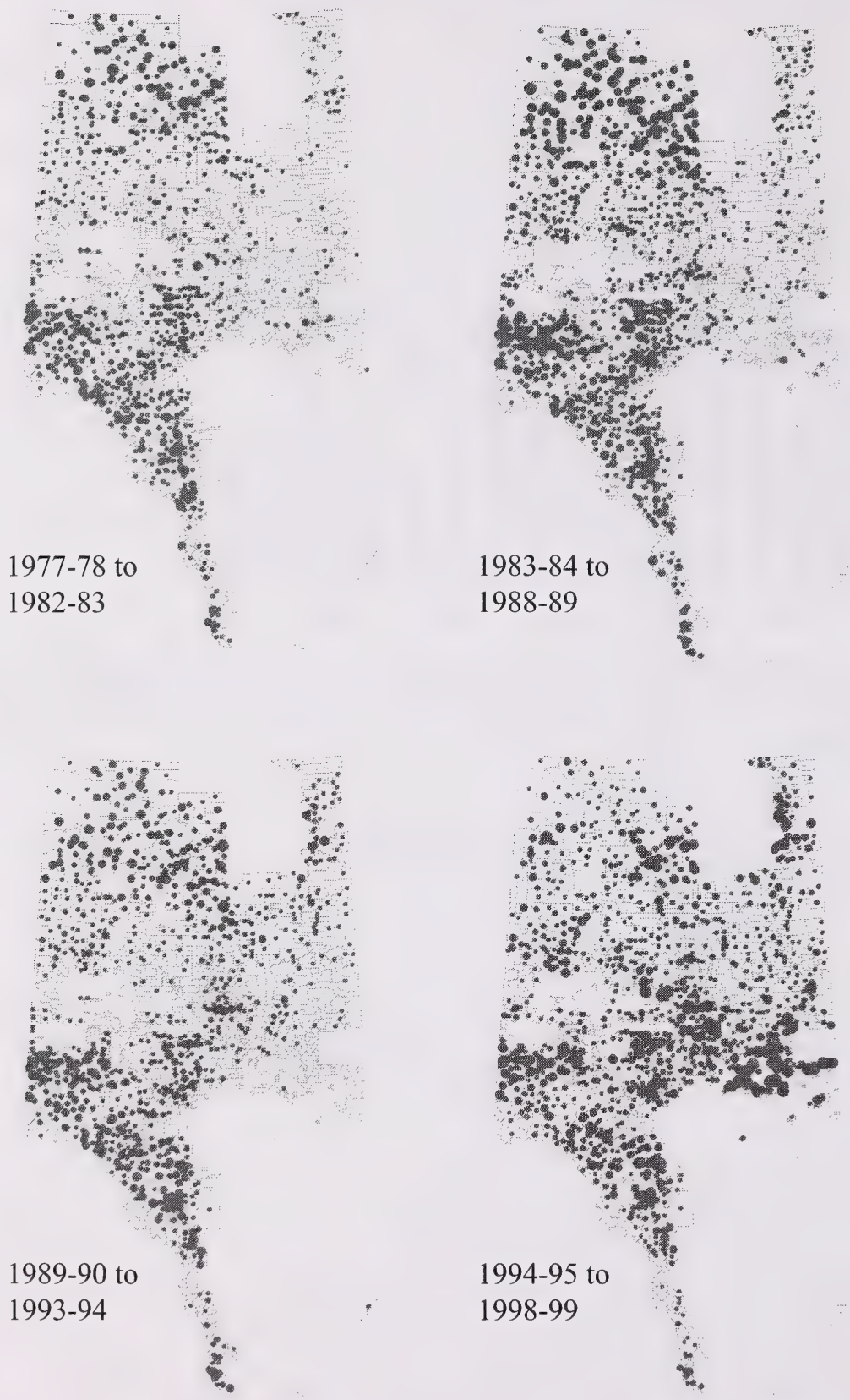

Figure 23. Average annual marten harvest by RFMA, for 4 time periods from 1977-78 to 199899. Harvests were scaled to RFMA size. Graduated symbols were consistent among time periods. 

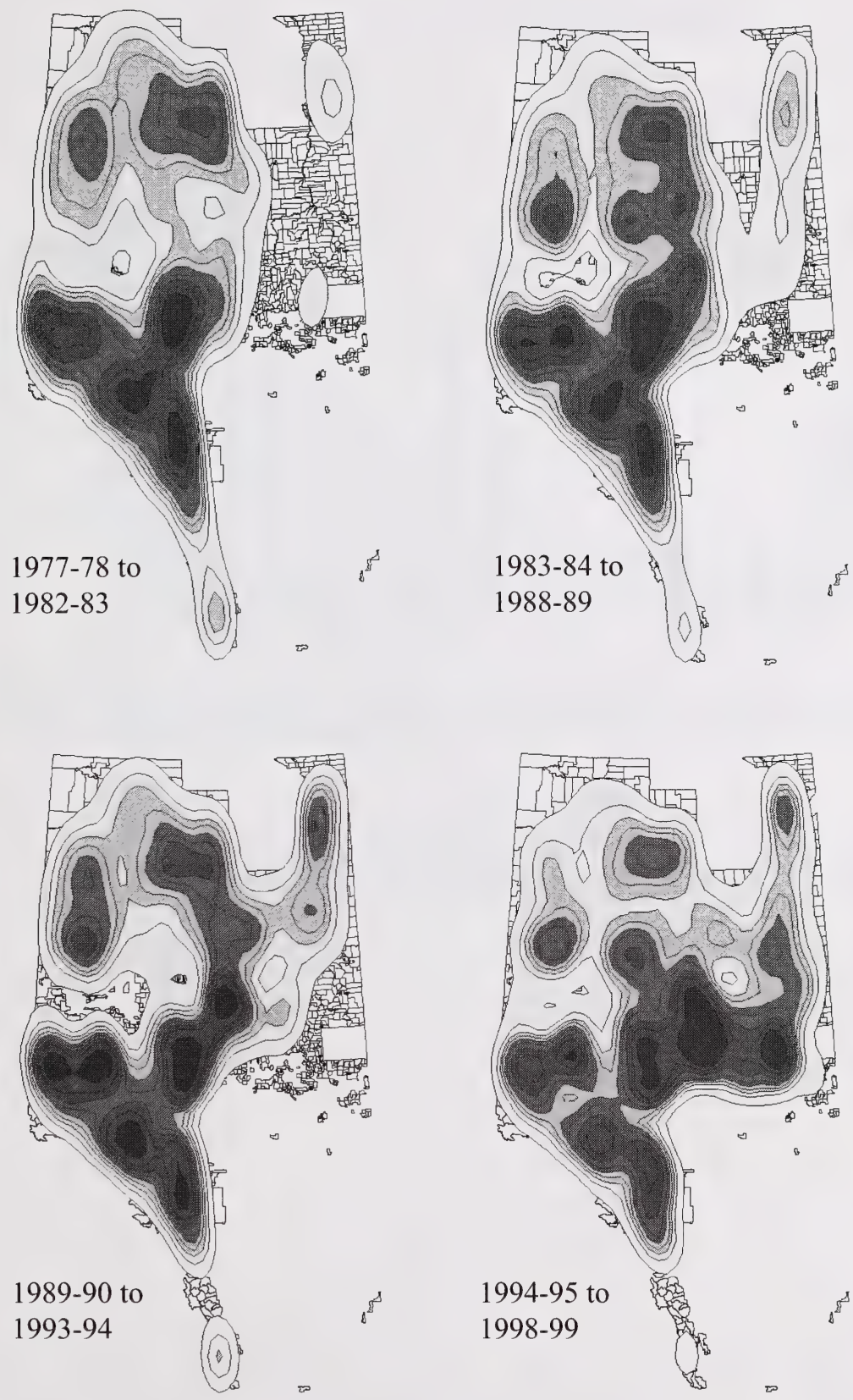

Figure 24. Adaptive kernel contours (darkest to lightest colour gradients from $0-10 \%, 10-30 \%$, $30-50 \%, 50-70 \%$ and $70-90 \%$ of harvest distribution; $10 \%$ lines) for Alberta marten harvest by RFMA, for 4 time periods from 1977-78 to 1998-99. Harvests were scaled to RFMA size. 


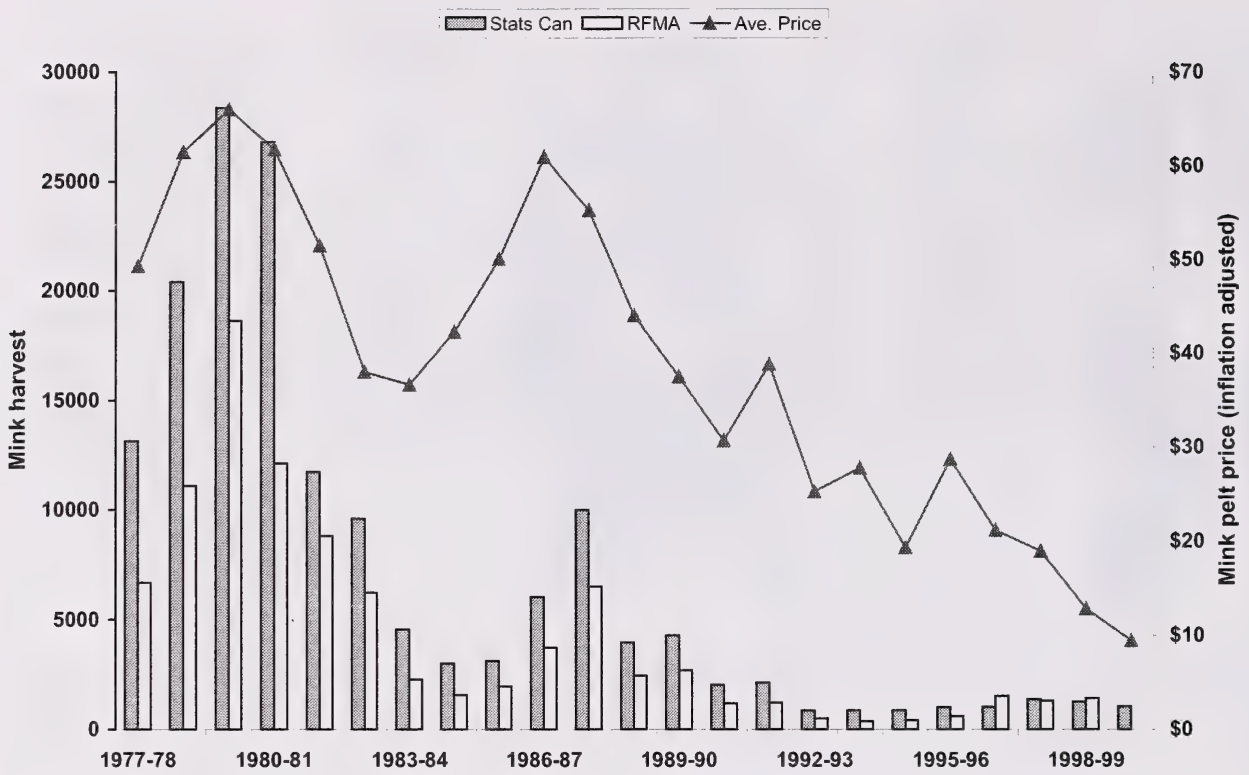

Figure 25. Alberta mink harvest from Statistics Canada (1977-78 - 1999-2000; grey bars) and Alberta data for RFMAs (1977-78 - 1998-99; open bars), with average pelt price (line).

Mink

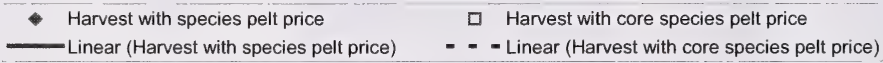

30000

25000

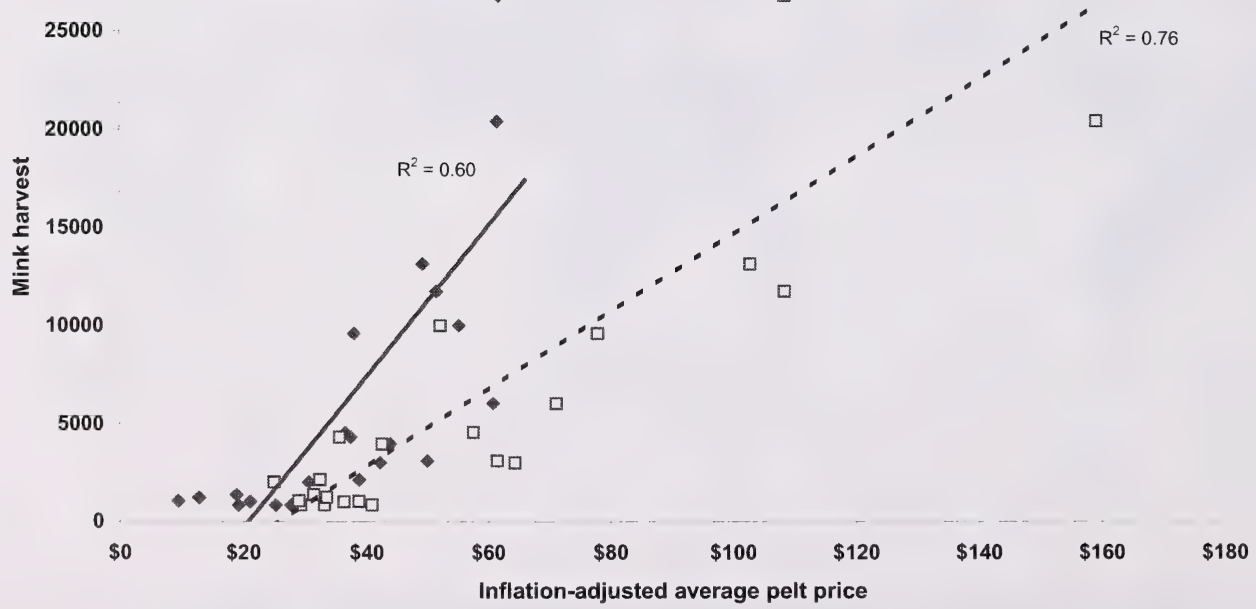

Figure 26. Relationship between annual mink harvest and annual mink pelt price, and 4 core species pelt price (solid symbols and line), and 4 core species pelt price (open symbols and dashed line), 1977-78 - 1999-2000. 


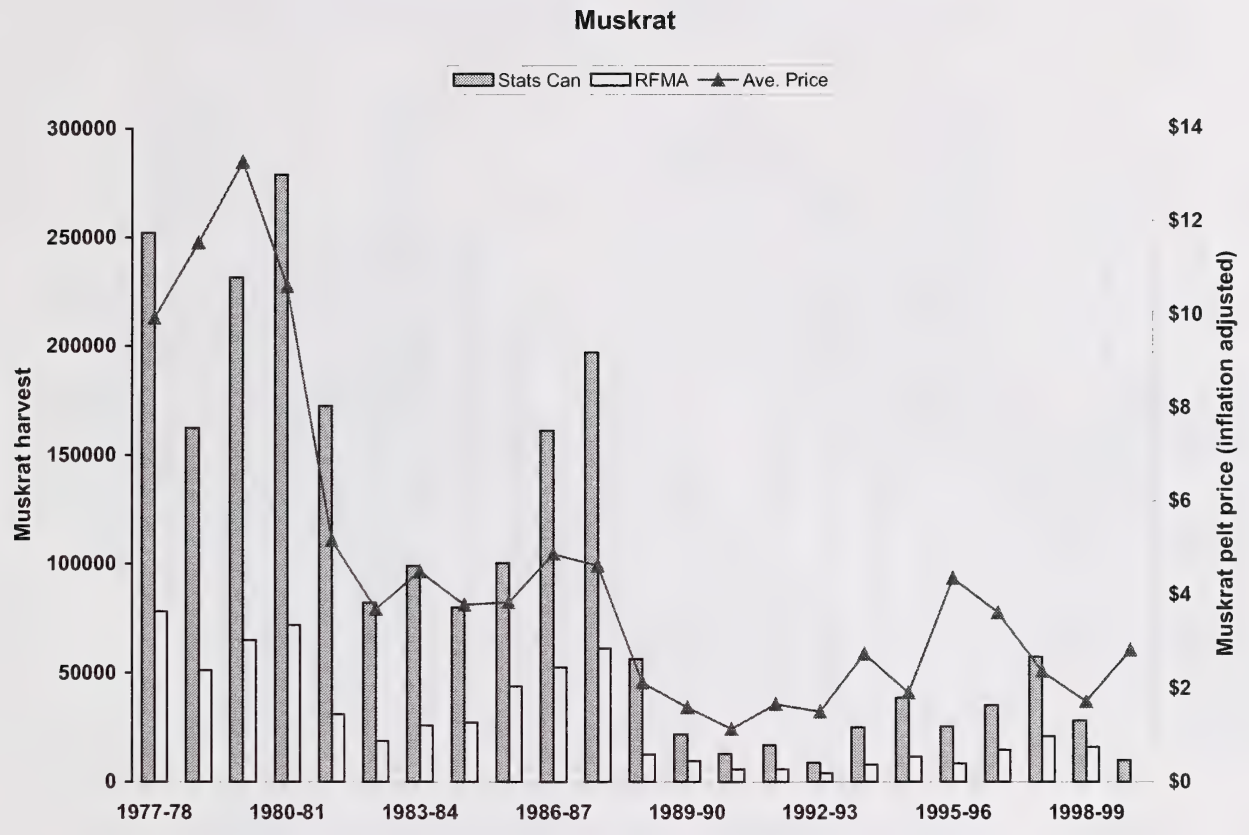

Figure 27. Alberta muskrat harvest from Statistics Canada (1977-78 - 1999-2000; grey bars) and Alberta data for RFMAs (1977-78 - 1998-99; open bars), with average pelt price (line).

\section{Muskrat}

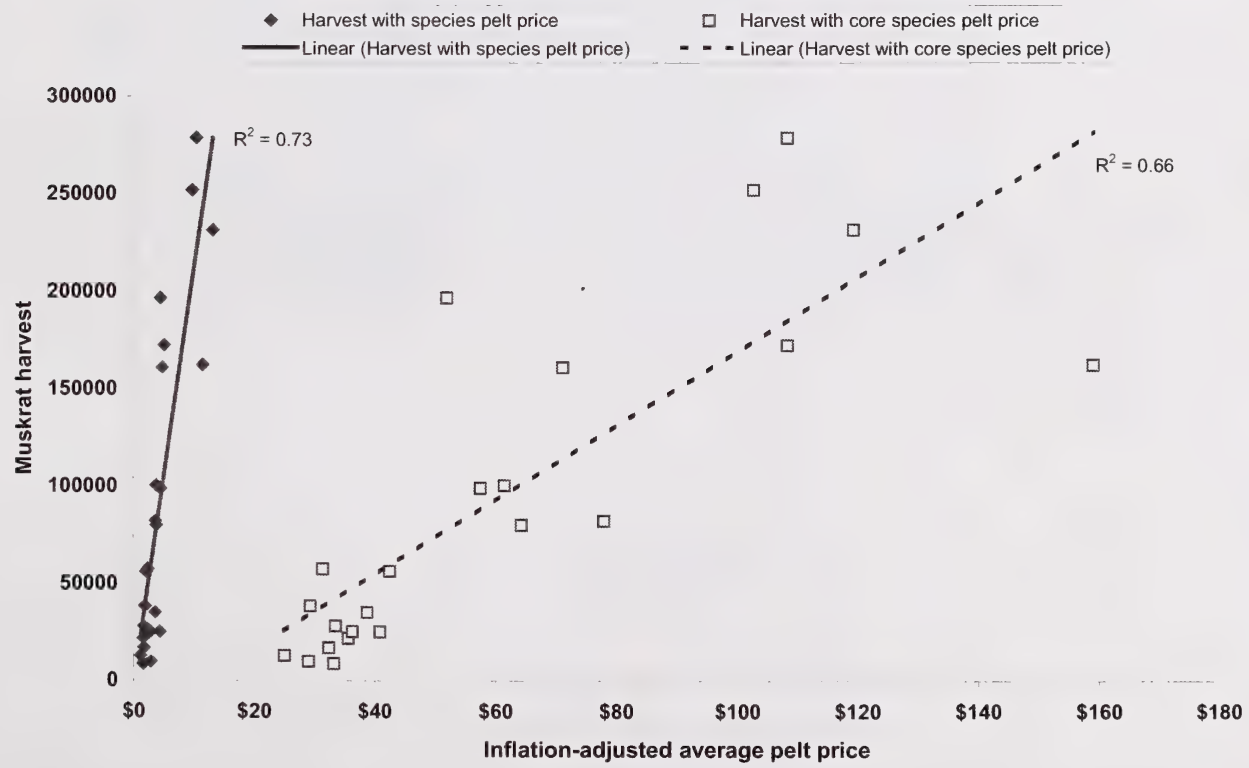

Figure 28. Relationship between annual muskrat harvest and annual muskrat pelt price, and 4 core species pelt price (solid symbols and line), and 4 core species pelt price (open symbols and dashed line), 1977-78 - 1999-2000. 


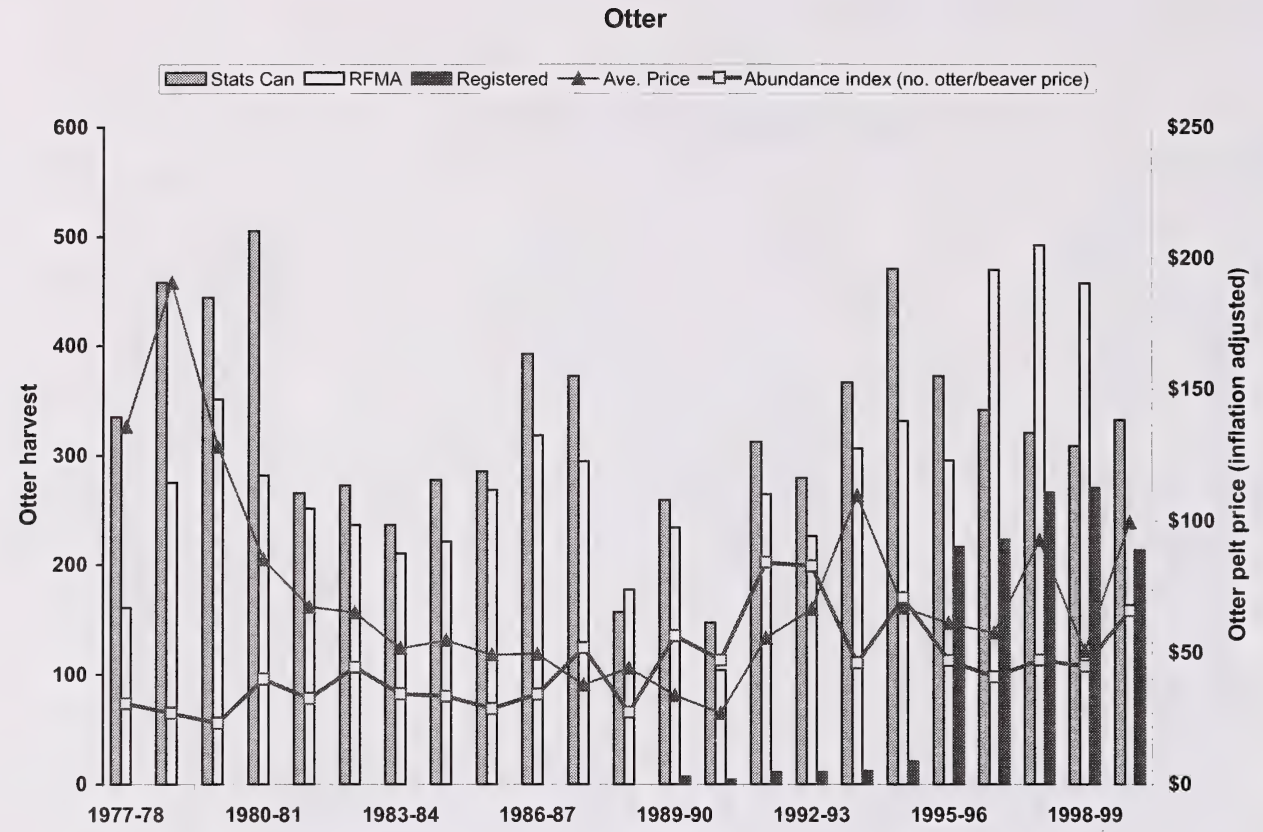

Figure 29. Alberta otter harvest from Statistics Canada (1977-78 - 1999-2000; grey bars), Alberta data for RFMAs (1977-78 - 1998-99; open bars), and registered data (1989-90 - 19992000; black bars) with average pelt price (light line) and abundance index (heavy line).

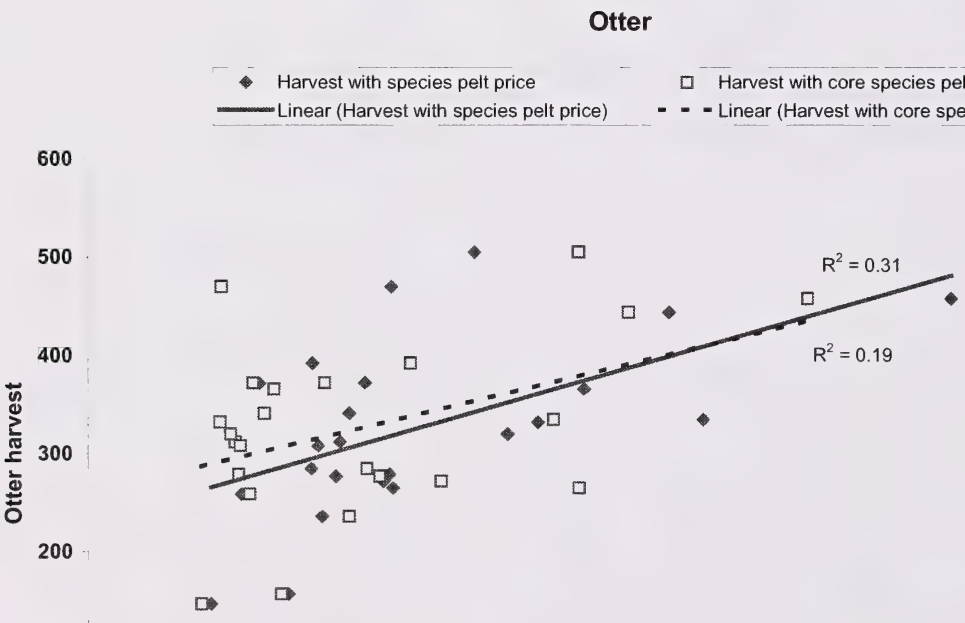

100

0 $\$ 0$

$\$ 50$

$\$ 100$

$\$ 150$

$\$ 200$

$\$ 250$

Inflation-adjusted average pelt price

Figure 30. Relationship between annual otter harvest and annual otter pelt price, and 4 core species pelt price (solid symbols and line), and 4 core species pelt price (open symbols and dashed line), 1977-78 - 1999-2000. 


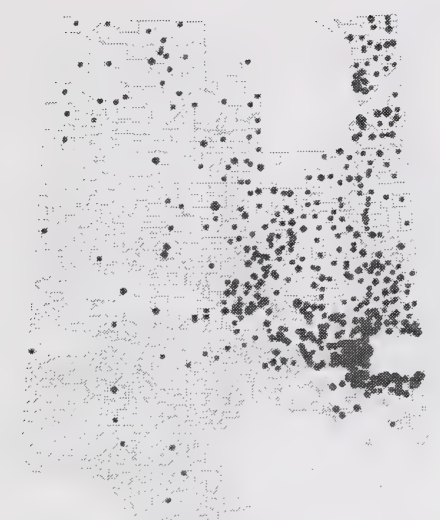

$1977-78$ to

1982-83

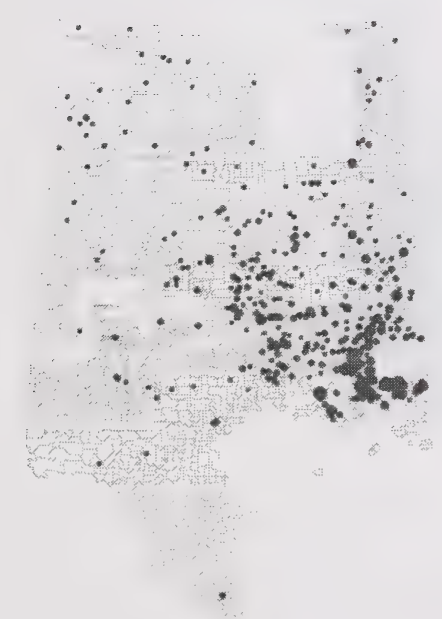

$1989-90$ to

1993-94

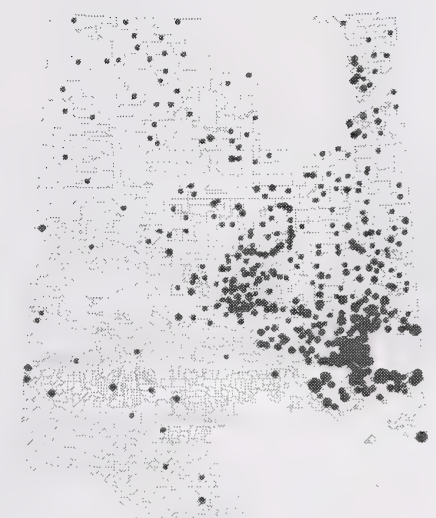

1983-84 to

1988-89

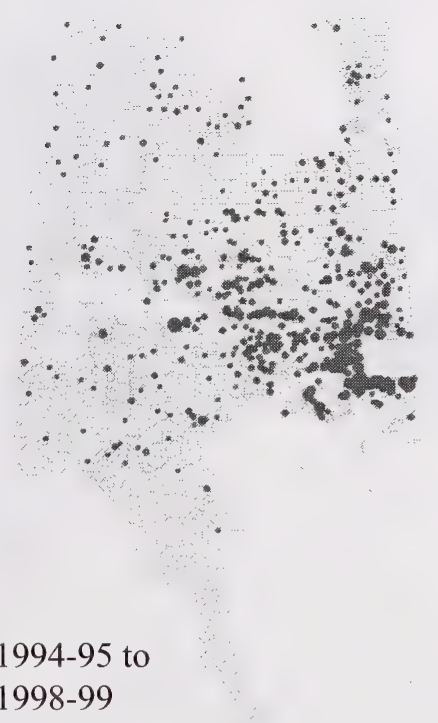

Figure 31. Average annual otter harvest by RFMA, for 4 time periods from 1977-78 to 1998-99. Harvests were scaled to RFMA size. Graduated symbols were consistent among time periods. 

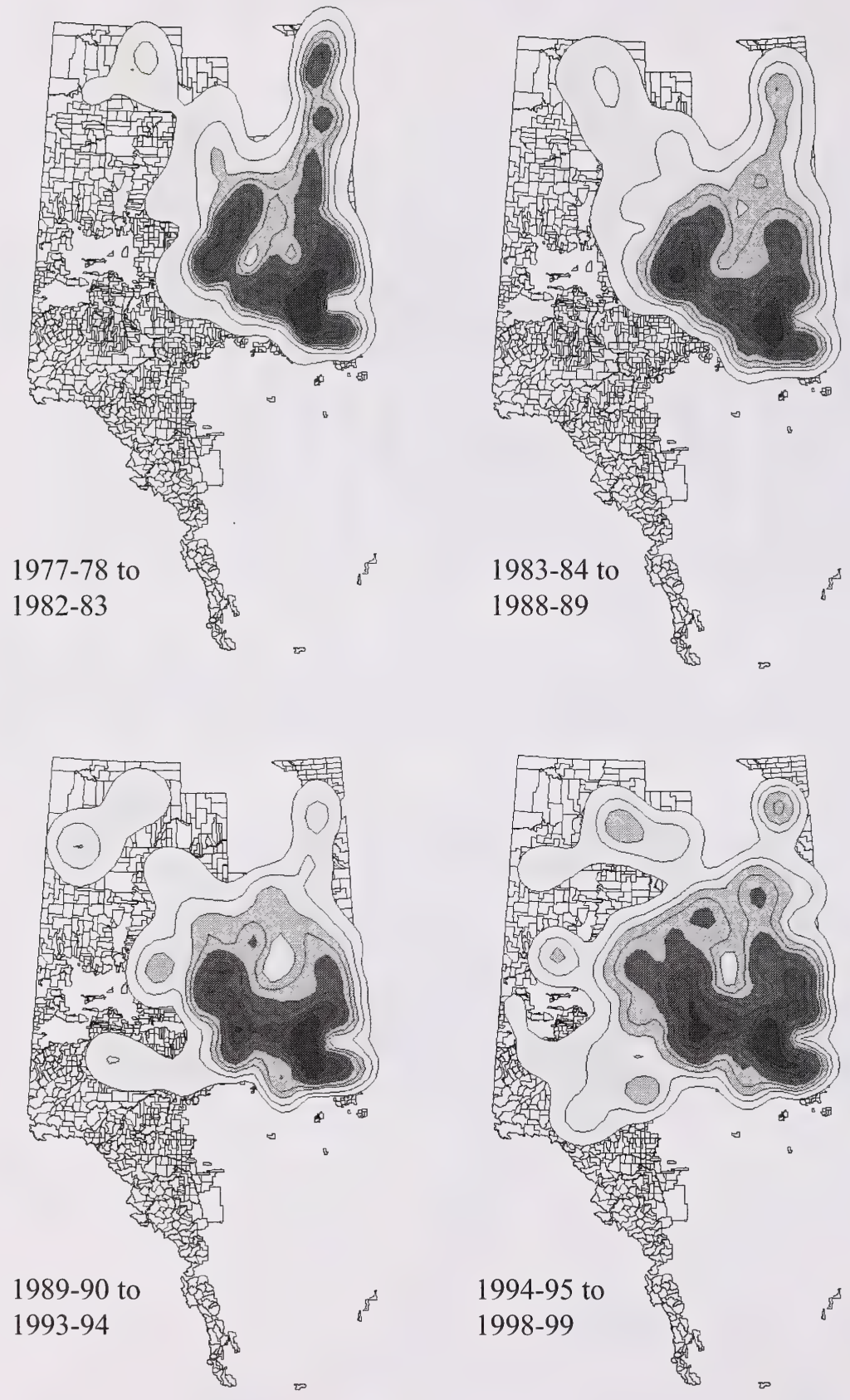

Figure 32. Adaptive kernel contours (darkest to lightest colour gradients from $0-10 \%, 10-30 \%$, $30-50 \%, 50-70 \%$ and $70-90 \%$ of harvest distribution; $10 \%$ lines) for Alberta otter harvest by RFMA, for 4 time periods from 1977-78 to 1998-99. Harvests were scaled to RFMA size. 


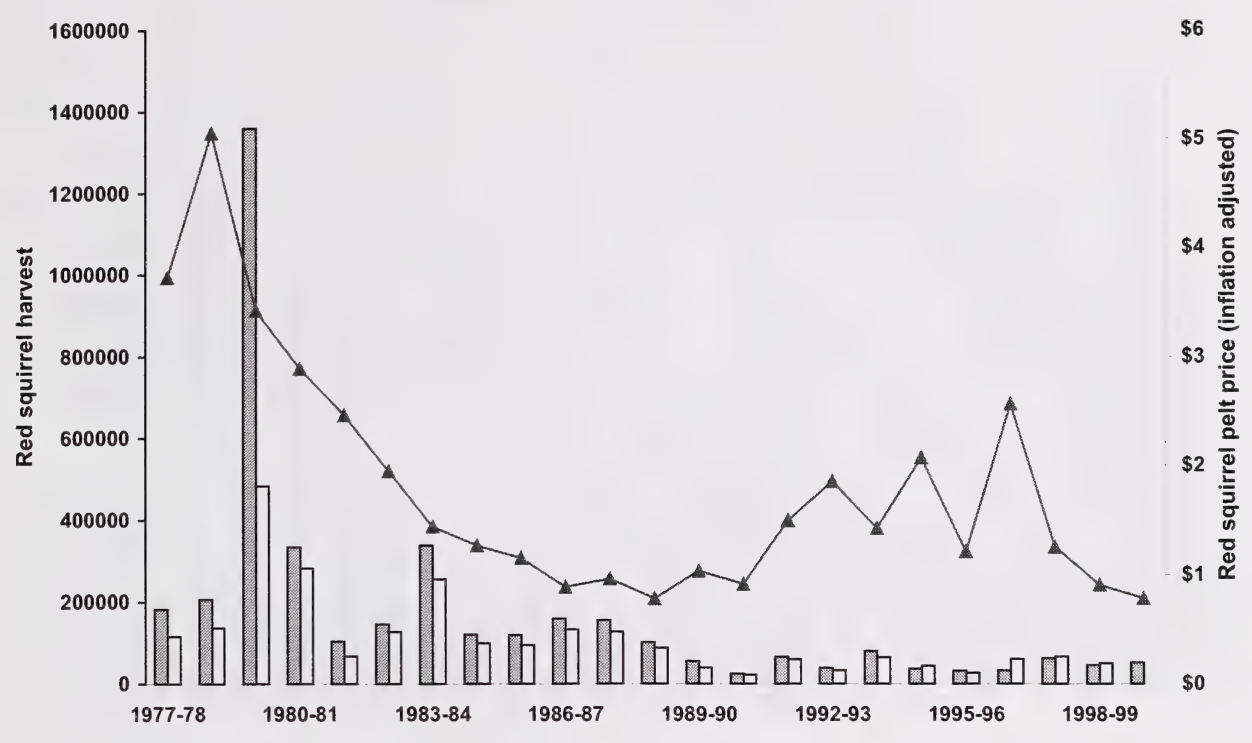

Figure 33. Alberta red squirrel harvest from Statistics Canada (1977-78 - 1999-2000; grey bars) and Alberta data for RFMAs (1977-78 - 1998-99; open bars), with average pelt price (line).

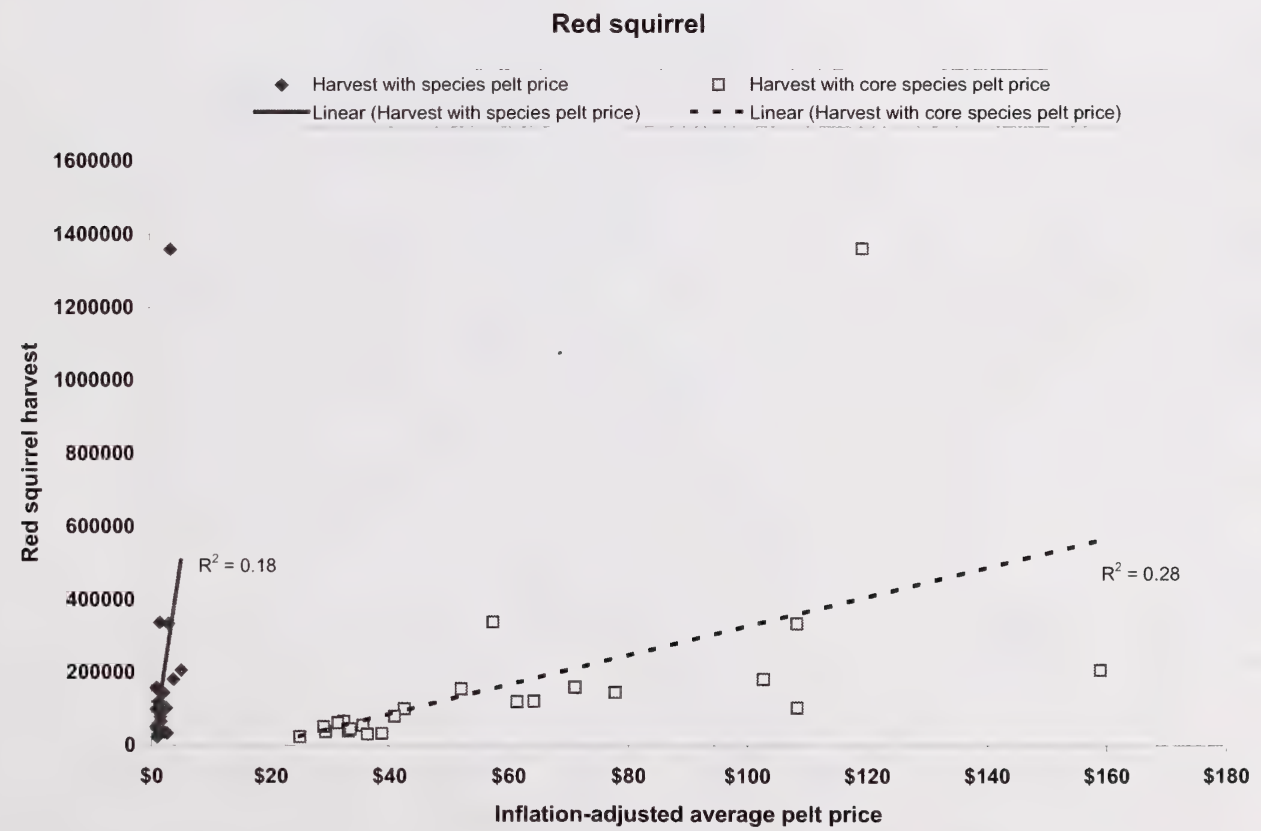

Figure 34. Relationship between annual red squirrel harvest and annual red squirrel pelt price, and 4 core species pelt price (solid symbols and line), and 4 core species pelt price (open symbols and dashed line), 1977-78 - 1999-2000. 


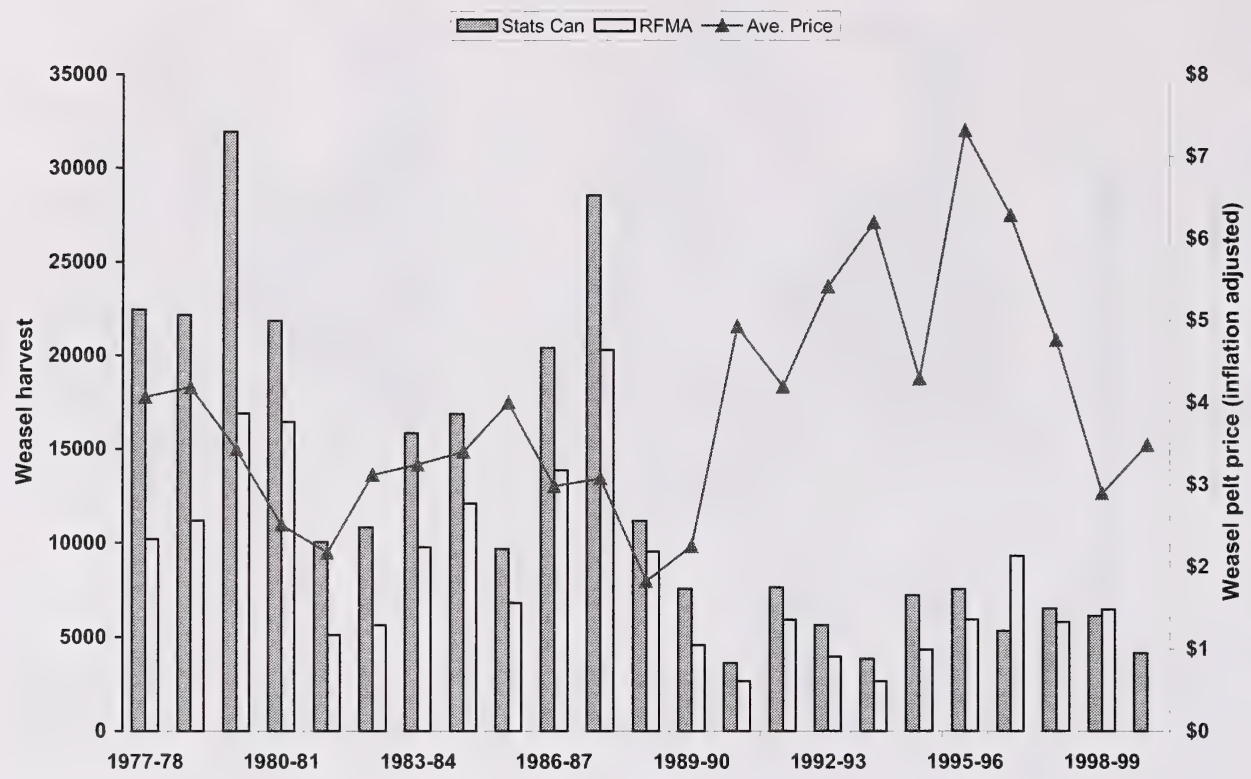

Figure 35. Alberta weasel harvest from Statistics Canada (1977-78 - 1999-2000; grey bars) and Alberta data for RFMAs (1977-78 - 1998-99; open bars), with average pelt price (line).

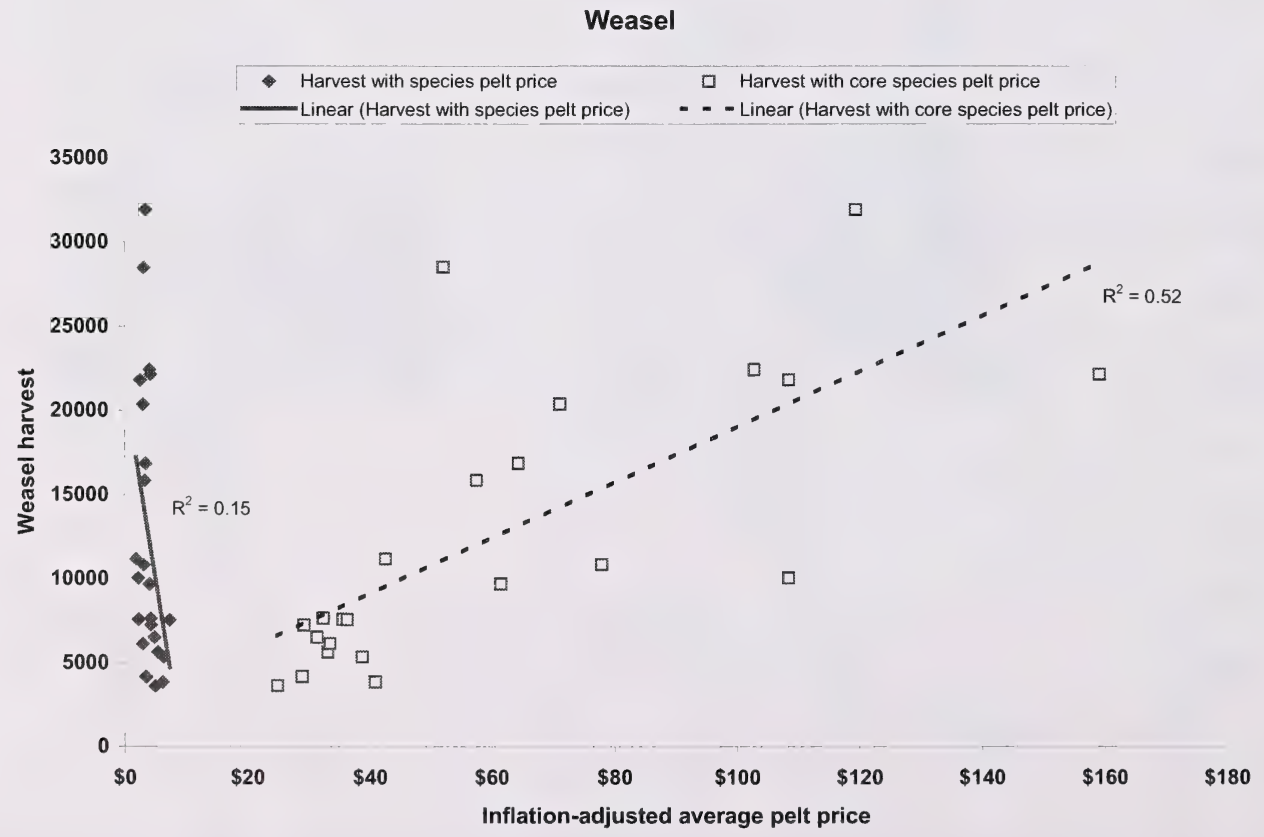

Figure 36. Relationship between annual weasel harvest and annual weasel pelt price, and 4 core species pelt price (solid symbols and line), and 4 core species pelt price (open symbols and dashed line), 1977-78 - 1999-2000. 


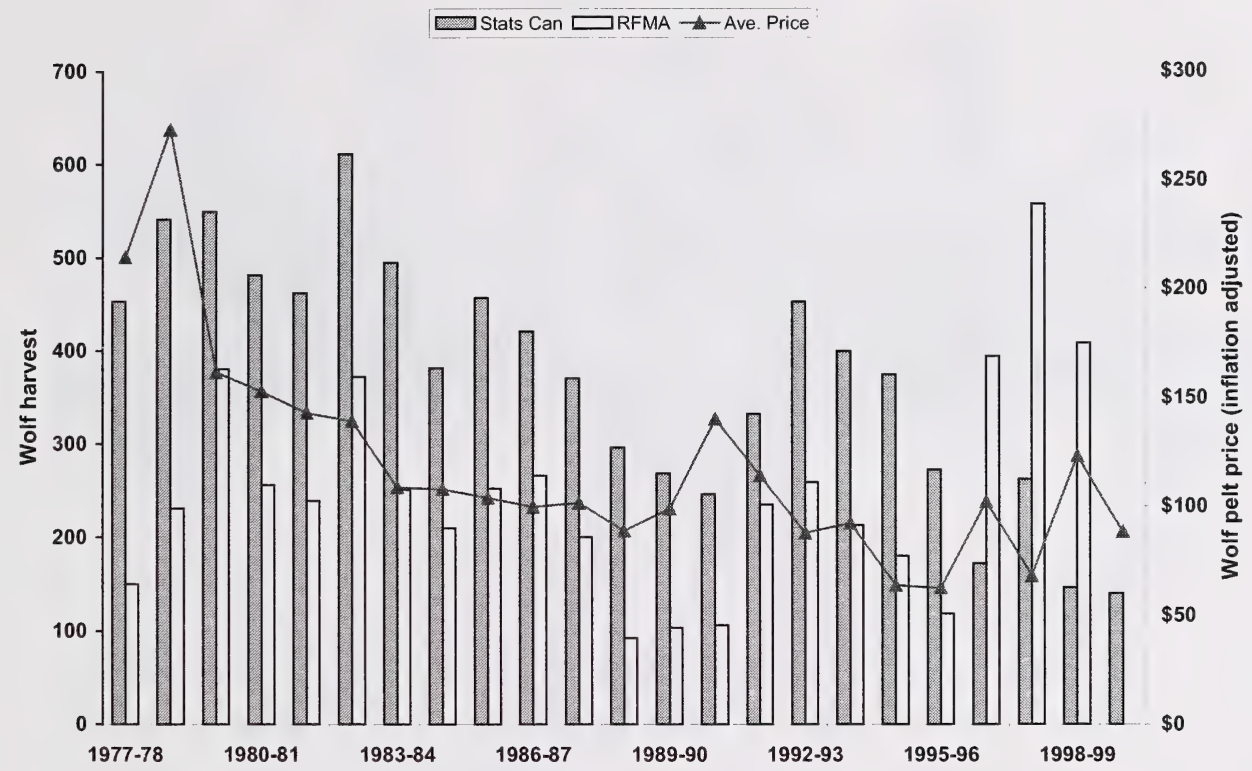

Figure 37. Alberta wolf harvest from Statistics Canada (1977-78 - 1999-2000; grey bars) and Alberta data for RFMAs (1977-78 - 1998-99; open bars), with average pelt price (line).

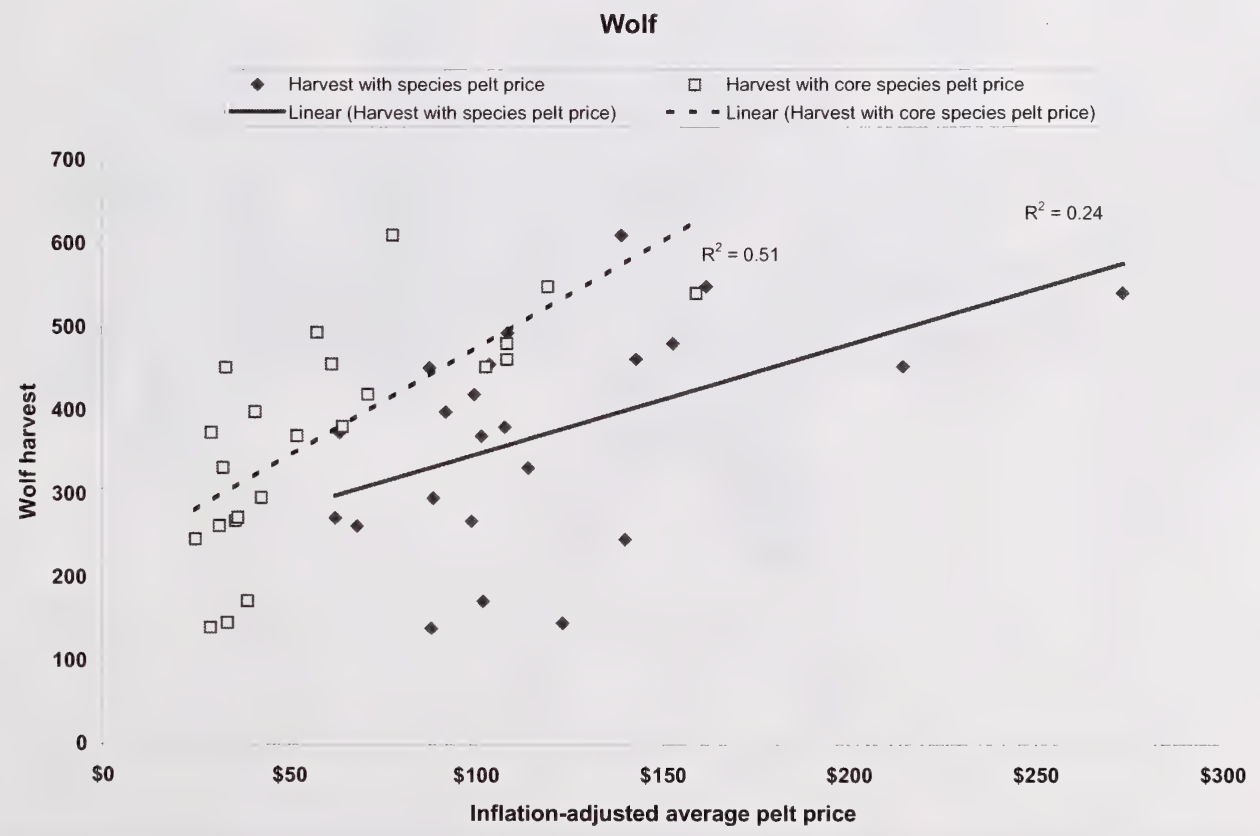

Figure 38. Relationship between annual wolf harvest and annual wolf pelt price, and 4 core species pelt price (solid symbols and line), and 4 core species pelt price (open symbols and dashed line), 1977-78 - 1999-2000. 


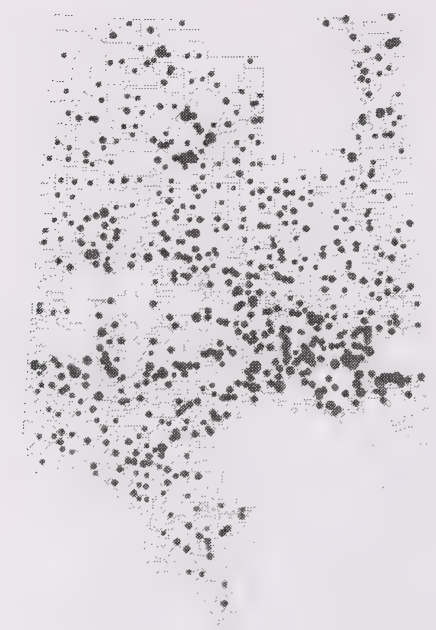

$1977-78$ to

1982-83

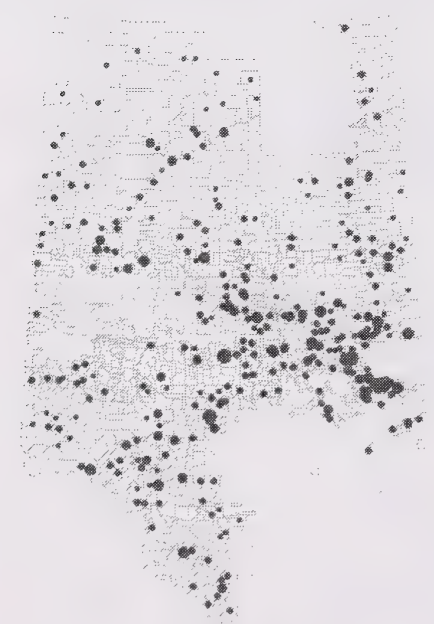

$1989-90$ to

1993-94

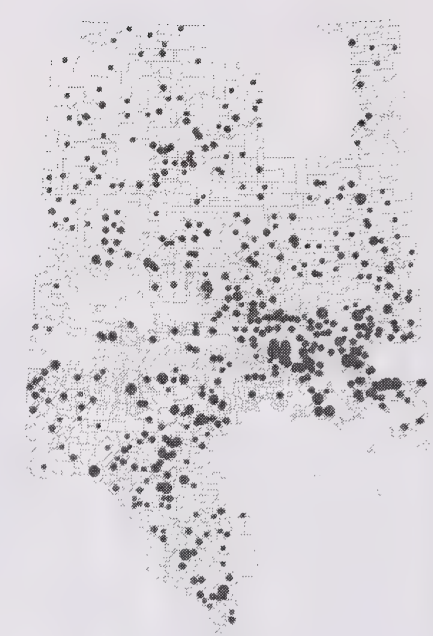

1983-84 to

1988-89

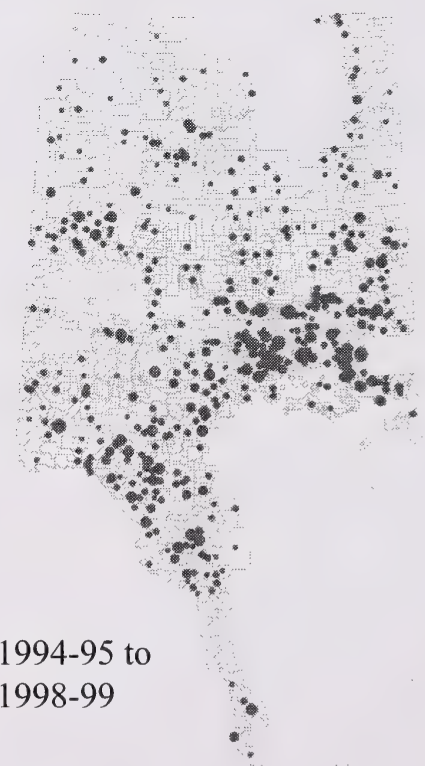

Figure 39. Average annual wolf harvest by RFMA, for 4 time periods from 1977-78 to 1998-99. Harvests were scaled to RFMA size. Graduated symbols were consistent among time periods. 

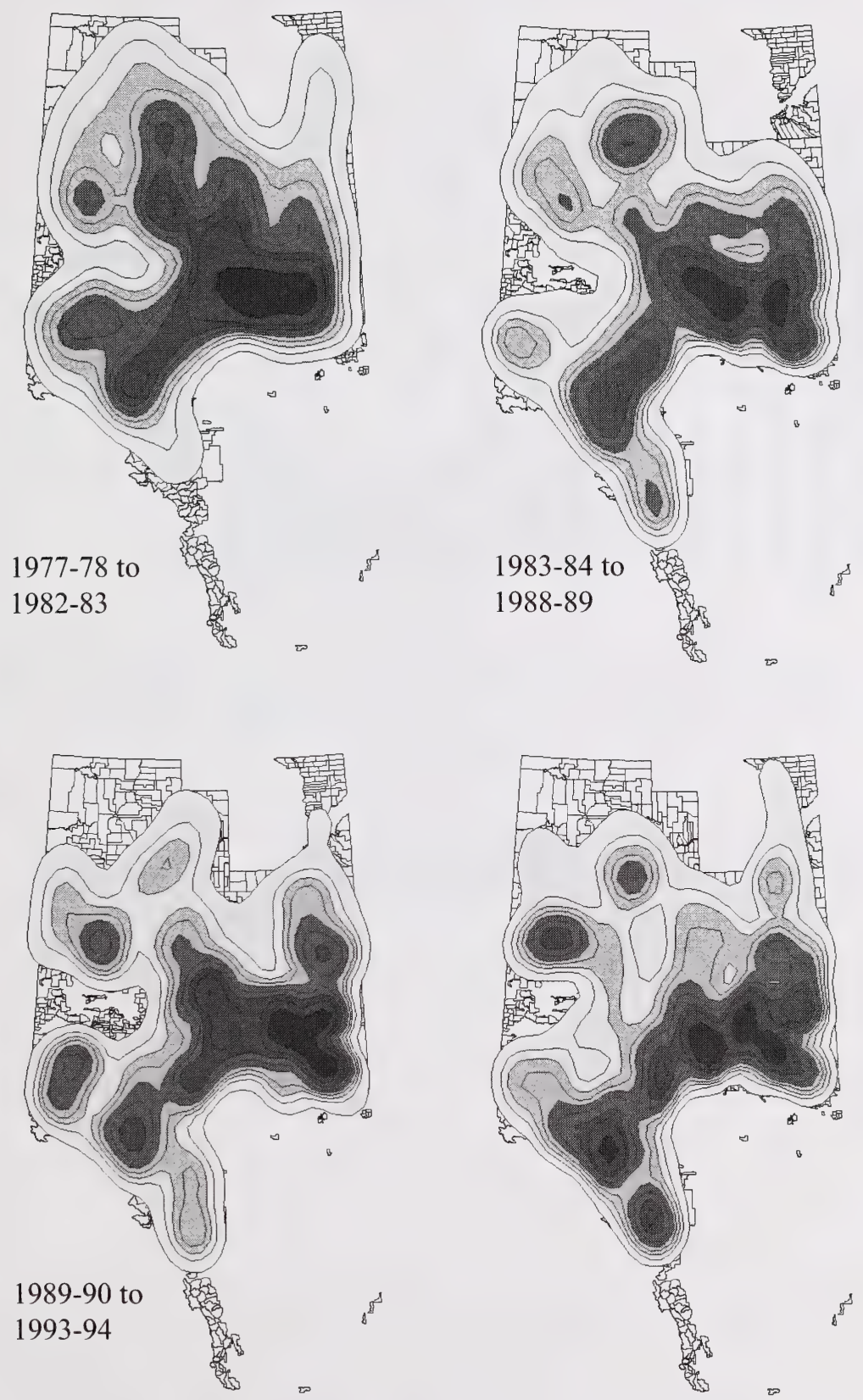

Figure 40. Adaptive kernel contours (darkest to lightest colour gradients from $0-10 \%, 10-30 \%$, $30-50 \%, 50-70 \%$ and $70-90 \%$ of harvest distribution; $10 \%$ lines) for Alberta wolf harvest by RFMA, for 4 time periods from 1977-78 to 1998-99. Harvests were scaled to RFMA size. 


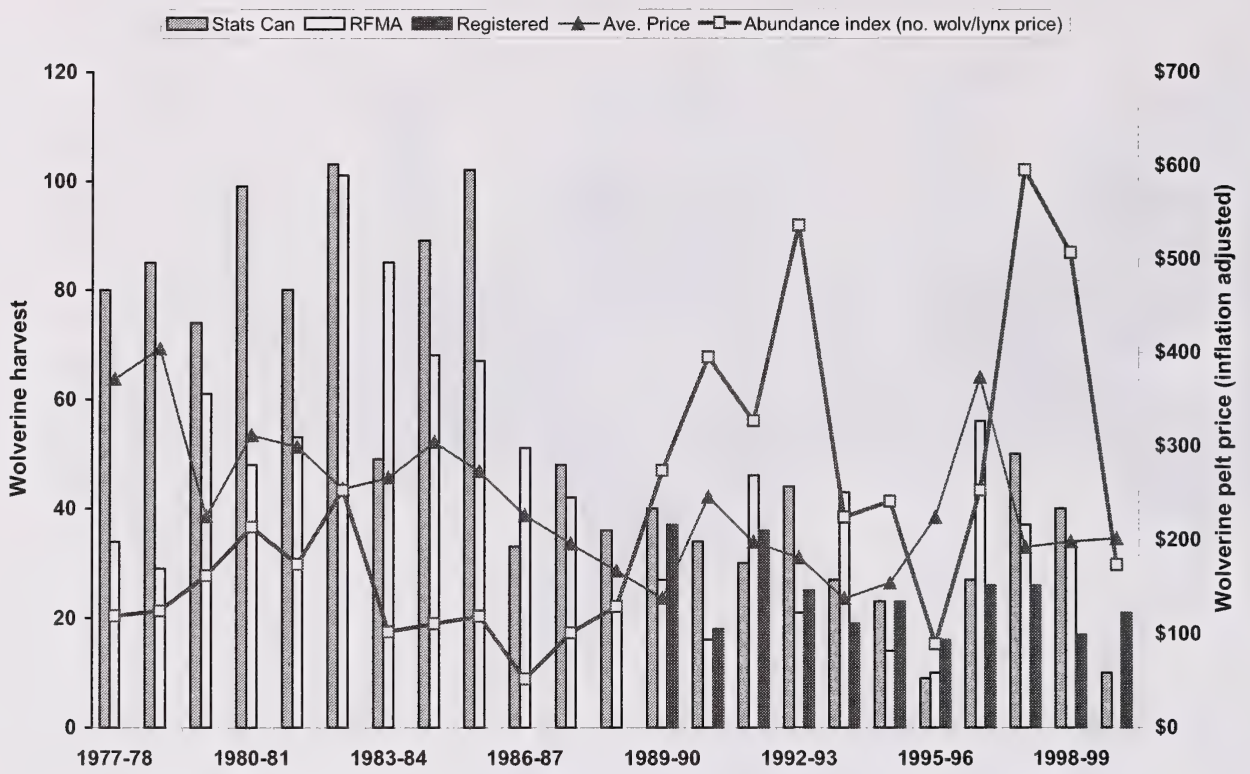

Figure 41. Alberta wolverine harvest from Statistics Canada (1977-78 - 1999-2000; grey bars), Alberta data for RFMAs (1977-78 - 1998-99; open bars), and registered data (1989-90 - 19992000; black bars) with average pelt price (light line) and abundance index (heavy line).

Wolverine

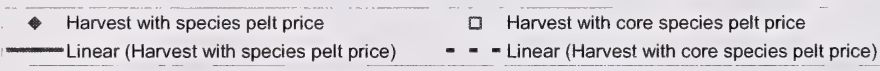

120

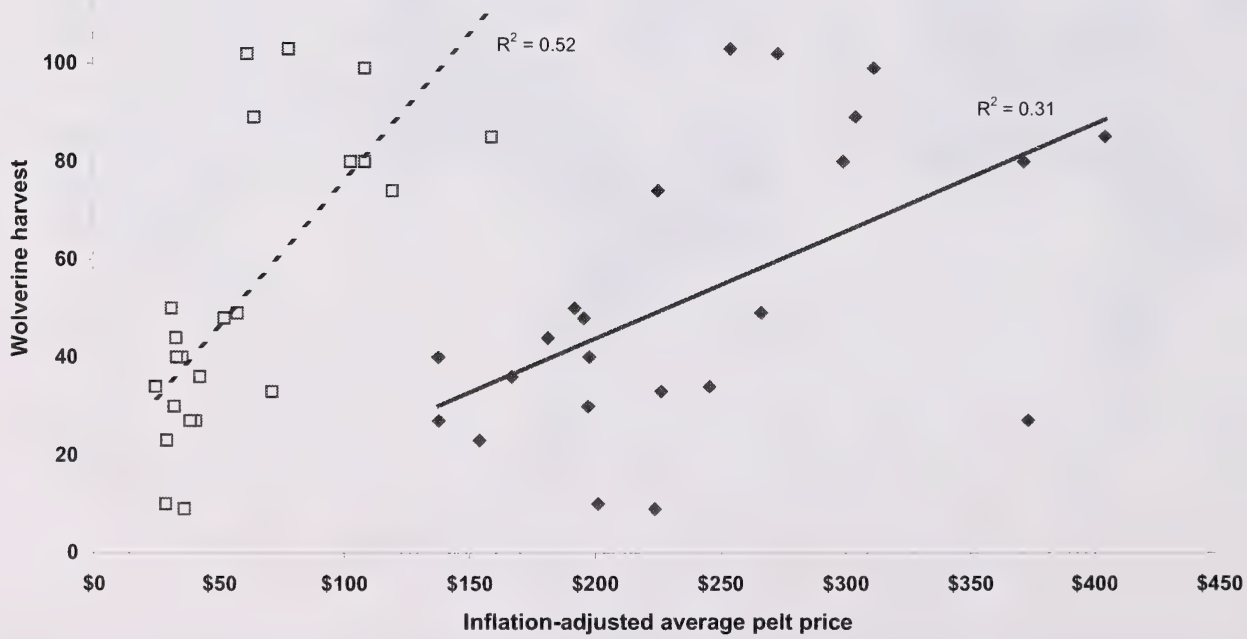

Figure 42. Relationship between annual wolverine harvest and annual wolverine pelt price, and 4 core species pelt price (solid symbols and line), and 4 core species pelt price (open symbols and dashed line), 1977-78 - 1999-2000. 

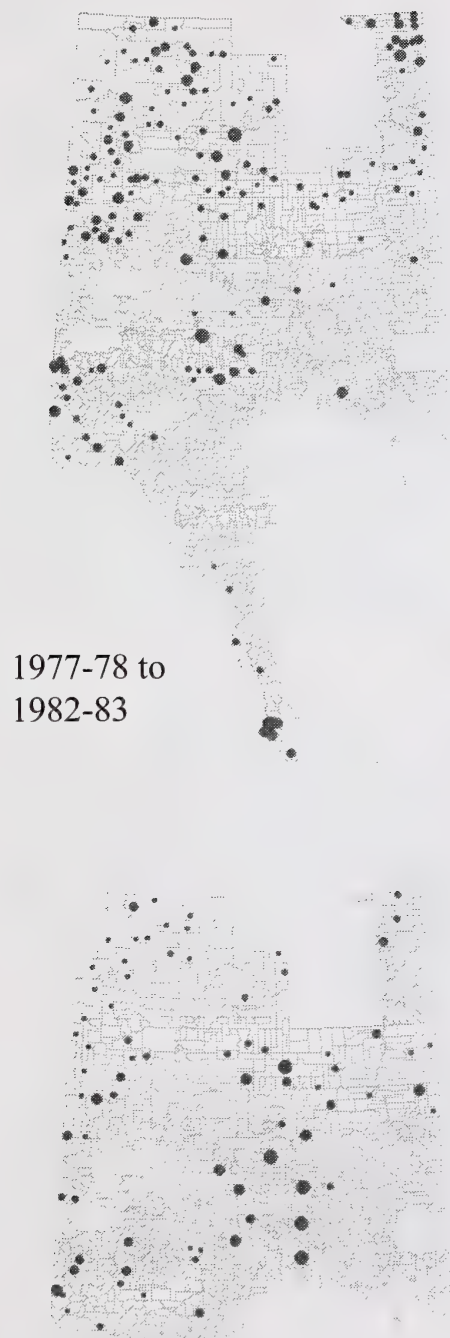

$\therefore$

1989-90 to

1993-94

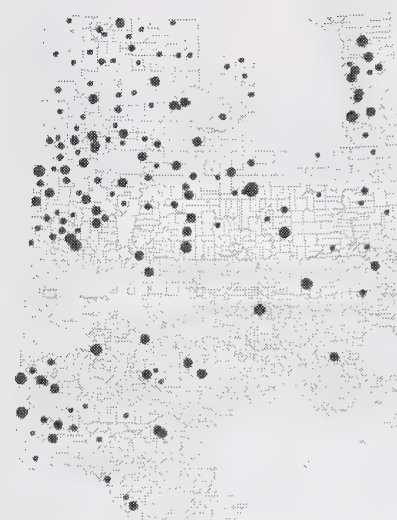

.

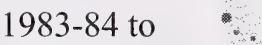

1988-89
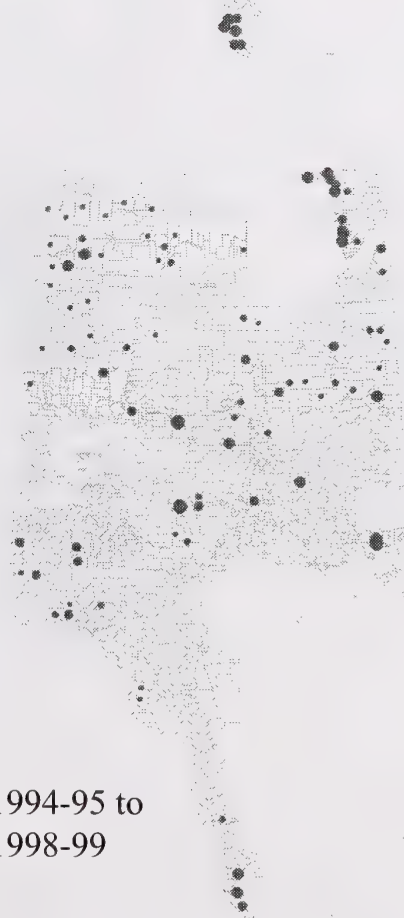

Figure 43. Average annual wolverine harvest by RFMA, for 4 time periods from 1977-78 to 1998-99. Harvests were scaled to RFMA size. Graduated symbols were consistent among time periods. 

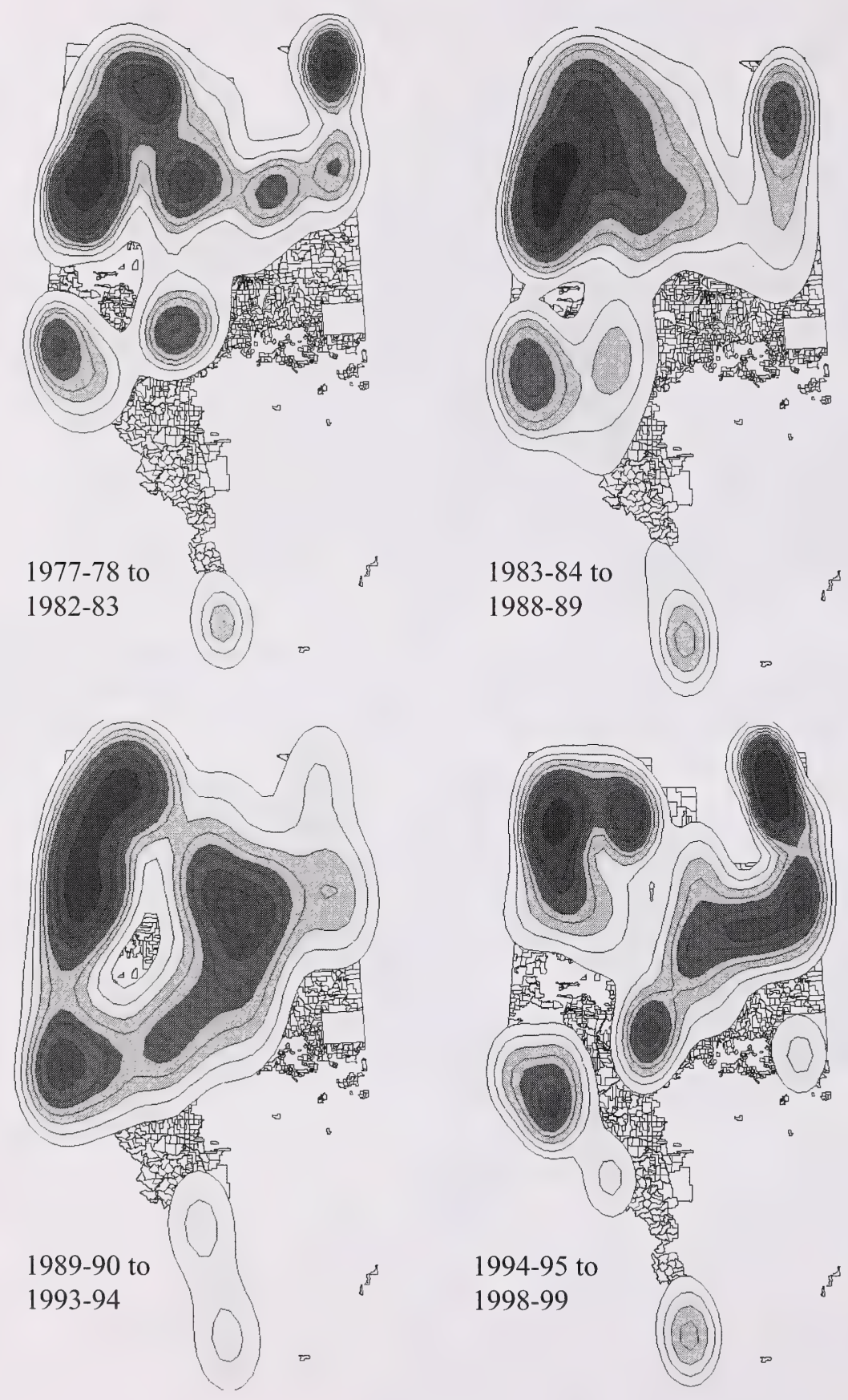

Figure 44. Adaptive kernel contours (darkest to lightest colour gradients from $0-10 \%, 10-30 \%$, $30-50 \%, 50-70 \%$ and $70-90 \%$ of harvest distribution; $10 \%$ lines) for Alberta wolverine harvest by RFMA, for 4 time periods from 1977-78 to 1998-99. Harvests were scaled to RFMA size. 


\subsection{CONCLUSIONS}

As summarized by Erickson (1982), harvest data are generally poor short-term indicators of animal abundance because of the dynamic character of the harvest system. Short-term changes in harvest may suggest changes in population, but harvest data should not replace independent population-trend data for furbearers. Long-term (20-50 yr) harvest data may depict trends in relative abundance, but these should be interpreted with caution and with the aid of other related information. The harvest levels of species of low commercial value are most likely to reflect relative abundances, because their harvests are subject to less direct influence by the fur market and regulatory processes. The harvest should be evaluated in relation to the variables that affect animal availability and annual harvest effort, including actual animal population size, reproduction, recruitment, pelt values, recreational demands, trapper numbers and effort, regulations, weather, and others (Erickson 1982). The literature suggests that it is not possible to infer trends in species abundance from harvest levels alone, given the number of factors that can influence trapper effort and success, and hence harvest returns.

A number of factors appear to limit the usefulness of the Alberta furbearer data. It is clear that the lack of data from resident trappers limits the usefulness of Alberta data for spatial analysis, and for annual summaries based on registered trapper affidavits. Inconsistencies in data collection and recording severely hampered data based on mandatory registration; it was hard to have confidence in (or know how to handle) data when so many errors were obvious. The Alberta data appears to suffer from a lack of reliability that has plagued furbearer harvest data from across North America (Obbard et al. 1987).

We do not believe that the data in its present form can be used to monitor species population size and trend. Our surrogate measure of effort (inflation-adjusted pelt price of 4 core species) appeared to correlate with harvest level for some species, but these indicate correlation, not a cause-effect relationship. Independent verification (long-term research studies) is required to verify cause-effect relationships between population indices and population size (Smith and Brisbin 1984). For some species, such as coyote (Fig. 9) and red fox (Fig. 15), it appeared that harvest level (and presumably effort) dropped slowly with decreasing pelt price, then dropped dramatically once a threshold price was reached (resulting in a logistic trend).

A number of furbearer harvest data sources have been used in the past, all with their own biases (summarized earlier). Alberta changed from use of fur dealer records to trapper affidavits in 1996-97. This change tended to compromise the provincial RFMA data for use in annual harvest trend analysis, since the assumption of standardized collection techniques was undoubtedly violated. If Statistics Canada data can be used as a constant base (derived from export permits), then according to the trapper affidavits there was a substantial increase in the relative harvest of most species in 1996-97, the first year of trapper affidavits. Trapper affidavits (in effect memory recall) are prone to a variety of response and non-response biases. These could include either understate actual harvests to "protect" productive trapping areas, or exaggerate their catch to inflate their egos or reflect what their catch should have been under "normal" circumstances. 
Mandatory registration should, in theory, provide an excellent and reliable source of harvest data from across the province, but we are perplexed why registration summaries were consistently and often substantially lower than annual summaries provided by either trapper affidavits or Statistics Canada data. While export permits may capture furs harvested from the entire province, they do not enumerate furs used within the province (which varies among species) or furs not sold for 1 to several years after entering the auction system. Fur dealer records also tend to capture all species harvested in the province, but are biased by sale date, not harvest date, and domestic use of pelts.

At present we suggest that one of the strongest use of the historic harvest data is for analysis of species distribution. Distributional data would have the greatest accuracy, and errors in the data set would have less impact on results. This information, if conducted for all species, could feed into broad scale biological diversity monitoring programs currently being considered for the province (Farr et al. 1999).

\subsection{Recommendations for Alberta Furbearer Data Analysis}

To make better use of current and future Alberta furbearer harvest data, we suggest the following for consideration:

1. Alberta trapper harvest data needs to be collected consistently for the entire province. This means setting up a process that includes non-crown and private lands trapped by resident trappers. If possible, harvest data from Federal lands (e.g., WBNP) should be included in this database as well as hunter harvests of relevant species such as coyotes, wolves and wolverines.

2. We suggest that harvest data collection be based on pelt counts, rather than unverified trapper affidavits (memory recall). Although there are biases involved, these data should be collected through licenced fur dealers, with a system that tracks fur sales, and makes fur dealers responsible for data submission and quality. Based on our experience with furbearer harvest data in western Canada, we believe that such a system will provide better quality data for use in spatial trend analysis and population trend analysis (with an index to trapper effort; see below). We acknowledge that this system will work only with conscientious fur dealers, and that some incentive may be required to encourage dealers to participate with accurate records. We also readily acknowledge that we do not have a good working knowledge of the Alberta furbearer harvest data collection system, and we suggest that a detailed examination of differences and biases among harvest data collection methods available to managers should be conducted. It may be prudent to work closely with a select group of trappers who are known to collect complete and accurate records, in order to explore some of these relationships and methods.

3. If Alberta decides to retain the trapper affidavit as the primary source for collection of harvest data, we suggest that affidavits be collected at the end of each fur season (MayJune) from all licenced trappers, rather than in the fall from those trappers that are renewing licences. This will help to ensure that the entire trapping community is tallied and reduces "memory loss". 
4. We suggest that weasel species be recorded separately, regardless of the data system. Because weasel species are currently lumped in the harvest data, it is of little use for tracking population trend or distribution for any of the species.

5. We suggest that Alberta needs to develop an index of abundance for each species based on a thorough analysis of correlations between harvest and various indices of effort, and the findings of others. Catch per unit effort indices are most useful as indirect indicators of population trend, and work best when annual harvest efforts are relatively stable.

These indices are prone to biases, including the trapper's reaction (increases or decreases in trapping effort) to perceived increases or decreases in abundance. Alternatively, if a surrogate for effort is not determined, provincial harvest analysis should be restricted to examination of species distribution. More direct methods of measuring trapper effort are most desirable but are rarely practical.

6. Whichever data collection systems are used, data verification routines are essential and required to enhance among-year data consistency and comparisons (Chilelli et al. 1996). If appropriate, these would include front-end verification routines to catch entry errors (e.g., registration date 3 years before harvest date; 520 bobcats from an RFMA). In addition, each year all collected data should be summarized and scrutinized for accuracy and validity.

7. We have presented a preliminary examination of distribution for selected Alberta furbearers. A more detailed examination is warranted, but first a thorough clean-up of all databases needs to be done. Errors need to be reconciled using original dataforms and a single source selected for analysis. Further investigation of correlates to harvest may also be desirable using the cleaned database. 


\subsection{LITERATURE CITED}

Alberta Sustainable Resource Development. 2000. 2000 Alberta guide to trapping. Alberta Sustainable Resource Development, Edmonton, Alberta, Canada.

Bailey, T.N. 1981. Factors influencing furbearer populations and harvest on the Kenai National Moose Range, Alaska. rages 249-272 in J.A. Chapman and D. Pursley, editors. Proceedings of the worldwide furbearer conference, Frostburg, Maryland, USA.

Bailey, T.N., E.E. Bangs, M.F. Portner, J.C. Malloy, and R.J. McAvinchey. 1986. An apparent overexploited lynx population in the Kenai Peninsula, Alaska. Journal of Wildlife Management 50:279-290.

Boyd, M. 1977. Analysis of fur production records by individual fur-bearing species for Registered Trapping Areas in Alberta, 1970-75. Alberta Recreation, Parks and Wildlife, Research and Systems, unpublished report.

Boyd, M., A. Todd, and P. Rudulier. 1977. Results of computer-assisted analysis of fur production records for registered trapping areas in Alberta, 1970-75. Alberta Recreation, Parks and Wildlife, Fish and Wildlife Division, unpublished report.

Brand, C.J., and L.B. Keith. 1979. Lynx demography during a snowshoe hare decline in Alberta. Journal of Wildlife Management 43:827-849.

Butler, L. 1942. Fur cycles and conservation. Transactions of the North American Wildlife Conference 7:463-472.

Caughley, G. 1977. Analysis of vertebrate populations. John Wiley and Sons, New York, New York, USA.

Chabreck, R.H., T.L. Edwards, and G. Linscombe. 1985. Factors affecting the distribution and harvest of river otters in Louisiana. Proceedings of the Annual Conference of the Southeastern Association of Fish and wildlife Agencies 39:557-562.

Chilelli, M., B. Griffith, and D. J. Harrison. 1996. Interstate comparisons of river otter harvest data. Wildlife Society Bulletin 24:238-246.

Dixon, K.R. 1981. Data requirements for determining the status of furbearer populations. Pages 1360-1373 in J.A. Chapman and D. Pursley, editors. Proceedings of the worldwide furbearer conference, Frostburg, Maryland, USA.

Erickson, D.W. 1981. Furbearer harvest mechanics: an examination of variables influencing fur harvests in Missouri. Pages 1469-1491 in J.A. Chapman and D. Pursley, editors. Proceedings of the worldwide furbearer conference, Frostburg, Maryland, USA.

Erickson, D.W. 1982. Estimating and using furbearer harvest information. Pages 54-65 in G.C. Sanderson, editor. Midwest furbearer management. Proceedings of a symposium held at the $43^{\text {rd }}$ Midwest Fish and Wildlife Conference, Wichita, Kansas, USA.

Fagerstone, K.A. 1987. Black-footed ferret, long-tailed weasel, short-tailed weasel, and least weasel. Pages 549-573 in M. Novak, J.A. Baker, M.E. Obbard, and B. Malloch, editors. Wild furbearer management and conservation in North America. Ontario Trappers Association, North Bay, Ontario, Canada. 
Farr, D.R. et al. 1999. Monitoring forest biodiversity in Alberta: program framework. Alberta forest biodiversity monitoring program, Technical Report No. 3. Draft Report.

Fortin, C., and M. Cantin. 1990. Effets du piegeage sur une population nouvellement exploitée de martre d'Amérique, Martes Americana Americana, en milieu boreal. Ministier du Poisir, de la Chasse, et de la Pêche, Québec, Québec, Canada.

Lewis, J. C., and W. J. Zielinski. 1996. Historical harvest and incidental capture of fishers in California. Northwest Science 70:291-297.

Meredith, D.H., and A.W. Todd. 1979. A questionnaire survey of registered trappers in Alberta in 1977. Alberta Energy and Natural Resources, Fish and Wildlife Division unpublished report.

Mowat, G., K.G. Poole, and M. O'Donoghue. 2000. Ecology of lynx in northern Canada and Alaska. Pages 265-306 in L.F. Ruggiero, K.B. Aubry, S.W. Buskirk, G.M. Koehler, C.J. Krebs, K.S. McKelvey, and J.R. Squires, editors. Ecology and conservation of lynx in the United States. University Press of Colorado, Boulder, Colorado, USA.

Obbard, M.E., J.G. Jones, R. Newman, A. Booth, A.J. Satterthwaite, and G. Linscombe. 1987. Furbearer harvests in North America. Pages 1007-1034 in M. Novak, J.A. Baker, M.E. Obbard, and B. Malloch, editors. Wild furbearer management and conservation in North America. Ontario Trappers Association, North Bay, Ontario, Canada.

Parsons, G.R., and M.K. Brown. 1981. Season length as a method of achieving population objectives for beaver (Castor canadensis). Pages 1392-1403 in J.A. Chapman and D. Pursley, editors. Proceedings of the worldwide furbearer conference, Frostburg, Maryland, USA.

Petersen, S. 1997. Status of the wolverine (Gulo gulo) in Alberta. Alberta Environmental Protection, Wildlife Management Division, Wildlife Status Report No. 2, Edmonton, Alberta, Canada.

Poole, K.G. 1997. Dispersal patterns of lynx in the Northwest Territories. Journal of Wildlife Management 61:497-505.

Powell, R. A. 1993. The fisher: life history, ecology, and behavior. Second edition. University of Minnesota Press, Minneapolis, Minnesota, USA.

Quinn, N.W.S., and J.E. Thompson. 1987. Dynamics of an exploited Canada lynx population in Ontario. Journal of Wildlife Management 51:297-305.

Raphael, M. G. 1994. Techniques for monitoring populations of fishers and American martens. Pp 224-240 in S.W. Buskirk, A.S. Harestad, M.G. Raphael, and R.A. Powell, editors. Martens, sables, and fishers: biology and conservation. Cornell University Press, Ithaca, New York, USA.

Ricker, W.E. 1975. Computation and interpretation of biological statistics of fish populations. Information Canada Bulletin 191, Ottawa, Ontario, Canada.

Rodgers, A.R., and A.P. Carr. 1998. HRE: The Home Range Extension for ArcView ${ }^{\mathrm{TM}}$ : User's manual. Beta Test Version 0.9, July 1998. Centre for Northern Ecosystem Research, Ontario Ministry of Natural Resources, Thunder Bay, Ontario, Canada. 
SAS Institute. 1997. SAS/STAT software: changes and enhancements through release 6.12. SAS Institute, Cary, North Carolina, USA.

Skinner, D.L., and A. W. Todd. 1988. Distribution and status of selected mammals in Alberta as indicated by trapper questionnaires in 1987. Alberta Forestry, Lands and Wildlife, Fish and Wildlife Division, Wildlife Management Branch, Occasional Papers Number 4.

Slough, B.G. 1996. Estimating lynx population age ratio with pelt-length data. Wildlife Society Bulletin 24:495-499.

Slough, B.G., R.H. Jessup, D.I. McKay, and A.B. Stephenson. 1987. Wild furbearer management in western and northern Canada. Pages 1062-1076 in M. Novak, J.A. Baker, M.E. Obbard, and B. Malloch, editors. Wild furbearer management and conservation in North America. Ontario Trappers Association, North Bay, Ontario, Canada.

Slough, B.G., and G. Mowat. 1996. Population dynamics of lynx in a refuge and interactions between harvested and unharvested populations. Journal of Wildlife Management 60:946961.

Smith, L.M., and I.L. Brisbin. 1984. An evaluation of total trapline captures as estimates of furbearer abundance. Journal of Wildlife Management 48:1452-1455.

Statistics Canada. 2000. Fur production - annual reports 1920-1999. Catalogue number 23503.

Strickland, M. A. 1994. Harvest management of fishers and American martens. Pp 149-164 in S.W. Buskirk, A.S. Harestad, M.G. Raphael, and R.A. Powell, editors. Martens, sables, and fishers: biology and conservation. Cornell University Press, Ithaca, New York, USA.

Strickland, M.A., and C. W. Douglas. 1981. The status of fisher in North America and its management in Southern Ontario. Pp 1443-1458. In J.A. Chapman and D. Pursley, editors. Proceedings of the worldwide furbearer conference, Frostburg, Maryland, USA.

Thompson, I.D., and P.W. Colgan. 1987. Numerical responses of martens to a food shortage in northcentral Ontario. Journal of Wildlife Management 51:824-835.

Todd, A.W. 1985. The Canada lynx: ecology and management. Canadian Trapper 13:15-20.

Todd, A.W., and E.K. Boggess. 1987. Characteristics, activities, lifestyles, and attitudes of trappers in North America. Pages 59-76 in M. Novak, J.A. Baker, M.E. Obbard, and B. Malloch, editors. Wild furbearer management and conservation in North America. Ontario Trappers Association, North Bay, Ontario, Canada.

Wilson, D.E., F. R. Cole, J. D. Nichols, R. Rudran, and M. S. Foster (editors). 1996. Measuring and monitoring biological diversity. Smithsonian Institute Press, Washington. 


\section{List of Titles in This Series}

(as of January 2002)

No. 1 Alberta species at risk program and projects 2000-2001, by Alberta Sustainable Resource Development, Fish and Wildlife Division. (2001)

No. 2 Survey of the peregrine falcon (Falco peregrinus anatum) in Alberta, by R. Corrigan. (2001)

No. 3 Distribution and relative abundance of the shortjaw cisco (Coregonus zenithicus) in Alberta, by M.

Steinhilber and L. Rhude. (2001)

No. 4 Survey of the bats of central and northwestern Alberta, by M.J. Vonhof and D. Hobson. (2001)

No. 52000 survey of the Trumpeter Swan (Cygnus buccinator) in Alberta, by M.L. James and A. James. (2001)

No. 6 2000/2001 Brassy Minnow inventory at Musreau Lake and outlet, by T. Ripley. (2001)

No. 7 Colonial nesting waterbird survey in the Northwest Boreal Region - 2000, by M. Hanneman and M. Heckbert. (2001)

No. 8 Burrowing owl trend block survey and monitoring - Brooks and Hanna areas, by D. Scobie and R. Russell. (2000)

No. 9 Survey of the Lake Sturgeon (Acipenser fulvescens) fishery on the South Saskatchewan River, Alberta (June-September, 2000), by L.A. Winkel. (2000)

No. 10 An evaluation of grizzly bear-human conflict in the Northwest Boreal Region of Alberta (1991-2000) and potential mitigation, by T. Augustyn. (2001)

No. 11 Harlequin duck monitoring in the Northern East Slopes of Alberta: 1998-2000 preliminary results, by J. Kneteman and A. Hubbs. (2000)

No. 12 Distribution of selected small mammals in Alberta, by L. Engley and M. Norton. (2001)

No. 13 Northern leopard frog reintroduction. Raven River - Year 2 (2000), by K. Kendell. (2001)

No. 14 Cumulative effects of watershed disturbances on fish communities in the Kakwa and Simonette watersheds. The Northern Watershed Project. Study 3 Progress report, by T. Thera and A. Wildeman. (2001)

No. 15 Harlequin duck research in Kananaskis Country in 2000, by C.M. Smith. (2001)

No. 16 Proposed monitoring plan for harlequin ducks in the Bow Region of Alberta, by C.M. Smith. (2001)

No. 17 Distribution and relative abundance of small mammals of the western plains of Alberta as determined from great horned owl pellets, by D. Schowalter. (2001)

No. 18 Western blue flag (Iris missouriensis) in Alberta: a census of naturally occurring populations for 2000, by R. Ernst. (2000)

No. 19 Assessing chick survival of sage grouse in Canada, by C.L. Aldridge. (2000)

No. 20 Harlequin duck surveys of the Oldman River Basin in 2000, by D. Paton. (2000)

No. 21 Proposed protocols for inventories of rare plants of the Grassland Natural Region, by C. Wallis. (2001) 
No. 22 Utilization of airphoto interpretation to locate prairie rattlesnake (Crotalus viridis viridis) hibernacula in the South Saskatchewan River valley, by J. Nicholson and S. Rose. (2001)

No. 23 2000/2001 Progress report on caribou research in west central Alberta, by T. Szkorupa. (2001)

No. 24 Census of swift fox (Vulpes velox) in Canada and Northern Montana: 2000-2001, by A. Moehrenschlager and C. Moehrenschlager. (2001)

No. 25 Population estimate and habitat associations of the long-billed curlew in Alberta, by E.J. Saunders. (2001)

No. 26 Aerial reconnaissance for piping plover habitat in east-central Alberta, May 2001, by D.R.C. Prescott. (2001)

No. 27 The 2001 international piping plover census in Alberta, by D.R.C. Prescott. (2001)

No. 28 Prairie rattlesnake (Crotalus viridis viridis) monitoring in Alberta - preliminary investigations (2000), by S.L. Rose (2001)

No. 29 A survey of short-horned lizard (Phrynosoma hernandesi hernandesi) populations in Alberta, by J. James (2001)

No. 30 Red-sided garter snake (Thamnophis sirtalis parietalis) education and relocation project - final report, by L. Takats (2002)

No. 31 Alberta furbearer harvest data analysis, by K.G. Poole and G. Mowat (2001)

No. 32 Measuring wolverine distribution and abundance in Alberta, by G. Mowat (2001)

No. 33 Woodland caribou (Rangifer tarandus caribou) habitat classification in northeastern Alberta using remote sensing, by G.A. Sanchez-Azofeifa and R. Bechtel (2001)

No. 34 Peregrine falcon surveys and monitoring in the Parkland Region of Alberta, 2001, by R. Corrigan (2002) 



Library and Archives Canada
Bibliotheque et Archives Canada Bibliotheque et Archives Canada

33286532180144 